FABIANA PEREZ

\title{
A EVOLUÇÃO DOS RELATÓRIOS DE SUSTENTABILIDADE NO SETOR DE MINERAÇÃO
}



FABIANA PEREZ

\title{
A EVOLUÇÃO DOS RELATÓRIOS DE SUSTENTABILIDADE NO SETOR DE MINERAÇÃO
}

\author{
Dissertação apresentada à Escola \\ Politécnica da Universidade de São \\ Paulo para obtenção do título de Mestre \\ em Engenharia.
}

Área de concentração: Engenharia

Mineral

Orientador: Prof. Dr. Luis Enrique

Sánchez 
FICHA CATALOGRÁFICA

\section{Perez, Fabiana}

A evolução dos relatórios de sustentabilidade no setor de mineração / F. Perez. -- São Paulo, 2008.

$136 \mathrm{p}$.

Dissertação (Mestrado) - Escola Politécnica da Universidade de São Paulo. Departamento de Engenharia de Minas e de Petróleo.

1.Empreendimentos mineiros 2.Relatórios de sustentabilidade (Avaliação) I.Universidade de São Paulo. Escola Politécnica. Departamento de Engenharia de Minas e de Petróleo Il.t. 
Dedico este trabalho a todas as empresas de mineração que contribuem efetivamente para um desenvolvimento sustentável 


\section{AGRADECIMENTOS}

Ao Prof. Dr. Luis Enrique Sánchez, pela rica orientação e dedicação a esta pesquisa. Seu profissionalismo e vasto conhecimento foram motivadores e inspiradores.

Aos professores Giorgio de Tomi e Isak Kruglianskas, pelas valiosas sugestões no exame de qualificação e pela disponibilidade de contribuir para este trabalho.

A Cristina, Adalberto e Elias, pela contribuição para a revisão bibliográfica e formatação do texto final.

A Maristela e Washington, pelo apoio e gentileza no atendimento da secretaria.

Aos demais professores da Escola Politécnica e outras unidades da Universidade de São Paulo, que me deram a oportunidade de cursar disciplinas valiosas e que têm se dedicado à pesquisa e discussão da sustentabilidade em suas diferentes dimensões.

Às empresas pesquisadas, cujos relatórios permitiram que esse estudo fosse possível.

A minha tia Maria Luiza, que colaborou na pesquisa da metodologia.

Ao meu marido Luis Carlos, que amavelmente compreendeu a minha ausência para a dedicação a esse trabalho. A minha filha Alice, por renovar minhas energias nos momentos de descanso com sua alegria.

A minha mãe Inez, pela revisão e principalmente por cuidar da minha filha para que eu pudesse concluir o mestrado assim como o fizeram meu pai Iracélio, minhas irmãs Marina e Juliana e minha tia Madalena.

Agradeço também aos meus pais, por me transmitirem o prazer em estudar e em aprimorar meus conhecimentos. 


\section{RESUMO}

Nos últimos anos nota-se uma preocupação crescente das empresas com responsabilidade empresarial e desenvolvimento sustentável. A divulgação dos resultados por meio da publicação de relatórios de desempenho ambiental, de sustentabilidade e/ou balanços sociais pode demonstrar eficiência e melhorar as relações com as diversas partes interessadas. A publicação de estudos sobre a utilização de relatórios de sustentabilidade no setor de mineração contribui indiretamente para fomentar a evolução dessa prática nas empresas e contribuir para a melhora da imagem da mineração. $O$ objetivo desta pesquisa é investigar de que modo tem-se dado a evolução dos relatórios de sustentabilidade publicados pelas empresas do setor de mineração. Foi desenvolvido um roteiro de avaliação dos relatórios, baseado em referências internacionais de boas práticas e na literatura sobre o tema. A avaliação foi feita somente em termos de atendimento ou não a 62 requisitos ou tópicos que deveriam idealmente constar de relatórios de sustentabilidade de empresas desse setor. Os requisitos foram agrupados nas seguintes categorias: Contexto e compromissos, Gestão, Desempenho econômico, Desempenho social, Desempenho ambiental e Acessibilidade e garantia. $O$ roteiro foi aplicado a 35 relatórios preparados entre 1997 e 2006 por cinco grandes empresas multinacionais do setor de mineração. A hipótese de evolução na qualidade e na abrangência dos relatórios foi confirmada com uma tendência positiva. A alta média das pontuações totais dos relatórios analisados e a alta porcentagem de apresentação de informações recomendadas para o setor mostram - esforço dessas empresas na identificação de riscos e resposta às partes interessadas. As seis categorias de informação analisadas mostraram resultados diversos, tanto em pontuação obtida quanto à tendência de evolução $A$ categoria que recebeu as melhores pontuações foi "Contexto e Compromissos" enquanto a que recebeu as menores notas foi "Acessibilidade e Garantia". O método de avaliação mostrou-se eficaz para a avaliar a abrangência ou completude dos relatórios. Nas empresas analisadas os processos de processos de publicação estão estabelecidos, e é possível não só continuar evoluindo para discussões mais profundas, como também compartilhar informações e lições aprendidas para difundir a prática em todo o setor. Passada a fase inicial de amadurecimento dos relatórios, é momento para as empresas avançarem nas suas práticas de divulgação, buscando atender às melhores práticas e expectativas das partes interessadas de uma maneira mais completa, atingindo o próximo patamar de qualidade em relatórios de sustentabilidade.

Palavras-chave: Relatórios de sustentabilidade. Relatórios corporativos. Avaliação. Mineração. 


\begin{abstract}
During last years companies have an increasing concern about corporate social responsibility and sustainable development. Performance disclosure through sustainability, social or environmental reports can demonstrate efficiency and improve the relationship with stakeholders. Publishing researches about the usage of sustainability reports in mining sector can indirectly promote the evolution of this practice in companies and contribute to improve the public image of the sector. The goal of this research is investigating how sustainability reports are evolving in mining companies. A method was developed for reports assessment, based on international good practices and literature about sustainability reports. The assessment was made in terms of presence or not of 62 topics which ideally should be presented in sustainability reports of this sector. The topics were organized in the following categories: Context and Commitment, Management, Economic performance, Social performance, Environmental performance and Assurance and accessibility. The method was applied to 35 reports published between 1997 and 2006 by five big multinational mining companies. The assumption of evolution in report quality and completeness was confirmed, with a positive trend. A high mean of reports score as well as a high percentage of disclosing mining specific information show the effort of these companies in risk identification and response to stakeholders. It was noticed that the six information categories analyzed presented different results, both in adherence to the developed framework and in evolution trend. The category which had the highest score was "Context and Commitments" while the category which had the lowest scores was "Assurance and accessibility". The assessment method was efficient to assess comprehensiveness or completeness of reports. The reporting process is established in the companies analyzed, and it is possible to keep evolving with orientation to deeper issues, as well as sharing information and lessons learned to disseminate good practices in the mining sector. Beyond the initial phase of reporting, it is time for companies to improve their reporting processes by complying with all best practices available and responding to stakeholders' expectations in a more comprehensive way, reaching the next level of quality in sustainability reporting.
\end{abstract}

Keywords: Sustainability reports. Corporate reporting. Assessment. Mining. 


\section{LISTA DE ILUSTRAÇÕES}

Figura 1 - Relatórios não-financeiros corporativos 1990-2003 .............................28

Figura 2 - Modelo de cinco estágios - Resultados de 1994 e 1997 ........................44

Figura 3 - Modelo de cinco estágios revisado - Resultados de 1997 .....................44

Figura 4 - Evolução temporal (Anglo American) ..............................................70

Figura 5 - Evolução temporal (BHP Billiton) ................................................ 73

Figura 6 - Evolução temporal (Cemex) ..................................................... 76

Figura 7 - Evolução temporal (Lafarge) ................................................... 79

Figura 8 - Avaliação do relatório $($ Samarco, 2006) ......................................... 82

Figura 9 - Evolução temporal (Samarco) ................................................ 82

Figura 10 - Evolução temporal (cinco empresas) .........................................84

Figura 11 - Evolução temporal da categoria "Contexto e Compromissos" .............128

Figura 12 - Evolução temporal da categoria "Gestão" ........................................128

Figura 13 - Evolução temporal da categoria "Desempenho econômico" ................129

Figura 14 - Evolução temporal da categoria "Desempenho social” ......................129

Figura 15 - Evolução temporal da categoria "Desempenho ambiental" .................130

Figura 16 - Evolução temporal da categoria “Acessibilidade e Garantia” ...............130 


\section{LISTA DE QUADROS}

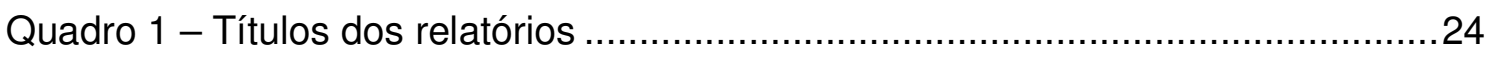

Quadro 2 - Direcionadores dos primeiros relatórios ........................................26

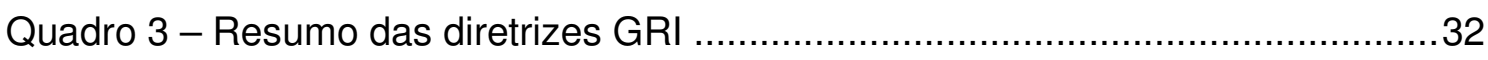

Quadro 4 - Critérios para declaração do nível de aplicação ................................33

Quadro 5 - Princípios para definição do conteúdo do relatório segundo GRI G3 e AA

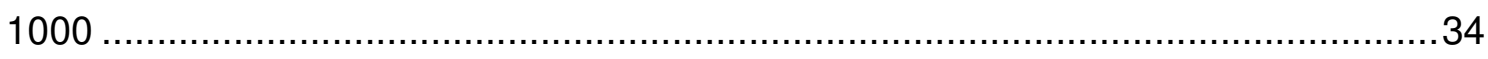

Quadro 6 - Resumo dos estudos sobre relatórios de sustentabilidade ..................40

Quadro 7 - Modelo revisado de cinco estágios de maturidade ............................43

Quadro 8 - Conceitos de avaliação dos requisitos ........................................52

Quadro 9 - Ranking das maiores empresas de mineração .................................61

Quadro 10 - Ranking (Materiais de Construção) ............................................62

Quadro 11 - Empresas selecionadas ......................................................63

Quadro 12 - Algumas diretrizes para elaboração de relatórios não-financeiros .....136 


\section{LISTA DE TABELAS}

Tabela 1 - Número de relatórios registrados por setor .........................................29

Tabela 2 - Porcentual médio - Avaliações de 1997 a 2006 ................................... 42

Tabela 3 - Desempenho do setor de mineração nos relatórios "Global Reporters".. 46

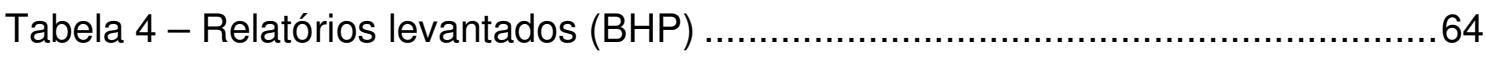

Tabela 5 - Relatórios levantados (Anglo American) ……….................................65

Tabela 6 - Relatórios levantados (Cemex) ………........................................66

Tabela 7 - Relatórios levantados (Lafarge) ……….......................................67

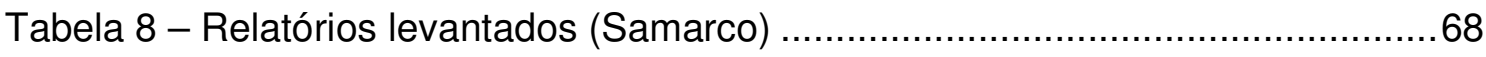

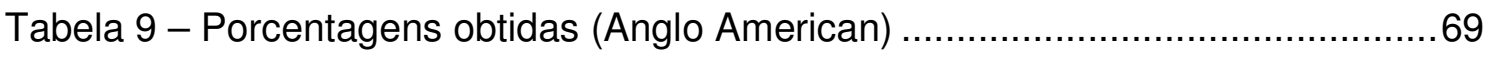

Tabela 10 - Informações adicionais (Anglo American) ………...............................71

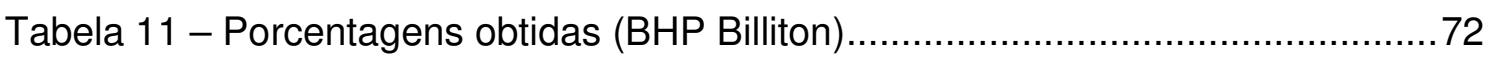

Tabela 12 - Informações adicionais (BHP Billiton) ............................................... 74

Tabela 13 - Porcentagens obtidas (Cemex) ………........................................75

Tabela 14 - Informações adicionais (Cemex) …….........................................77

Tabela 15 - Porcentagens obtidas (Lafarge) ………….................................. 78

Tabela 16 - Informações adicionais (Lafarge) ………...................................... 80

Tabela 17 - Porcentagens obtidas (Samarco) ………..................................... 81

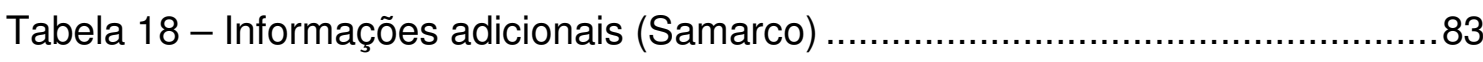

Tabela 19 - Porcentagem total dos relatórios por empresa para os mesmos anos.. 84

Tabela 20 - Pontuação média das empresas entre 2002 e 2006 .............................85

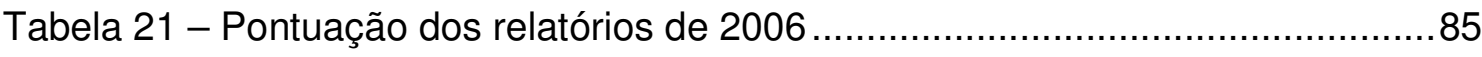

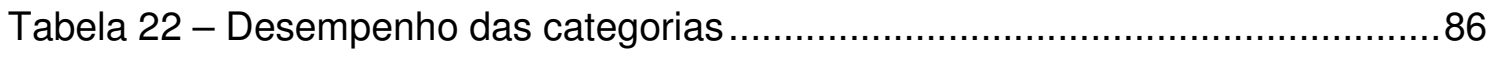

Tabela 23 - Comportamento da pontuação ao longo dos anos ..................................86

Tabela 24 - Comparação de itens apresentados (2002 a 2006)...............................87

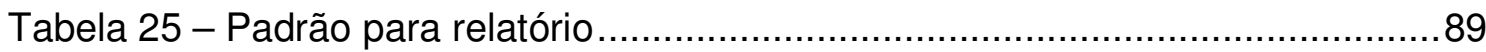

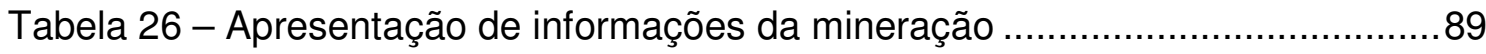

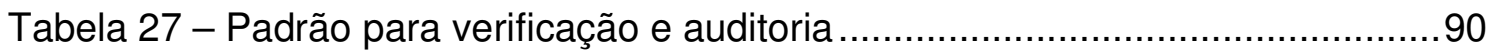

Tabela 28 - Freqüência de uso das referências no formulário de coleta de dados 117

Tabela 29 - Ranking Covalence Ethical 2005 - Mining \& Metals ...........................132

Tabela 30 - Ranking RMG 2004 - Metal Mining.................................................. 132

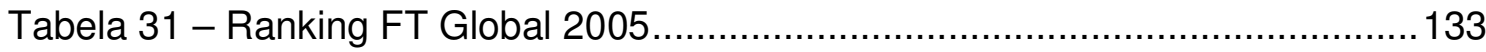

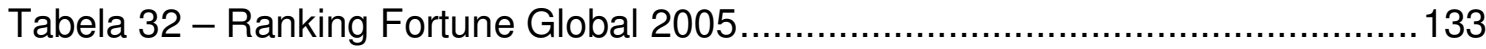

Tabela 33 - Ranking Forbes Global 2005 ........................................................134 


\section{LISTA DE ABREVIATURAS E SIGLAS}

\begin{tabular}{|c|c|}
\hline AA & AccountAbility \\
\hline $\mathrm{ABI}$ & Abstracted Business Information \\
\hline ACCA & Association of Chartered Certified Accountants \\
\hline CERES & Coalition for Environmentally Responsible Economies \\
\hline CICA & Canadian Institute of Chartered Accountants \\
\hline CIPMA & Centro de Investigación y Planificación del Medio Ambiente \\
\hline DTTI & Deloitte Touche Tohmatsu International \\
\hline EITI & Extractive Industries Transparency Initiative \\
\hline ESRA & European Sustainability Reporting Awards \\
\hline FSR & Foreningen Statsautoriserede Revisorer \\
\hline FT & Financial Times \\
\hline FTSE & Financial Times Stock Exchange \\
\hline GMI & Global Mining Initiative \\
\hline GRI & Global Reporting Initiative \\
\hline IBASE & Instituto Brasileiro de Análises Sociais e Econômicas \\
\hline ICC & International Chamber of Commerce \\
\hline ICMM & International Council on Mining \& Metals \\
\hline IDW & Institut der Wirtschaftsprüfer \\
\hline IFAC & International Federation of Accountants \\
\hline IIED & International Institute for Environment and Development \\
\hline IISD & International Institute for Sustainable Development \\
\hline ISAE & International Standard on Assurance Engagements \\
\hline ISI & Institute for Scientific Information \\
\hline ISO & International Standards Organization \\
\hline KPMG & Klynveld, Peat, Marwick and Goerdeler \\
\hline MERN & Mining \& Environment Research Network \\
\hline MMSD & Mining, Minerals and Sustainable Development \\
\hline MS & Microsoft \\
\hline NIVRA & Nederlands Instituut van Registeraccountants \\
\hline
\end{tabular}




$\begin{array}{ll}\text { RMG } & \text { Raw Materials Group } \\ \text { SRI } & \text { Socially Responsible Investments } \\ \text { TRI } & \text { Toxic Releases Inventory } \\ \text { UNCED } & \text { United Nations Conference on Environment and Development } \\ \text { UNEP } & \text { United Nations Environment Programme } \\ \text { WBCSD } & \text { World Business Council for Sustainable Development } \\ \text { WCED } & \text { World Commission on Environment and Development } \\ \text { WIMM } & \text { Wetenschappelijk Instituut voor MilieuManagement }\end{array}$




\section{SUMÁRIO}

1 INTRODUÇÃO

1.1 DESENVOLVIMENTO SUSTENTÁVEL E MINERAÇÃO............................................16

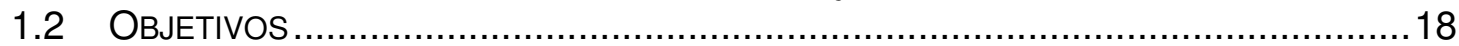

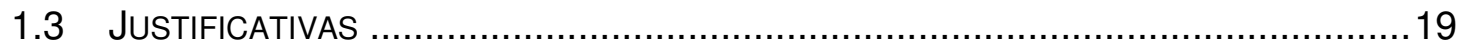

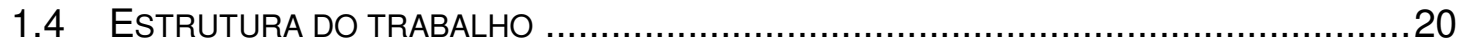

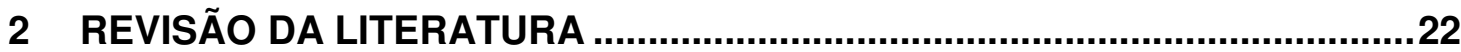

2.1 VISÃO GERAL DE RELATÓRIOS DE SUSTENTABILIDADE..................................22

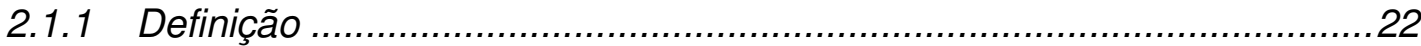

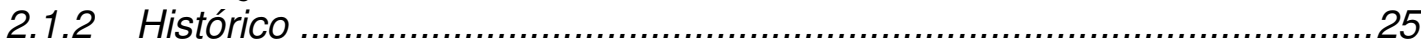

2.1.3 Marco regulatório.......................................................................30

2.2 DIRETRIZES E AVALIAÇÕES DE RELATÓRIOS DE SUSTENTABILIDADE .......................31

2.2.1 Recomendações e diretrizes para relatórios de sustentabilidade ............31

2.2.2 Verificação ou auditoria externa ........................................................37

2.2.3 Avaliação de relatórios de sustentabilidade .........................................39

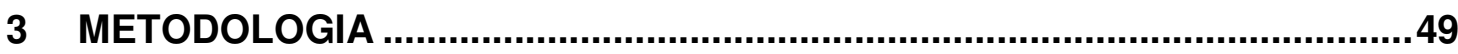

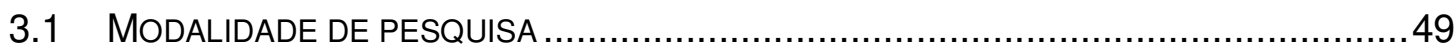

3.2 IDENTIFICAÇÃO E LOCALIZAÇÃO DAS FONTES ……….................................50

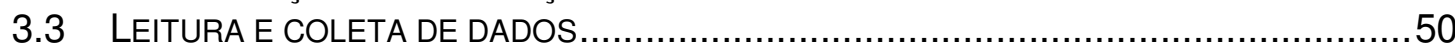

3.3.1 Análise de conteúdo ...................................................................51

3.3.2 Instrumento de coleta de dados (roteiro de avaliação)............................51

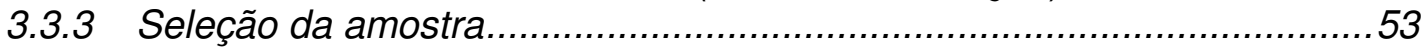

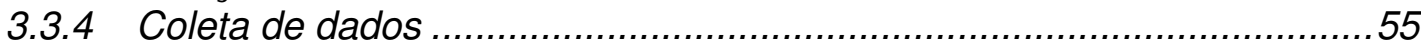

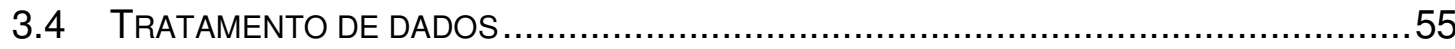

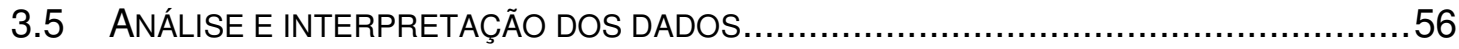

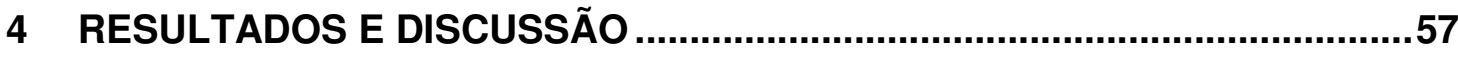

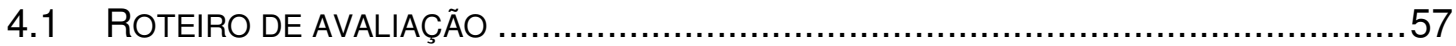

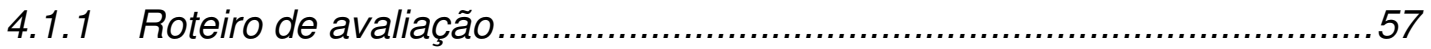

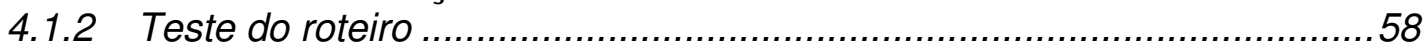

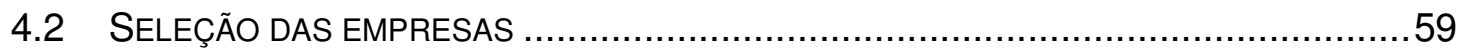

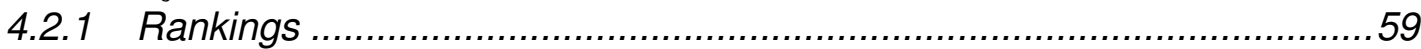

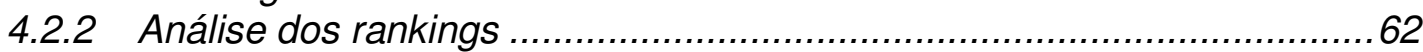

4.3 LEVANTAMENTO DOS RELATÓRIOS PUBLICADOS .............................................63

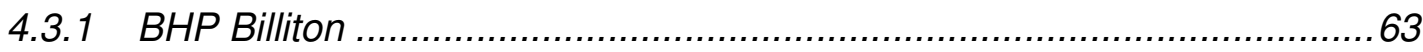

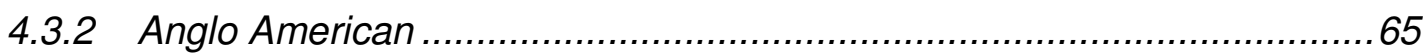

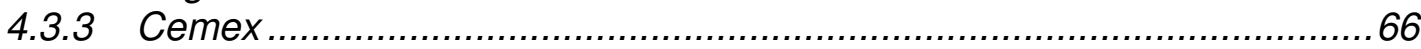

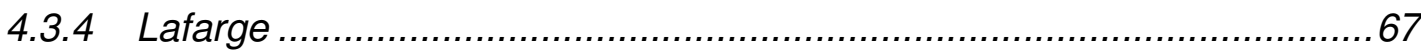

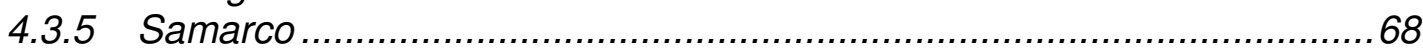

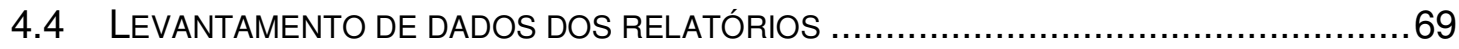

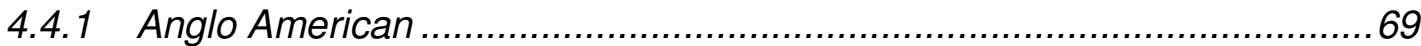

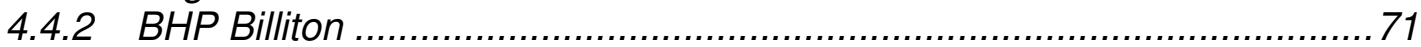

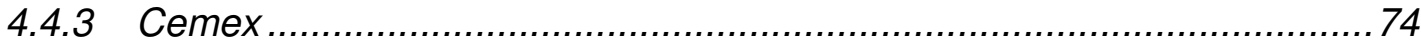

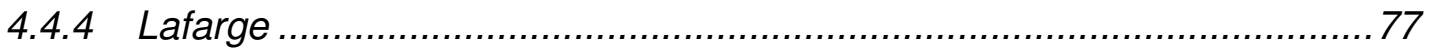

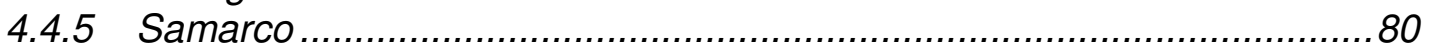


4.4.6 Comparação entre empresas ....................................................... 83

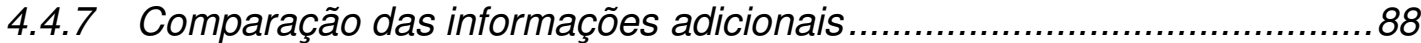

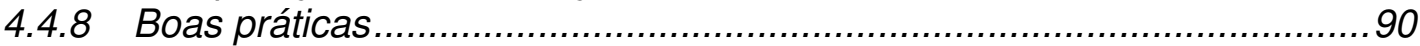

4.5 ANÁLISE E INTERPRETAÇÃO DOS DADOS....................................................

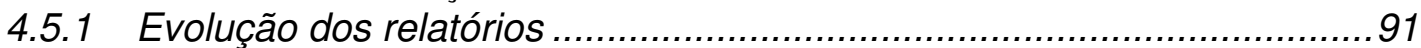

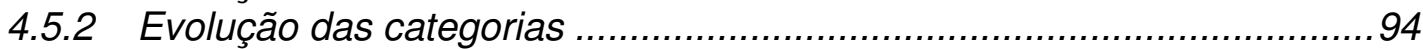

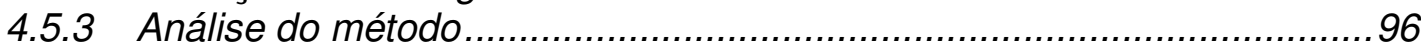

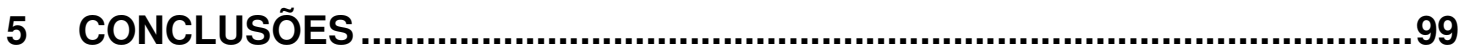

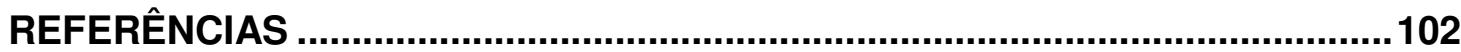

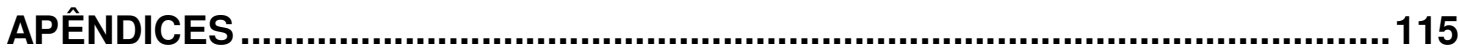

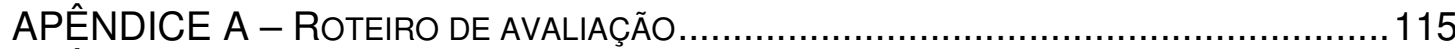

APÊNDICE B - ROTEIRO COMPLETO - ANGLO AMERICAN …................................118

APÊNDICE C - ROTEIRO COMPLETO - BHP BILLITON .......................................120

APÊNDICE D - ROTEIRO COMPLETO - CEMEX ……..........................................122

APÊNDICE E - ROTEIRO COMPLETO - LAFARGE ……......................................... 124

APÊNDICE F - ROTEIRO COMPLETO - SAMARCO ……...................................126

APÊNDICE G - GRÁFICOS DA EVOLUÇÃO TEMPORAL DE CADA CATEGORIA.................128

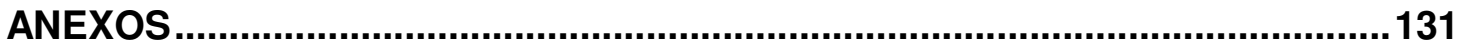

ANEXO A - METODOLOGIA DE AVALIAÇÃO DA CONSULTORIA SUSTAINABILITY .............131

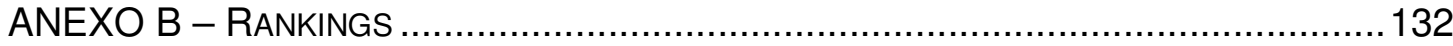

ANEXO C - DIRETRIZES PARA ELABORAÇÃO DE RELATÓRIOS ................................136 


\section{INTRODUÇÃO}

\subsection{Desenvolvimento Sustentável e Mineração}

Desenvolvimento sustentável, conforme definição do relatório "Nosso futuro comum" (WORLD COMMISSION ON ENVIRONMENT AND DEVELOPMENT, 1988), é o desenvolvimento que satisfaz as necessidades do presente, sem comprometer a capacidade das gerações futuras em satisfazer as suas próprias necessidades. Esse desenvolvimento deve levar em conta os três pilares da sustentabilidade ("Triple Bottom Line") - além da tradicional visão econômica, deve-se considerar também o desempenho nas áreas social e ambiental (ELKINGTON, 2001).

O desempenho econômico reflete os impactos positivos ou negativos da empresa sobre as circunstâncias econômicas das partes interessadas ${ }^{1}$ e sobre o sistema econômico. O desempenho ambiental mostra os impactos positivos ou negativos da organização sobre sistemas naturais - vivos ou não - incluindo ecossistemas, terra, ar e água. O desempenho social reflete os impactos positivos ou negativos da organização sobre os sistemas sociais nos quais opera (GLOBAL REPORTING INITIATIVE, 2006b).

Nos últimos anos nota-se uma preocupação crescente das empresas com responsabilidade empresarial e desenvolvimento sustentável. Os riscos envolvidos podem ser diretos, como passivos ambientais e ações legais, ou riscos indiretos como comprometimento da imagem e conseqüente diminuição de vendas e do valor das ações.

Em todos os casos o prejuízo financeiro é uma possibilidade que faz com que as

1 O termo "partes interessadas" é a tradução mais freqüente para a palavra inglesa stakeholders, que segundo SustainAbility, DTTI e IISD (1993) são os grupos com potencial interesse na lucratividade, nas operações, nos impactos e nas metas de melhoria de uma empresa. Incluem tipicamente comunidades locais, clientes, acionistas, investidores, analistas financeiros, fornecedores, associações de classe, trabalhadores diretors e indiretos, autoridades locais, associações nãogovernamentais, imprensa, instituições educacionais, etc. Nesse texto, os termos partes interessadas, stakeholders e grupos de interesse serão usados como sinônimos. 
empresas estejam atentas a essa "responsabilidade moral", que pode ser definida como uma atitude que as partes interessadas consideram como comportamento ético (SUSTAINABILITY, 2004a).

Essa preocupação crescente faz com que algumas empresas implantem medidas que visam melhorar seu desempenho e sua imagem como implantação de sistemas de gestão ambiental ou de saúde e segurança do trabalho, certificação em responsabilidade social, programas signatários, programas de voluntariado empresarial, entre outros. No entanto, além de buscar melhorar os processos internos, as empresas também precisam se preocupar em responder à crescente pressão da sociedade pela divulgação pública de seus resultados. As eventuais melhorias nos processos ou nos produtos muitas vezes não são visíveis ou compreensíveis para todos os públicos. Assim a prestação de contas das empresas, além de demonstrar uma preocupação com a transparência, é uma ação de comunicação de fato.

Após os escândalos contábeis nos EUA, Europa e Ásia, as empresas têm sentido cada vez mais a demanda das partes interessadas em prestar contas de suas ações de uma maneira mais completa - por meio de, entre outras coisas, maior transparência e divulgação (SUSTAINABILITY; UNEP, 2002). A divulgação dos resultados através da publicação de relatórios de desempenho ambiental, de sustentabilidade e/ou balanços sociais pode demonstrar eficiência e melhorar as relações com as diversas partes interessadas. Esses relatórios são apresentados em vários modelos e podem conter indicadores de vários tipos, como geração de resíduos, emissão de poluentes e indicadores sociais internos e externos. Como os princípios de sustentabilidade englobam a recomendação de comunicação e interação com as partes interessadas, algumas empresas divulgam em relatórios públicos os resultados não-financeiros de suas atividades, de seu desempenho ambiental e de suas iniciativas em sustentabilidade.

Especificamente na mineração, a repercussão negativa de eventuais acidentes ambientais ou do trabalho pode produzir desgaste e conflito com a sociedade civil. Seria interessante, então, que as empresas de mineração direcionassem seus esforços no sentido da sustentabilidade e publicassem seus resultados como 
prestação de contas às diversas partes interessadas.

Informar de maneira realista os impactos negativos do setor, bem como os impactos positivos, pode ter um efeito benéfico na opinião pública. A divulgação das medidas tomadas e metas de melhoria são respostas às necessidades e expectativas dos vários públicos. Além disso, a iniciativa demonstra transparência e abertura para o diálogo, o que contribui para o relacionamento com as partes interessadas e para o aumento da confiança na empresa.

A publicação de estudos sobre a utilização de relatórios de sustentabilidade no setor pode indiretamente fomentar a evolução dessa prática nas empresas e contribuir para a melhora da imagem da mineração. Para tanto fazem-se necessários estudos acadêmicos mais detalhados para avaliar a adoção dessa prática de gestão

Considerando que esse conhecimento pode ser relevante para outras pesquisas e para auxiliar as empresas do setor, esta pesquisa foi desenvolvida a partir do seguinte problema: Como as empresas de mineração (especificamente as grandes empresas) estão avançando no sentido da divulgação do seu desempenho em sustentabilidade? Essas empresas seguem as melhores práticas recomendadas pela literatura?

\subsection{Objetivos}

A premissa da qual parte esta pesquisa é a de que existe uma evolução (ou mudança positiva) nas práticas de publicação de relatórios corporativos nãofinanceiros pelo setor de mineração. Essa evolução se daria no formato, conteúdo, metodologia e escopo, passando de relatórios ambientais ou de segurança do trabalho a relatórios de sustentabilidade, que abarcam as três dimensões centrais do desenvolvimento sustentável, a saber, a econômica, a social e a ambiental.

Para descrever melhor esse fenômeno, o objetivo geral definido para esta pesquisa é investigar de que modo se dá a evolução dos relatórios de sustentabilidade pelas 
empresas do setor de mineração. Espera-se constatar que existam diversas dimensões dessa evolução, que não necessariamente estão no mesmo estágio ou assumem a mesma importância.

Adicionalmente, espera-se atingir os seguintes objetivos específicos:

- Identificar as recomendações da literatura sobre a publicação de relatórios de sustentabilidade

- Elaborar um roteiro para avaliação de relatórios

- Identificar as principais características de relatórios já publicados

- Encontrar oportunidades de melhorias nos relatórios de sustentabilidade

O estudo não tem a pretensão de ser exaustivo ou de comparar os desempenhos e/ou impactos das empresas analisadas, e sim a qualidade dos relatórios publicados em suas forma, apresentação e objetivos. Os resultados dessa pesquisa não representarão os desempenhos ambiental, social e econômico das empresas, e sim a eficiência na elaboração do conteúdo dos relatórios.

\subsection{Justificativas}

O tema escolhido justifica-se em função dos seguintes fatos:

- A demonstração da contribuição das empresas para a sustentabilidade (ou o desenvolvimento sustentável) é uma preocupação recente. São recentes as publicações e estudos acadêmicos sobre a aplicação dos relatórios e sua utilização no Brasil e no mundo (os primeiros estudos sobre relatórios não-financeiros foram publicados na metade dos anos 90).

- Algumas empresas com limitada capacidade para lidar com falhas e minas abandonadas prejudicam a imagem do setor (INTERNATIONAL INSTITUTE FOR ENVIRONMENT AND DEVELOPMENT, 2002). Segundo um estudo feito pelo Centro de Investigación y Planificación del Medio Ambiente - CIPMA, a sociedade brasileira tem uma percepção basicamente negativa sobre a atividade de extração mineral. Existem esforços do setor para melhorar a informação e também as condições de acesso à informação, mas no momento o processo é deficiente 
(MINING, MINERALS, AND SUSTAINABLE DEVELOPMENT PROJECT, 2002). Por isso, é importante divulgar os bons exemplos de conduta das empresas de mineração.

- Devido às incertezas sobre a sustentabilidade da extração de recursos naturais não-renováveis e a relevância da mineração nesse contexto, é importante que sejam feitos trabalhos que visem à discussão da demonstração da sustentabilidade do setor.

- Para as empresas que planejam implantar um processo de comunicação do seu desempenho não-financeiro, é útil poder identificar referências no setor de mineração. É importante que o tema seja disseminado para que empresas de todos os portes possam se auto-avaliar e utilizar essa informação na formulação de suas estratégias.

- Alguns trabalhos sobre o tema concentraram os estudos em relatórios de um único país, e relatórios de um determinado ano em vários países ou vários setores.

O trabalho poderá servir como um documento informativo, motivador e orientador, apresentando um cenário para discussão. Pretende-se colaborar para maior compreensão dessa importante ferramenta gerencial, motivando as empresas para a utilização desses relatórios e permitindo aprimoramento das que já divulgam os resultados das suas práticas em sustentabilidade.

\subsection{Estrutura do trabalho}

Esta dissertação está dividida nos seguintes capítulos:

II. Pesquisa bibliográfica: Feita em bases de dados de artigos, bibliotecas da USP e Internet, com foco na contextualização do tema e do setor, histórico da avaliação de desempenho não-financeiro e levantamento de boas práticas e estudos sobre publicação de relatórios de sustentabilidade. A pesquisa nas bibliotecas da USP (pelo catálogo on-line global - Dedalus) foi feita a partir de palavras chave (como sustentabilidade, sustentável, sustainability, sostenible, sostenibilidad, indicadores, indicators, mineração, mining), incluindo teses e dissertações de pesquisadores, 
bem como publicações nacionais e internacionais. Os artigos foram encontrados através de pesquisa em bases de dados como Science Direct, ISI Web of Science, $\mathrm{ABI} /$ Inform, Compendex e Scopus, com palavras-chave como corporate sustainability report. A internet forneceu pesquisas e padrões de empresas e instituições dedicadas ao estudo da sustentabilidade e de relatórios corporativos.

III. Delimitação do campo de observação: Levantamento dos critérios para a seleção de empresas que publicam relatórios de sustentabilidade e seleção das empresas a serem pesquisadas.

IV. Levantamento de dados documentais: Levantamento dos dados necessários para investigação: relatórios publicados pelas empresas selecionadas, em websites corporativos e por contato via correio eletrônico.

V. Elaboração de instrumento para coleta de dados: Elaboração de roteiro de observação para a leitura e tratamento dos dados dos relatórios, na ferramenta MS Excel. Aplicação teste e eventual revisão do instrumento.

VI. Coleta e tratamento de dados: Leitura dos relatórios e preenchimento do formulário. Elaboração dos quadros, tabelas e gráficos adicionais.

VII. Análise e interpretação dos dados: Segundo o critério estabelecido, seguindo-se a uma síntese que visa à reconstituição da representação do cenário em cada empresa e do conjunto de empresas.

VIII. Redação final: Consolidação do texto final da dissertação após revisão e aprovação pela banca de qualificação. 


\section{REVISÃO DA LITERATURA}

\subsection{Visão geral de relatórios de sustentabilidade}

\subsubsection{Definição}

Há uma crença crescente de que a informação financeira isolada não é um indicador suficiente da saúde e riqueza de uma empresa. Mesmo os acionistas tradicionais estão procurando mais informações relevantes. Novos públicos estão procurando informação não-financeira que possa ser usada para fins de investimento, como FTSE4Good ${ }^{2}$ ou o Índice de Sustentabilidade Dow Jones ${ }^{3}$. Cada vez mais empresas estão respondendo através da publicação de relatórios anuais que discutem seus impactos e desempenho não-financeiros. As empresas de sucesso estão descobrindo que podem usar códigos, padrões e outros instrumentos de responsabilidade corporativa (accountability ${ }^{4}$ ) como os relatórios para ajudar a compreender a relação complexa entre desenvolvimento sustentável e suas estratégias de negócios (WORLD BUSINESS COUNCIL FOR SUSTAINABLE DEVELOPMENT, 2005).

Segundo World Business Council for Sustainable Development - WBCSD (2005), uma pesquisa de opinião realizada com 21.000 pessoas em 20 países pela empresa de pesquisa Globescan no final de 2003, organizações não-governamentais foram

\footnotetext{
${ }^{2}$ FTSE4GOOD Index Series: índices de responsabilidade social para o público interessado em investimentos socialmente responsáveis. As empresas constituintes devem passar por um critério de eligibilidade, demonstrando como elas identificam, gerenciam e reportam os seus riscos social e ambiental aos seus acionistas e outras partes interessadas. Lançado em 2001. (FINANCIAL TIMES STOCK EXCHANGE, 2005).

3 Dow Jones Sustainability Indexes: índices para monitorar o desempenho de empresas líderes em sustentabilidade corporativa. A metodologia avalia as oportunidades e riscos derivados das dimensões econômica, ambiental e social dos primeiros $10 \%$ das empresas incluídas no Dow Jones Global Index. Lançado em 1999 (SAM INDEXES GMBH, 2005).

${ }^{4} \mathrm{O}$ termo inglês accountability ainda não possui um similar em português. A abrangência do termo vai além de "responsabilidade" ou "prestação de contas", e por isso será traduzido neste trabalho como "responsabilidade corporativa". O dicionário Longman (PEARSON EDUCATION, 2006) define accountable como alguém responsável pelo efeito de suas ações e disposto a explicar ou ser criticado por elas. O dicionário Cambridge (CAMBRIDGE UNIVERSITY PRESS, 2006) define accountable como alguém completamente responsável pelo que faz e capaz de dar uma razão satisfatória para isso.
} 
identificadas como as mais confiáveis, e as empresas multinacionais como as menos confiáveis. A empresa de consultoria Sustainability e United Nations Environment Programme (UNEP) (1997) acredita que a confiança nos negócios e nos mercados será mais forte onde houver altos níveis de transparência e responsabilidade corporativa.

Algumas pesquisas e trabalhos acadêmicos começam a estudar a relação entre valor da empresa e uma adequada prestação de contas. Pesquisas citadas pelo WBCSD (2005) mostram que as empresas que entendem e agem de acordo com sua responsabilidade social alcançam melhores retornos para acionistas. Um estudo feito pela empresa de pesquisa em investimento Innovest (2004) constatou que em $85 \%$ das avaliações feitas (em literatura e estudos de casos) foi encontrada uma correlação positiva entre governança ambiental ${ }^{5}$ e desempenho financeiro.

Existem várias definições para relatórios de sustentabilidade, todas semelhantes na essência. Segundo WBCSD (2002), são relatórios públicos feitos pelas empresas para fornecer às partes interessadas internas e externas uma visão da posição e atividades corporativas nas dimensões econômicas, ambientais e sociais. Segundo a consultoria KPMG e o Instituto de Gestão Ambiental da Universidade de Amsterdã são relatórios que incluem informação quantitativa e qualitativa sobre os desempenhos financeiro/econômico, social/ético e ambiental de uma maneira balanceada (KPMG ; WETENSCHAPPELIJK INSTITUUT VOOR MILIEUMANAGEMENT, 2002).

Segundo DAUB (2007), um relatório pode ser considerado relatório de sustentabilidade se é público e se informa ao leitor como a empresa está enfrentando os desafios corporativos em sustentabilidade. Deve conter informação qualitativa e quantitativa sobre o quanto a empresa melhorou suas eficácia e eficiência econômica, ambiental e social no período reportado e como integra esses aspectos em um sistema de gestão da sustentabilidade.

\footnotetext{
${ }^{5}$ O estudo define "governança ambiental" como a gestão que uma empresa faz dos seus impactos, riscos, desempenho e oportunidades ambientais, incluindo valores, política, visão, processos e monitoramento.
} 
As empresas intitulam seus relatórios de várias maneiras diferentes. Os relatórios são identificados como ambientais, de saúde e segurança, da comunidade, social, social e ambiental, de cidadania corporativa ou responsabilidade social empresarial. (SUSTAINABILITY; UNEP, 2000). Enquanto em 1990 quase todos os relatórios eram chamados "ambientais", somente $41 \%$ dos 100 relatórios analisados em uma pesquisa feita pela Sustainability e UNEP (2002) ainda levavam esse título. Conforme apresentado no Quadro 1, 22\% dos relatórios já apresentavam um título relacionado a sustentabilidade. No entanto, mesmo que a palavra sustentabilidade não seja mencionada no título, a maioria dos relatórios continha informação significativa sobre pelo menos duas dimensões do tripé da sustentabilidade (SUSTAINABILITY; UNEP, 2002).

Quadro 1 - Títulos dos relatórios

\begin{tabular}{|l|c|}
\hline \multicolumn{2}{|c|}{ Quadro 1 } \\
\hline \multicolumn{2}{|c|}{ Parte prítulos dos relatórios } \\
\hline Desempenho ambiental & Porcentagem de relatórios (\%) \\
Sustentabilidade & 41 \\
Desempenho social & 22 \\
Relatórios anuais & 12 \\
Saúde e segurança & 4 \\
Responsabilidade corporativa & 4 \\
"Triple bottom line" & 2 \\
\hline
\end{tabular}

Fonte: Adaptado de SUSTAINABILITY e UNEP (2002)

Algumas razões pelas quais as empresas publicam relatórios de sustentabilidade são: preocupações das partes interessadas, requerimentos legais, condições ambientais atreladas a financiamentos, pressões internas, da cadeia de suprimentos, de pares ou da sociedade (MINING AND ENVIRONMENT RESEARCH NETWORK, 1998).

Líderes de negócio já reconhecem como os maiores benefícios dos relatórios sociais e ambientais:

- melhorar as relações com as partes interessadas (37\%),

- melhorar a gestão da sustentabilidade (30\%),

- proteger a licença social (15\%),

- melhorar a reputação (12\%) e

- evitar regulamentação (2\%), entre outros (4\%) (SUSTAINABILITY; UNEP, 2002). 
Além desses, um estudo da consultoria Deloitte (2007b) apresenta outros benefícios como: diminuição do perfil de risco, aumento da eficiência operacional e inovação do produtos e serviços, novos acessos a formadores de opinião, maior facilidade no recrutamento e retenção, acesso a financiamentos, maior fidelidade do cliente e suporte ao planejamento de longo prazo. O uso de indicadores e a prática de elaboração de relatórios de sustentabilidade nas organizações torna as mesmas mais transparentes e facilita a prática de benchmarking, bem como o monitoramento do seu desempenho ambiental, social e econômico ao longo do tempo (AMARAL, 2003).

É importante, todavia, lembrar que um único relatório impresso dificilmente atenderá por igual todas as necessidades das partes interessadas. É necessário integrar os relatórios em um processo de comunicação completo, reconhecendo que diferentes partes interessadas têm interesses, preocupações e necessidades de informação diferentes. Devem-se consultar as partes interessadas sobre o formato apropriado para o relatório e suas fronteiras, fornecer-Ihes informação útil e relevante que lhes permita compreender, comparar e responder prontamente às suas necessidades $\mathrm{e}$ opiniões (SUSTAINABILITY; UNEP, 2000).

Um relatório bem feito não necessariamente implica em bom desempenho. Por outro lado, a inexistência de um relatório público (ou um relatório mal feito) não significa desempenho ruim. Ao invés disso, a divulgação pública desses relatórios demonstra o desejo das empresas de serem transparentes e de prestarem contas, comprometendo-se a embarcar em um ciclo de melhoria contínua (SUSTAINABILITY; UNEP, 1997).

\subsubsection{Histórico}

Nos primeiros anos do século 21 houve fortes mudanças em relação à transparência corporativa. Empresas como Shell, Monsanto, Nike, Enron e Andersen foram expostas a grandes pressões pela opinião pública e imprensa. Uma série de incidentes envolvendo perda de confiança forçou as empresas a saírem do estágio de concepção dos relatórios ambientais. Nessa época a indústria resistia à demanda 
de maior transparência corporativa e potenciais usuários não sabiam que informação solicitar.

A necessidade de ganhar a confiança dos diversos públicos demandou transparência e as primeiras informações sobre o desempenho ambiental são publicadas. Para enfrentar o desafio da sustentabilidade, por exemplo, as empresas de mineração do Canadá, na primeira metade dos anos 90, usavam as seguintes abordagens estratégicas : (i) investimento em pesquisa e desenvolvimento; (ii) envolvimento das partes interessadas; (iii) encorajamento de uma rede internacional de empresas de mineração; (iv) implementação de padrões de gestão ambiental e (v) implementação de acordos voluntários (SÁNCHEZ, 1998). Nesse contexto surgiram os direcionadores do processo de publicação de relatório não-financeiros, alguns dos quais apresentados no Quadro 2.

Quadro 2 - Direcionadores dos primeiros relatórios

\begin{tabular}{|c|c|c|}
\hline Ano & Direcionador & Descrição \\
\hline 1987 & $\begin{array}{l}\text { Toxic Releases Inventory (TRI) - } \\
\text { Inventário de emissões tóxicas }\end{array}$ & $\begin{array}{l}\text { Divulgação pública e obrigatória do uso e } \\
\text { emissões de produtos regulados (EUA). }\end{array}$ \\
\hline 1988 & Atuação Responsável & $\begin{array}{l}\text { Código de conduta das indústrias químicas, que } \\
\text { inclui relatórios de desempenho. }\end{array}$ \\
\hline 1989 & Princípios de CERES Valdez & $\begin{array}{l}\text { Código de conduta que inclui relatório ambiental } \\
\text { público. }\end{array}$ \\
\hline 1991 & $\begin{array}{l}\text { International Chamber of Commerce - } \\
\text { Business Charter for Sustainable } \\
\text { Development }\end{array}$ & $\begin{array}{l}\text { Código de conduta com um dos princípios sobre } \\
\text { divulgação do desempenho ambiental. }\end{array}$ \\
\hline 1992 & Agenda 21 & $\begin{array}{l}\text { Ação global das Nações Unidas para } \\
\text { desenvolvimento sustentável, que inclui relatórios } \\
\text { ambientais corporativos. }\end{array}$ \\
\hline
\end{tabular}

Fonte: Adaptado de SUSTAINABILITY e UNEP (2002)

O princípio 10 da agenda 21, adotada pela United Nations Conference on Environment and Development (UNCED) no Rio de Janeiro em 1992, promove a divulgação e disseminação da informação sobre o desempenho ambiental das empresas. O capítulo 30 encoraja as empresas a "informar anualmente sobre seus resultados ambientais, bem como sobre seu uso de energia e recursos naturais e adotar códigos de conduta que promovam as melhores práticas ambientais [...] e informar sobre sua implementação" (MINISTÉRIO DO MEIO AMBIENTE, 1992). Posteriormente, em 2000, foi adotada uma agenda complementar denominada "Objetivos do Milênio", que são oito objetivos e 21 metas a serem alcançados até 2015 pelos países membros das Nações Unidas (UNITED NATIONS, 2000) 
No site Corporate Register (em que voluntariamente as empresas anexam seus relatórios não-financeiros) o primeiro relatório registrado foi publicado em 1988 (Health and Safety Annual Report 1987), pela empresa British Nuclear Fuels. A empresa Norsk Hydro - empresa norueguesa produtora de alumínio e energia publicou seu primeiro relatório ambiental em 1990 (Norsk Hydro Environmental Report 1989), ano em que também o fizeram as empresas BASF e Dow Chemical (CORPORATE REGISTER, 2008). A empresa Monsanto divulga suas emissões de acordo com o TRI desde 1987 e foi a primeira a publicar relatórios ambientais na América do Norte em 1991 (MONSANTO COMPANY, 1997) .

Os relatórios ambientais se espalharam rapidamente, sobretudo entre empresas multinacionais. Houve maior divulgação de relatórios ambientais em comparação com relatórios de sustentabilidade porque os problemas ambientais relacionados com o crescimento foram publicados anteriormente (DAUB, 2007).

Houve uma evolução no foco dos relatórios, que de ambiental somente, passou a abranger também dimensões econômicas, sociais e éticas do desempenho do negócio (SUSTAINABILITY; UNEP, 2000). Assim, surgiram os balanços sociais em resposta às demandas de 1970 para que as empresas introduzissem uma contabilidade social (DAUB, 2007).

Segundo o Instituto Brasileiro de Análises Sociais e Econômicas (Ibase), o balanço social é um demonstrativo publicado anualmente pela empresa reunindo um conjunto de informações sobre os projetos, benefícios e ações sociais dirigidas aos empregados, investidores, analistas de mercado, acionistas e a comunidade. É também um instrumento estratégico para avaliar e multiplicar o exercício da responsabilidade social corporativa (INSTITUTO BRASILEIRO DE ANÁLISES ECONÔMICAS E SOCIAIS, 2005).

Com freqüência, preocupações com desenvolvimento social e econômico sobrepõem-se às questões ambientais nos países em desenvolvimento, simplesmente por causa de necessidades humanas urgentes. Isto se reflete, por exemplo, na adoção brasileira do balanço social - produzido por 150 empresas em 
2002. Já no âmbito mundial foi lançado em 1999 o programa voluntário "Pacto Global", que contém 10 princípios com o objetivo de encorajar o alinhamento das políticas e práticas empresariais com declarações universais nas áreas de direitos humanos, direitos do trabalho, proteção ambiental e combate à corrupção (PROGRAMA DAS NAÇÕES UNIDAS PARA O DESENVOLVIMENTO, 2008).

$\mathrm{Na}$ última década, houve um grande aumento na publicação de relatórios nãofinanceiros, conforme mostra a Figura 1:

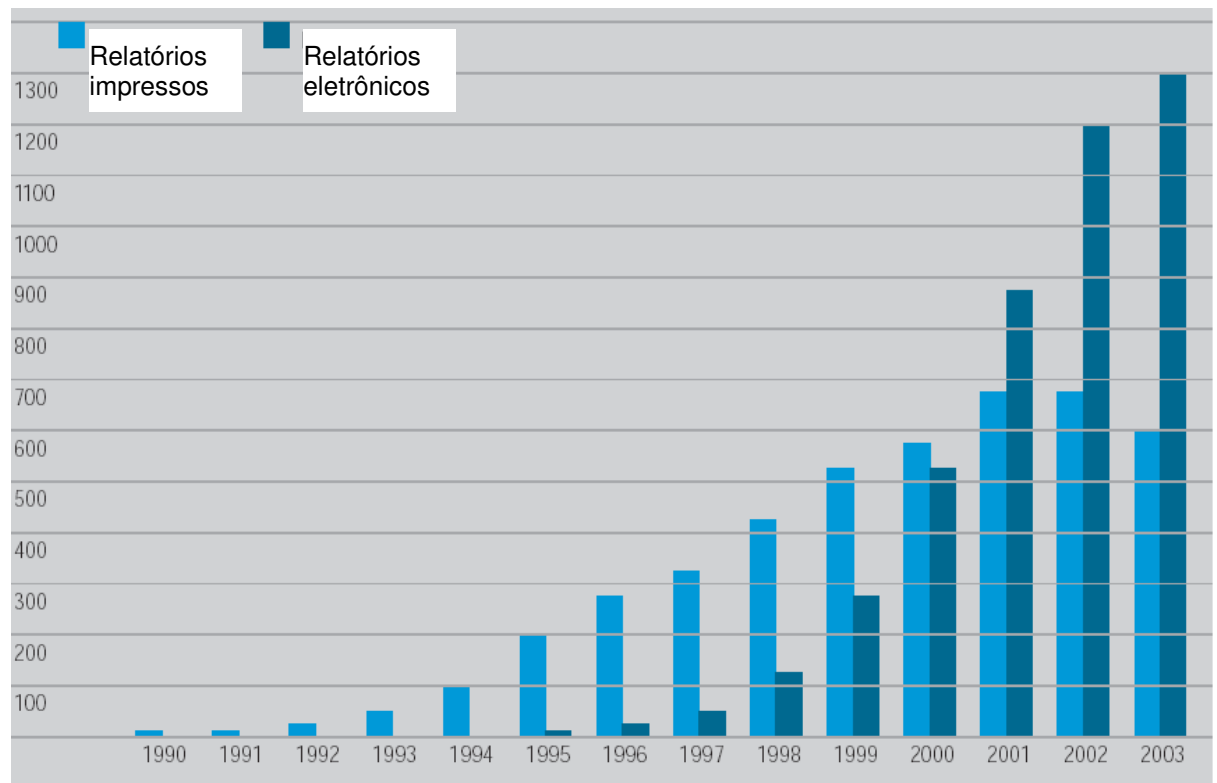

Figura 1 - Relatórios não-financeiros corporativos 1990-2003 Fonte: SUSTAINABILITY, UNEP e STANDARD \& POOR'S (2004)

Atualmente $^{6}$ há 16.092 relatórios de 4.183 empresas registrados no site Corporate Register, dos quais 893 são do setor de mineração. A Tabela 1 compara os relatórios registrados para vários setores.

\footnotetext{
${ }^{6}$ Consulta feita em 10 de fevereiro de 2008
} 
Tabela 1 - Número de relatórios registrados por setor

\begin{tabular}{|c|c|c|}
\hline Posição & Setor & $\begin{array}{c}\text { Número de relatórios } \\
\text { publicados }\end{array}$ \\
\hline 1 & Químico & 1170 \\
\hline 2 & Eletricidade & 1107 \\
\hline 3 & Óleo e Gás & 947 \\
\hline 4 & Transporte & 929 \\
\hline 5 & Bancos & 914 \\
\hline 6 & Mineração & 893 \\
\hline 7 & Materiais de construção & 722 \\
\hline 8 & Serviços & 643 \\
\hline 9 & Equipamentos eletro-eletrônicos & 625 \\
\hline 10 & Papel e Florestas & 563 \\
\hline 11 & Automobilístico & 539 \\
\hline 12 & Tecnologia da Informação Hardware e Software & 478 \\
\hline 13 & Aço e outros metais & 468 \\
\hline 14 & Engenharia e Máquinas & 431 \\
\hline 15 & Retailers & 429 \\
\hline 16 & Indústrias diversas & 420 \\
\hline 17 & Água & 413 \\
\hline 18 & Farmacêutica e Biotecnologia & 411 \\
\hline 19 & Telecomunicação & 409 \\
\hline 20 & Alimentos & 362 \\
\hline 21 & Utilidades & 330 \\
\hline 22 & Artigos residenciais e Têxteis & 314 \\
\hline 23 & Bebidas & 280 \\
\hline 24 & Mídia e Fotografia & 270 \\
\hline 25 & Governos e Agências & 255 \\
\hline 26 & Seguros & 248 \\
\hline 27 & Saúde & 190 \\
\hline 28 & Entretenimento e Hotéis & 190 \\
\hline 29 & Serviços Financeiros & 177 \\
\hline 30 & Cuidados pessoais & 147 \\
\hline 31 & Tabaco & 133 \\
\hline 32 & Imobiliário & 114 \\
\hline 33 & Outros & 106 \\
\hline 34 & Distribuição de gás & 97 \\
\hline 35 & Defesa e Aeroespaço & 91 \\
\hline 36 & Educação & 84 \\
\hline 37 & Embalagem & 77 \\
\hline 38 & Seguro de vida & 48 \\
\hline 39 & Distribuidores & 44 \\
\hline 40 & Investimentos & 23 \\
\hline
\end{tabular}

Fonte: Adaptado de Corporate Register (2008)

Apesar do aumento claro na quantidade de empresas que publicam esses relatórios, os números são ainda pequenos perto da quantidade total de organizações comerciais, públicas e não-governamentais. Para que haja um efeito transformador verdadeiro, os relatórios não-financeiros devem cobrir uma comunidade muito maior do que a atual (SUSTAINABILITY; UNEP, 2000). Estima-se que 50.000 empresas multinacionais ainda publicam relatórios não-financeiros, sem contar os milhões de pequenas empresas operando em diferentes partes do mundo (SUSTAINABILITY; 
UNEP; STANDARD \& POOR'S, 2004). As empresas freqüentemente alegam restrições de recursos - tempo e dinheiro - como a principal razão para não publicar relatórios não-financeiros (SUSTAINABILITY; UNEP, 2002).

As empresas estão usando diferentes canais de comunicação (como relatórios anuais, Internet, disquetes, CD-ROMs, etc.) para disseminar informação sobre questões ambientais e sociais. No entanto, como isso pode adicionar complexidade aos relatórios, é crucial que existam ligações claras entre os diferentes tipos de comunicação, o que freqüentemente não ocorre (SUSTAINABILITY; UNEP, 1997)

Com relação à utilização da Internet, uma pesquisa de 1999 analisou 150 websites para verificar quais ofereciam relatórios para impressão e download (por exemplo, em formato pdf). Concluiu-se que $48 \%$ deles tinham relatórios financeiros para download, $31 \%$ disponibilizavam os relatórios ambientais e somente $6 \%$ contavam com relatórios sociais para download (SUSTAINABILITY; UNEP, 2000).

\subsubsection{Marco regulatório}

Alguns países já começaram a prever a obrigatoriedade legal da publicação de relatórios não-financeiros. Nos países germânicos, existe um catálogo com recomendações mínimas publicado pela German Trades Union Federation, em julho de 1979. Essas recomendações são similares à lei francesa 77.769 de 1977 que, em 1982, passou a ser obrigatória para empresas com mais de 300 funcionários. (DAUB, 2007). Também na França, em 2002, o governo requisitou que todas as empresas listadas na bolsa de valores francesa incluíssem informação social, ambiental e laboral nos seus relatórios anuais para os acionistas (SUSTAINABILITY; UNEP, 2002).

$\mathrm{Na}$ Noruega e na Inglaterra, por exemplo, há novas leis declarando o direito do público à informação ambiental (SUSTAINABILITY; UNEP, 2002). Atualmente, diversos outros países da Europa, entre os quais estão Bélgica, Inglaterra, Holanda, Espanha e Portugal, adotam a obrigatoriedade da elaboração do balanço social. (BERNARDO et al., 2005). 
No Brasil, entretanto, ainda não há uma legislação em nível federal voltada para a obrigatoriedade da publicação de balanço social ou de relatórios de sustentabilidade. Porém, em alguns estados e municípios (como Amazonas, Rio Grande do Sul, e municípios de Santo André - São Paulo, Uberlândia - Minas Gerais, João Pessoa Paraíba e Porto Alegre - Rio Grande do Sul ) já existem leis incentivando a publicação desse demonstrativo (BERNARDO et al., 2005).

\subsection{Diretrizes e avaliações de relatórios de sustentabilidade}

\subsubsection{Recomendações e diretrizes para relatórios de sustentabilidade}

Com o objetivo de melhorar a qualidade e o rigor dos relatórios, foram criados modelos, padrões e/ou diretrizes para a elaboração de relatórios de sustentabilidade, que apresentam métodos consistentes e que concentram os esforços de desenvolvimento. Freqüentemente esses modelos são de utilização voluntária e são elaborados por um conjunto de partes interessadas, representando as necessidades e as demandas da indústria, comunidade e pesquisadores.

As empresas podem usar esses padrões e diretrizes como informação (para compreender os conceitos e a prática em questão) ou como referência normativa, pois a adoção de um modelo aceito pelas partes interessadas pode ser benéfico para a imagem e para as negociações da empresa.

Existem vários padrões e modelos para relatórios corporativos não-financeiros. Quando bem desenhados e testados, são considerados importantes por um grande número de partes interessadas. Idealmente, ajudam os executivos a simplificar os sistemas e unificar comportamentos na empresa, assim como tranqüilizar algumas partes interessadas que buscam níveis mínimos de informação e comportamento responsável das empresas. Outra vantagem é poder comparar o desempenho de empresas diferentes, ou da mesma empresa ao longo dos anos. Críticos desses modelos questionam a demanda gerada por serviços de consultoria e auditoria. (SUSTAINABILITY; UNEP, 2000). 
O mais difundido dos padrões atuais é o da Global Reporting Initiative ${ }^{7}$ (GRI). A primeira versão das "Diretrizes para Relatórios de Sustentabilidade GRI" foi publicada em 2002. Existe uma nova versão (G3) publicada em agosto de 2006. Alguns dos modelos existentes são apresentados no anexo C.

No site da Corporate Register há aproximadamente 900 empresas identificadas como usuárias das diretrizes GRI, que juntas publicaram 2279 relatórios (CORPORATE REGISTER, 2008). O Quadro 3 apresenta uma visão geral das diretrizes do GRI. A diretriz contém 79 indicadores de desempenho, dos quais $62 \%$ são classificados como essenciais.

\begin{tabular}{|c|c|c|c|}
\hline Introdução & $\begin{array}{l}\text { Parte } 1 \\
\text { Definição de } \\
\text { Conteúdo, Qualidade } \\
\text { e Limite do Relatório }\end{array}$ & $\begin{array}{l}\text { Parte } 2 \\
\text { Conteúdo do relatório }\end{array}$ & $\begin{array}{l}\text { Esclarecimentos } \\
\text { Gerais sobre a } \\
\text { Elaboração de } \\
\text { Relatórios }\end{array}$ \\
\hline $\begin{array}{l}\text { Orientações gerais } \\
\text { sobre as diretrizes }\end{array}$ & $\begin{array}{l}\text { Definição do Conteúdo } \\
\text { do Relatório, Princípios } \\
\text { para Assegurar a } \\
\text { Qualidade do Relatório } \\
\text { e Orientações para o } \\
\text { Estabelecimento do } \\
\text { Limite do } \\
\text { Relatório }\end{array}$ & $\begin{array}{l}\text { Especificação para } \\
\text { perfil do relatório e } \\
\text { indicadores de } \\
\text { desempenho } \\
\text { econômico, ambiental } \\
\text { e social }\end{array}$ & $\begin{array}{l}\text { Recomendações sobre } \\
\text { Coleta de Dados, } \\
\text { Forma e Periodicidade } \\
\text { do Relatório e } \\
\text { verificação, além do } \\
\text { glossário. }\end{array}$ \\
\hline
\end{tabular}

Fonte: Adaptado de GRI (2006b)

As diretrizes permitem a flexibilidade de utilização, pois as empresas decidem que tópicos irá atender, bem como os indicadores que vai apresentar. No entanto é recomendado que a empresa declare o nível de aplicação das diretrizes, cujo critério é apresentado no Quadro 4.

\footnotetext{
${ }^{7}$ A GRI foi criada em 1997 em Amsterdã como uma iniciativa conjunta da americana Coalition for Environmentally Responsible Economies (CERES) e o United Nations Environment Programme (UNEP).
} 
Quadro 4 - Critérios para declaração do nível de aplicação

\begin{tabular}{|c|c|c|}
\hline & GRI 2002 & GRI G3 \\
\hline Nível & $\begin{array}{l}\text { "Com referência a" (With reference to) } \\
\text { "De acordo com" (In accordance) }\end{array}$ & $\begin{array}{l}\text { Níveis C Iniciante), B (intermediário) e A } \\
\text { (avançado) e "GRI checked". Também é } \\
\text { possível um ponto a mais (+) em cada nível } \\
\text { (por exemplo, C+) caso tenha sido utilizada } \\
\text { verificação externa. }\end{array}$ \\
\hline Critério & $\begin{array}{l}\text { 1. Publicar determinados elementos } \\
\text { 2. Incluir um Sumário de Conteúdo GRI } \\
\text { 3. Incluir todos os indicadores essenciais } \\
\text { (informando os dados relativos ao indicador } \\
\text { ou explicando a omissão) } \\
\text { 4. Garantir que o relatório satisfaça os } \\
\text { princípios da Parte B. } \\
\text { 5. Incluir declaração "de acordo com", } \\
\text { assinada pelo Conselho ou pelo diretor- } \\
\text { presidente }\end{array}$ & $\begin{array}{l}\text { 1) Quantidade e tipo dos indicadores } \\
\text { apresentados } \\
\text { 2) Existência ou não de divulgação da } \\
\text { abordagem gerencial para cada } \\
\text { categoria de indicadores } \\
\text { 3) Apresentação de determinadas } \\
\text { informações } \\
\text { A GRI também pode fazer a verificação do } \\
\text { relatório se solicitado. }\end{array}$ \\
\hline
\end{tabular}

Fonte: Adaptado de GRI (2006a)

Segundo a consultoria Sustainability, 60\% dentre os 50 melhores relatórios de 2002 eram usuários da diretriz GRI. Em 2000, os usuários-piloto do GRI tiveram pontuações levemente superiores (5\%) que a média e em 2002 a diferença aumentou para $8 \%$. Nos 50 melhores de 2004, 47 relatórios (94\%) eram usuários do GRI (SUSTAINABILITY ; UNEP, 2002 ; SUSTAINABILITY; UNEP; STANDARD \& POOR'S, 2004).

O relatório "Trust Us" (SUSTAINABILITY; UNEP, 2002) questiona alguns aspectos da diretriz da GRI:

- A natureza onerosa de coletar e publicar alguns indicadores supera seus benefícios.

- Para algumas partes interessadas, os indicadores recomendados podem ser inúteis, sendo assim injustificados.

- As diretrizes não auxiliam as empresas a julgar o que é realmente importante para as partes interessadas e para o negócio. Algumas empresas podem, portanto, publicar várias informações, mas não necessariamente os impactos mais significativos do negócio.

- Os 11 princípios (parte B) requerem uma compreensão qualitativa considerável e podem ser insuficientemente interpretados pelas empresas

- $\quad$ O foco é a definição de indicadores e não de padrões. 
- Há uma grande necessidade de auditoria para que as empresas não declarem estar em conformidade quando não estão.

- $\quad$ As diretrizes foram elaboradas e adotadas muito rapidamente, não permitindo que houvesse um processo de maturação. Além disso, as novas versões podem fazer com que o investimento da empresa em adotar as diretrizes seja perdido.

Segundo Moneva, Archel e Correa (2006), o conceito de desenvolvimento sustentável da GRI revela alguns problemas:

- Risco de perder o foco em questões amplas de sustentabilidade.

- Integração de indicadores que contribuam para uma visão integrada da sustentabilidade do negócio.

- Redução da percepção de sustentabilidade, colocando as três dimensões no mesmo nível, e não considerando a interação e participação desses constituintes.

- $\quad$ Promoção da construção de um conjunto de indicadores, e não o reforço de valores de desenvolvimento sustentável

As diretrizes GRI e AccountAbility 1000 (AA 1000 - diretriz para verificação externa) recomendam alguns princípios para a definição do conteúdo do relatório, resumidos no Quadro 5.

Quadro 5 - Princípios para definição do conteúdo do relatório segundo GRI G3 e AA 1000

\begin{tabular}{|c|c|c|}
\hline Princípio & GRI G3 & AA1000 \\
\hline MATERIALIDADE & $\begin{array}{l}\text { As informações no relatório devem } \\
\text { cobrir temas e indicadores que } \\
\text { reflitam os impactos econômicos, } \\
\text { ambientais e sociais significativos da } \\
\text { organização ou possam influenciar de } \\
\text { forma substancial as avaliações e } \\
\text { decisões das partes interessadas. }\end{array}$ & $\begin{array}{l}\text { A organização relatora deve incluir no } \\
\text { relatório informação sobre seu } \\
\text { desempenho e sustentabilidade } \\
\text { requeridas pelas partes interessadas } \\
\text { para que elas possam fazer } \\
\text { julgamentos, decisões e ações } \\
\text { baseados em informações. }\end{array}$ \\
\hline $\begin{array}{l}\text { INCLUSÃO DAS } \\
\text { PARTES } \\
\text { INTERESSADAS }\end{array}$ & $\begin{array}{l}\text { A organização relatora deve identificar } \\
\text { suas partes interessadas e explicar no } \\
\text { relatório que medidas foram tomadas } \\
\text { em } \\
\text { resposta a seus interesses e } \\
\text { expectativas procedentes. }\end{array}$ & 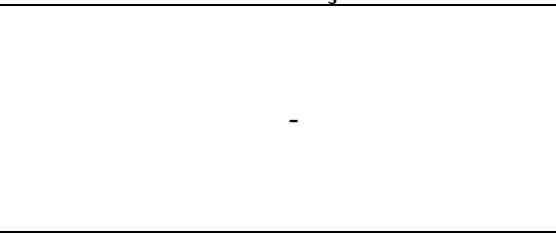 \\
\hline $\begin{array}{c}\text { CONTEXTO DA } \\
\text { SUSTENTABILIDADE }\end{array}$ & $\begin{array}{l}\text { O relatório deverá apresentar o } \\
\text { desempenho da organização no } \\
\text { contexto mais amplo da } \\
\text { sustentabilidade. }\end{array}$ & - \\
\hline
\end{tabular}


conclusão

\begin{tabular}{|c|ll|}
\hline Princípio & \multicolumn{1}{|c|}{ GRI G3 } & \multicolumn{1}{c|}{ AA1000 } \\
\hline & $\begin{array}{l}\text { A cobertura dos temas e indicadores } \\
\text { relevantes, assim } \\
\text { como a definição do limite do relatório, } \\
\text { deverão ser suficientes para refletir os } \\
\text { impactos econômicos, ambientais e } \\
\text { sociais significativos e permitir que as } \\
\text { partes interessadas avaliem o } \\
\text { desempenho da organização no } \\
\text { período analisado. }\end{array}$ & $\begin{array}{l}\text { A extensão em que a organizaço } \\
\text { relatora pode identificar e entender os } \\
\text { aspectos materiais do seu } \\
\text { desempenho em sustentabilidade. }\end{array}$ \\
\hline $\begin{array}{c}\text { CAPACIDADE DE } \\
\text { RESPOSTA }\end{array}$ & - & $\begin{array}{l}\text { A organização relatora deve } \\
\text { responder às preocupações, políticas } \\
\text { e padrões das partes interessadas e } \\
\text { comunicar adequadamente estas } \\
\text { respostas no relatório. }\end{array}$ \\
\hline
\end{tabular}

Fonte: Adaptado de GRI (2006b) e Accountability (2003)

Outra definição de materialidade por Sustainability, UNEP e Standard \& Poor's (2004) diz que algo é "material" se tem o potencial de afetar a percepção das partes interessadas sobre a empresa ou qualquer decisão que possam tomar como resultado. A diretriz GRI G3 também recomenda princípios para assegurar a qualidade do relatório: equilíbrio, comparabilidade, exatidão, periodicidade, clareza e confiabilidade.

Além das diretrizes genéricas, também existem modelos e diretrizes voltados para o setor da mineração, como um suplemento da GRI - Mining and Metals Sector Supplement (GRI, 2005) - e um suplemento similar publicado pelo Instituto Ethos chamado Indicadores Ethos Setoriais de Responsabilidade Social Empresarial Mineração (INSTITUTO ETHOS, 2005). Na intenção de estimular uma abordagem comum para os relatórios, Azapagic (2004) propôs um conjunto de indicadores de desempenho em desenvolvimento sustentável para empresas de mineração.

A consultoria Deloitte desenvolveu um guia com recomendações para a publicação de provisões para fechamento e reabilitação de minas (DELOITTE TOUCHE TOHMATSU, 2007a). A Extractive Industries Transparency Initiative (EITI) promove a transparência na divulgação de pagamentos ao governo (EITI, 2003).

Em 1999, nove empresas de mineração (Anglo American, BHP Billiton, Codelco, Newmont, Noranda, Phelps Dodge, Placer Dome, Rio Tinto e WMC Limited) lançaram a Global Mining Initiative (GMI) que liderou a formação do projeto Mining, 
Metals and Sustainable Development (MMSD). As atividades da GMI foram encerradas em maio de 2002 com o lançamento do relatório final do MMSD (Breaking New Ground) e uma conferência sobre boas práticas e discussões sobre o ciclo de vida da mineração e a contribuição do setor para o desenvolvimento sustentável.

Como parte das ações da GMI, grandes empresas de mineração formaram em 2001 o International Council on Mining \& Metals (ICMM) para seguir a agenda identificada no relatório do MMSD, desenvolver ferramentas para melhorar o desempenho em sustentabilidade e compartilhar boas práticas. O ICMM desenvolveu um modelo de referência para o desenvolvimento sustentável (ICMM Sustainable Development Framework) composto por três elementos - 10 princípios, um guia para publicação de relatórios e um procedimento piloto para auditoria independente. O ICMM também trabalhou em conjunto com a GRI para a elaboração do suplemento para o setor de mineração e metais (ICMM, 2006).

Pode-se fazer um paralelo com as diretrizes para relatórios de recursos e reservas minerais, processo iniciado em 1999 com uma publicação canadense de recomendações para os relatórios e depois seguido por outros padrões nacionais. $A$ qualidade dos relatórios de recursos e de reservas minerais aumentou significativamente nas últimas décadas e o processo agora atingiu um ponto em que os principais países industrializados estão trabalhando para ter definições e padrões comuns para publicação desses relatórios (RENDU ; MISKELLY, 2001) Por exemplo, o código australiano (Australasian Code for Reporting of Mineral Resources and Ore Reserves ou "The JORC Code") contém três princípios: transparência, materialidade e competência (AUSTRALASIAN JOINT ORE RESERVES COMMITTEE, 2004) com objetivos similares aos princípios publicados pela GRI e AA1000.

O debate em torno dos padrões foca na tensão entre flexibilidade e o estabelecimento de requisitos mínimos. Por um lado, os padrões devem garantir que as empresas tenham reserva suficiente para contar sua história apropriadamente, e de maneira útil e inteligível. Por outro lado, eles devem manter uma base de informação adequada que permita comparação, para garantir que as empresas 
estejam tratando suas questões de maneira completa e confiável. A aderência a um modelo de relatório ou de indicador não garante coerência ou desempenho (SUSTAINABILITY; UNEP, 2002).

Existem também estudos específicos sobre indicadores de sustentabilidade (MEADOWS, 1998 ; BOSSEL, 1999). Esses trabalhos são voltados a natureza, modelos e cálculo de indicadores, para avaliação do desenvolvimento sustentável em regiões, países ou cidades.

\subsubsection{Verificação ou auditoria externa}

É importante saber se é possível confiar nos dados e nas informações de um relatório, se a empresa está incluindo as questões relevantes ou se está compilando seus dados de maneira adequada. Para resolver essas questões, pode ser usada a prática de verificação ou garantia de terceira parte - definida pela International Federation of Accountants (IFAC) como a expressão de uma conclusão desenhada com critérios por uma terceira parte para melhorar o grau de confiabilidade que os usuários possam ter sobre o assunto (IFAC, 2003).

Empresas de auditoria, consultorias, organizações não-governamentais, grupos ou especialistas (como Deloitte \& Touche, KPMG, Ernst \& Young, Aspinwall, ERM e SustainAbility, entre outros) são chamados para essa verificação, que pode variar de uma simples assinatura do relatório a recomendações de melhoria (SUSTAINABILITY; UNEP, 1997). Segundo Scott (2000), uma verificação completa dos relatórios deve incluir os seguintes elementos:

- Condução por uma empresa genuinamente independente

- Especificação das áreas examinadas e metodologia usada

- Verificação da precisão de dados e declarações

- Verificação do relatório inteiro e do balanceamento entre as questões

- Especificação das falhas e recomendações

A utilização de padrões para a verificação e auditoria dos relatórios parece ter um impacto positivo na qualidade e na utilidade das declarações de garantia. 
(SUSTAINABILITY; UNEP; STANDARD \& POOR'S, 2004). Segundo Sustainability, UNEP e Standard \& Poor's (2004) e Deloitte (2007b), os padrões mais comumente usados para auditora externa de relatórios de sustentabilidade são:

- "International Standard on Assurance Engagements 3000" (ISAE 3000)

- o alemão IDW PS820,

- o canadense "Canadian Institute of Chartered Accountants (CICA) Standards for Assurance Engagements",

- AA 1000 (Assurance Standard Guidance Principles): especificamente desenvolvido para a garantia de relatórios de sustentabilidade e

- ISO 19011 (Diretrizes para auditorias de sistema de gestão da qualidade e/ou ambiental).

A resposta corporativa para a necessidade de verificação externa tem sido intensa. Em 2002, 13\% das primeiras 250 empresas do ranking Global Fortune 500 publicaram relatórios com verificação externa (PARK; BRORSON, 2005). Em 2002, $68 \%$ dos 50 melhores relatórios analisados usaram algum tipo de auditoria externa, 12\% a mais que em 2000 e em 2004 esse número subiu para 78\%. (SUSTAINABILITY; UNEP, 2002, 2004). Em 2004, entre 39 relatórios que apresentaram algum tipo de revisão, $41 \%$ das declarações foram feitas por uma das empresas de auditoria conhecidas como "Big Four" (Deloitte, Ernst \& Young, KPMG and PricewaterhouseCoopers), $10 \%$ foram feitas por organizações interessadas ou especialistas e $49 \%$ vieram de profissionais de garantia de empresas menores (como ERM, JustAssurance e CSR Network) (SUSTAINABILITY; UNEP; STANDARD \& POOR'S, 2004).

Segundo SUSTAINABILITY, UNEP e Standard \& Poor's (2004), a auditoria é um dos maiores custos associados com ao relatório. Apesar dessa desvantagem, possivelmente, no futuro, a verificação passará de uma opção para um requerimento padrão. (SUSTAINABILITY; UNEP, 1997).

Park e Brorson (2005) recomendaram melhorias nas verificações de terceira parte após a análise de relatórios de empresas suecas: garantir que todo relatório seja coberto pela verificação, aplicar diretrizes e critérios de verificação geralmente 
aceitos e prestar atenção no que as partes interessadas apreciariam mais para atender a essas preocupações.

\subsubsection{Avaliação de relatórios de sustentabilidade}

As avaliações das práticas de relatórios das empresas existem em várias formas há muitos anos. Em muitos países, por exemplo, jornais especializados listam os relatórios anuais das empresas em índices de bolsas de valores, testando uma vez ao ano a qualidade do conteúdo e desenho. Outro método de avaliação visto freqüentemente é premiar relatórios anuais bem elaborados como faz a Association of Chartered Certified Accountants (ACCA) na Grã-Bretanha que concede um prêmio para melhor relatório ambiental desde 1991. Em 1999, criou-se outro prêmio para melhor relatório social e, em 2001, para melhor relatório de sustentabilidade (DAUB, 2007).

Um prêmio europeu - "European Sustainability Reporting Awards" (ESRA) - foi criado pela ACCA e por suas similares holandesa e dinamarquesa, a Royal Nederlands Instituut van Registeraccountants (Royal NIVRA) e Foreningen Statsautoriserede Revisorer (FSR). Nas últimas premiações (em 2002, 2003, 2004 e 2005) os ganhadores foram, respectivamente: The Co-operative Bank plc (Reino Unido), Novo Nordisk (Noruega), Co-operative Financial Services - CFS (Reino Unido) e Rabobank Group (Holanda) (ACCA, 2006).

Pouco depois da publicação dos primeiros relatórios, surgiram as primeiras análises dos mesmos. Há mais de uma década, artigos e estudos de empresas privadas analisam a qualidade de relatórios de sustentabilidade, no setor de mineração e outros setores. O Quadro 6 apresenta as principais características de alguns desses estudos. 
Quadro 6 - Resumo dos estudos sobre relatórios de sustentabilidade

\begin{tabular}{|c|c|c|c|}
\hline Artigo & Abrangência & Categorias & Método de avaliação \\
\hline $\begin{array}{l}\text { Sustainability } \\
(1993,1997, \\
2000,2002, \\
2004,2006)\end{array}$ & $\begin{array}{l}\text { Amostra de relatórios } \\
\text { premiados e } \\
\text { referenciados no ano }\end{array}$ & $\begin{array}{l}\text { Contexto e compromissos } \\
\text { Qualidade da gestão } \\
\text { Desempenho } \\
\text { Acessibilidade e garantia }\end{array}$ & $\begin{array}{l}48 \text { requisitos avaliados de } \\
0 \text { a } 4 \text {. } \\
\text { (Os requisitos de } \\
\text { avaliação são } \\
\text { apresentados no Anexo } \\
\text { A.) }\end{array}$ \\
\hline MERN (2000) & $\begin{array}{l}50 \text { maiores empresas de } \\
\text { mineração (segundo } \\
\text { Financial Times) } \\
\text { Relatórios de } 1998\end{array}$ & $\begin{array}{l}\text { Política da empresa } \\
\text { Outras empresas } \\
\text { Empregados } \\
\text { Comunidades locais } \\
\text { ONGs e governo } \\
\text { População geral } \\
\text { Meio ambiente }\end{array}$ & $\begin{array}{l}95 \text { requisitos avaliados } \\
\text { em disponível }(X) \text { ou não. } \\
\text { (Adaptação dos } 16 \\
\text { princípios de Gestão } \\
\text { Ambiental do The } \\
\text { Business Charter for } \\
\text { Sustainable Development) }\end{array}$ \\
\hline Scott (2000) & $\begin{array}{l}14 \text { grandes empresas de } \\
\text { mineração } \\
\text { Relatórios de } 1996 \text { a } \\
1999\end{array}$ & $\begin{array}{l}\text { Gestão ambiental } \\
\text { Social e Comunidade } \\
\text { Saúde e segurança } \\
\text { Operações da empresa } \\
\text { Informação do relatório }\end{array}$ & $\begin{array}{l}33 \text { requisitos avaliados } \\
\text { em Descritos em texto e } \\
\text { Descrito sem texto e } \\
\text { Dados }\end{array}$ \\
\hline $\begin{array}{l}\text { Peck e Sinding } \\
\text { (2003) }\end{array}$ & $\begin{array}{l}50 \text { maiores empresas de } \\
\text { mineração (base de } \\
\text { dados Raw Materials } \\
\text { Group - RMG } \\
\text { Relatórios de } 1998 \text { e } \\
1999\end{array}$ & $\begin{array}{l}\text { Gestão ambiental } \\
\text { Saúde e segurança } \\
\text { Compromissos } \\
\text { ambientais e sociais } \\
\text { Comparabilidade e } \\
\text { verificação } \\
\text { Indicadores de } \\
\text { desempenho operacional }\end{array}$ & $\begin{array}{l}26 \text { critérios avaliados de } 0 \\
\text { a } 2 \\
\text { (Baseado no Australian } \\
\text { Minerals Industry Code for } \\
\text { Environmental } \\
\text { Management - atual } \\
\text { "Enduring Value") }\end{array}$ \\
\hline $\begin{array}{l}\text { KPMG }(2003, \\
2006)\end{array}$ & $\begin{array}{l}44 \text { empresas do setor de } \\
\text { mineração de vários } \\
\text { países } \\
\text { Relatórios publicados no } \\
\text { ano }\end{array}$ & $\begin{array}{l}\text { Foco do relatório } \\
\text { Garantia } \\
\text { Princípios do negócio e } \\
\text { referências a padrões } \\
\text { Questões chave }\end{array}$ & $\begin{array}{l}\text { Freqüência em } \\
\text { porcentagem dos } \\
\text { relatórios que apresentam } \\
\text { as informações }\end{array}$ \\
\hline Kolk (2003) & $\begin{array}{l}250 \text { primeiras empresas } \\
\text { do ranking Fortune Global } \\
500 \\
\text { Relatórios de } 1998 \text { a } \\
2001\end{array}$ & $\begin{array}{l}\text { Relatórios por país } \\
\text { Relatórios por setor } \\
\text { Tópicos sociais } \\
\text { Indicadores de } \\
\text { desempenho social }\end{array}$ & $\begin{array}{l}\text { Freqüência em } \\
\text { porcentagem dos } \\
\text { relatórios que apresentam } \\
\text { as informações }\end{array}$ \\
\hline $\begin{array}{l}\text { Jenkins e } \\
\text { Yakovleva } \\
(2006)\end{array}$ & $\begin{array}{l}10 \text { maiores empresas de } \\
\text { mineração } \\
\text { Relatórios de } 1999 \text { a } \\
2003\end{array}$ & $\begin{array}{l}\text { Tipo de relatório } \\
\text { Conteúdo da política } \\
\text { Formato do relatório }\end{array}$ & $\begin{array}{l}17 \text { requisitos avaliados } \\
\text { em presente ou ausente }\end{array}$ \\
\hline
\end{tabular}




\begin{tabular}{|c|c|c|c|}
\hline Artigo & Abrangência & Categorias & Método de avaliação \\
\hline Daub (2007) & $\begin{array}{l}100 \text { maiores empresas da } \\
\text { Suíça } \\
\text { Relatórios de } 2005\end{array}$ & $\begin{array}{l}\text { Contexto e cobertura } \\
\text { Política, Sistemas de } \\
\text { gestão e Relações com } \\
\text { partes interessadas } \\
\text { Dimensões do } \\
\text { desempenho } \\
\text { Transparência e Visão } \\
\text { geral }\end{array}$ & $\begin{array}{l}33 \text { requisitos avaliados } \\
\text { em uma escala de } 0 \text { a } 3\end{array}$ \\
\hline $\begin{array}{l}\text { Deloitte } \\
\text { (2007b) }\end{array}$ & $\begin{array}{l}36 \text { empresas de } \\
\text { mineração de vários } \\
\text { tamanhos e localidades } \\
\text { Relatórios de } 2006\end{array}$ & $\begin{array}{l}\text { Indicadores ambientais } \\
\text { Indicadores econômicos } \\
\text { Indicadores de práticas } \\
\text { laborais } \\
\text { Indicadores sociais } \\
\text { Análise de garantia }\end{array}$ & $\begin{array}{l}29 \text { requisitos, } \\
\text { classificados entre } \\
\text { Quantitativos, Qualitativos } \\
\text { e Não publicados. }\end{array}$ \\
\hline
\end{tabular}

O estudo feito por Daub (2007) resultou em uma pontuação média dos relatórios de $33.33 \%$ do total de pontos possível. A categoria mais fraca foi a relacionada aos indicadores de desempenho (28,3\%) e a mais forte foi Transparência e Visão Geral $(52,19 \%)$.

A Tabela 2 apresenta os resultados do relatório Global Reporters, pesquisa bienal feita pela consultoria Sustainability, que apresenta os cinqüenta melhores relatórios em cada ano. A avaliação é feita inicialmente por um analista que passa por semanas de treinamento e depois é revisada por um segundo analista. A pontuação final é dada após acordo entre os dois avaliadores.

Com relação ao tamanho do relatório mencionado anteriormente, a média em 1997 foi de 38 páginas (SUSTAINABILITY; UNEP, 1997). Entre 2000 e 2002, a média de páginas dos relatórios aumentou 45\%, sem aumento associado na qualidade geral dos relatórios (SUSTAINABILITY; UNEP, 2002). Segundo Sustainability e UNEP (2004; 2006) a média do número de páginas dos relatórios analisados era 72 páginas em 2004, e 90 páginas em 2006. 
Tabela 2 - Porcentual médio - Avaliações de 1997 a 2006

\begin{tabular}{l|c|c|c|c|c|}
\hline Categoria & $\mathbf{1 9 9 7 ^ { \mathbf { 6 } }}$ & $\mathbf{2 0 0 0}$ & $\mathbf{2 0 0 2}$ & $\mathbf{2 0 0 4}$ & $\mathbf{2 0 0 6}$ \\
\hline Pontuação média & $37 \%$ & $43 \%$ & $42 \%$ & $50 \%$ & - \\
Pontuação mais alta & $67 \%$ & $62 \%$ & $61 \%$ & $71 \%$ & $80 \%$ \\
Contexto e Compromissos & - & $50 \%$ & $48 \%$ & $57 \%$ & - \\
Qualidade da Gestão & - & $46 \%$ & $42 \%$ & $48 \%$ & - \\
Desempenho Econômico & - & $32 \%$ & $36 \%$ & $47 \%$ & - \\
Desempenho Social e Ético & - & $29 \%$ & $33 \%$ & $50 \%$ & - \\
Desempenho Ambiental & - & $53 \%$ & $44 \%$ & $47 \%$ & - \\
Desempenho Multidimensional & - & $50 \%$ & $33 \%$ & $36 \%$ & - \\
Acessibilidade e Garantia & - & $43 \%$ & $50 \%$ & $56 \%$ & $95 \%$ \\
\hline
\end{tabular}

Fonte: Adaptado de Sustainability e UNEP (1997, 2000, 2002, 2004, 2006)

A ênfase inicial em desempenho ambiental diminuiu para que os relatórios melhorassem em desempenho social e ético, mas com prejuízo para a dimensão ambiental. A dimensão econômica continua a ser o aspecto mais fraco, com predominância de informação financeira básica, com pouca interpretação ou associação com impactos econômicos mais amplos. A identificação de questões/riscos foi fraca na amostra de 2002, o que reflete em outras áreas como sistemas de gestão e resultados de desempenho. As pontuações evoluíram na categoria Acessibilidade e Garantia (SUSTAINABILITY; UNEP, 2002).

$\mathrm{Na}$ avaliação de 2004, houve uma expansão da dimensão econômica. Entretanto, mesmo com as altas pontuações, o foco estava mais em publicar que agir. Poucas empresas associam os resultados financeiros com os não-financeiros. A Tabela 2 mostra que houve avanço e melhoria na qualidade, mas as últimas avaliações têm mostrado que foi alcançado um platô (SUSTAINABILITY; UNEP; STANDARD \& POOR'S, 2004)

Peck e Sinding (2003) fizeram uma análise de relatórios da mineração e classificou as empresas analisadas entre iniciantes, resistentes, avarentos (hoaders) e "reporters". Com um objetivo semelhante, o estudo "Coming Clean" de 1993 define cinco níveis diferentes de maturidade, do estágio 1 (Green Glossies - "brilho verde")

\footnotetext{
${ }^{8}$ As pesquisas de 1993, 1996 e 1997 utilizaram categorias e critérios diferentes e por isso não podem ser comparadas com os anos posteriores.

${ }^{9}$ A pesquisa de 2006 apresentou os resultados consolidados de maneira diferente que nos anos anteriores
} 
ao estágio 5 (Relatório de Sustentabilidade) (SUSTAINABILITY; DELOITTE TOUCHE TOHMATSU INTERNATIONAL; INTERNATIONAL INSTITUTE FOR SUSTAINABLE DEVELOPMENT, 1993). Com a evolução das empresas, em alguns anos esse modelo tornou-se obsoleto, sendo revisado no relatório "Engaging Stakeholders" (SUSTAINABILITY; UNEP, 1997). O Quadro 7 mostra o modelo de cinco estágios revisado com os requisitos para cada um dos estágios e subestágios.

Quadro 7 - Modelo revisado de cinco estágios de maturidade

\begin{tabular}{|c|c|c|}
\hline Estágio & Nome & Características \\
\hline Estágio 1 & Green Glossy & $\begin{array}{l}\text { "Brilho verde", cartas e vídeos. Declaração curta no } \\
\text { relatório anual. }\end{array}$ \\
\hline Estágio 2 & One-off & $\begin{array}{l}\text { Relatório ambiental único, freqüentemente associado à } \\
\text { primeira declaração formal de política. }\end{array}$ \\
\hline Estágio 3 & Descritivo & $\begin{array}{l}\text { Relatório anual, associado ao sistema de gestão } \\
\text { ambiental, com mais textos que indicadores. } \\
\text { Comunicação de uma via com partes interessadas. }\end{array}$ \\
\hline Estágio 4 & Estado da arte & $\begin{array}{l}\text { Dados de desempenho completos em base anual. } \\
\text { Metas claras associadas à política e auditoria. }\end{array}$ \\
\hline Estágio 4.1 & Quantidade & $\begin{array}{l}\text { Relatórios corporativos e por operação. Comunicação } \\
\text { passiva, de duas vias, com fichas de avaliação e } \\
\text { pesquisas. }\end{array}$ \\
\hline Estágio 4.2 & Qualidade & $\begin{array}{l}\text { Publicação clara dos efeitos significativos e } \\
\text { desempenho com metas. Associação a questões } \\
\text { ambientais chave e prioridades globais. Verificação de } \\
\text { terceira parte. Provisões financeiras. Informação on } \\
\text { line e eletrônica. Diálogo ativo e multi-vias com } \\
\text { algumas partes interessadas. }\end{array}$ \\
\hline Estágio 4.3 & Comparabilidade & $\begin{array}{l}\text { Verificação externa. Publicação contra padrões globais } \\
\text { reconhecidos. Informação financeira detalhada. Uso e } \\
\text { discussão de indicadores setoriais e referências. } \\
\text { Versões históricas impressas e on line disponíveis }\end{array}$ \\
\hline \multirow{3}{*}{$\begin{array}{l}\text { Estágio } 5 \\
\text { Sustentabilidade }\end{array}$} & Empresa & $\begin{array}{l}\text { Relatórios ambientais, financeiros e sociais completos, } \\
\text { padronizados, estado da arte. Visão verdadeira e justa } \\
\text { dos impactos locais e globais. Publicação em todas as } \\
\text { regiões contra padrões operacionais globais. Avaliação } \\
\text { interna e externa do desempenho social e ambiental. }\end{array}$ \\
\hline & Governo & $\begin{array}{l}\text { Modelos com obrigações mínimas. Metodologia e } \\
\text { indicadores para contabilidade social e ambiental } \\
\text { comuns. Padrões de qualidade ambiental obrigatórios. } \\
\text { Medidas punitivas para desempenho não adequado. } \\
\text { Reforma de taxas ambientais e sociais. Investimentos } \\
\text { e compras públicos com sustentabilidade. }\end{array}$ \\
\hline & $\begin{array}{l}\text { Marketing } \\
\text { Sustentável }\end{array}$ & $\begin{array}{l}\text { Pressão para maior transparência corporativa de } \\
\text { acordo ao tripé da sustentabilidade. Necessidades de } \\
\text { informação explícitas. Uso de informação divulgada em } \\
\text { todos os investimentos e decisões de consumo. } \\
\text { Recompensa para bons desempenhos e penalidades } \\
\text { para desempenho lento. Balanço entre direitos e } \\
\text { necessidades como acionistas, consumidor e cidadão. }\end{array}$ \\
\hline
\end{tabular}


O relatório de 1997 demonstrou a evolução dos níveis dos relatórios das empresas com relação ao ano de 1994, conforme ilustrado pela Figura 2.

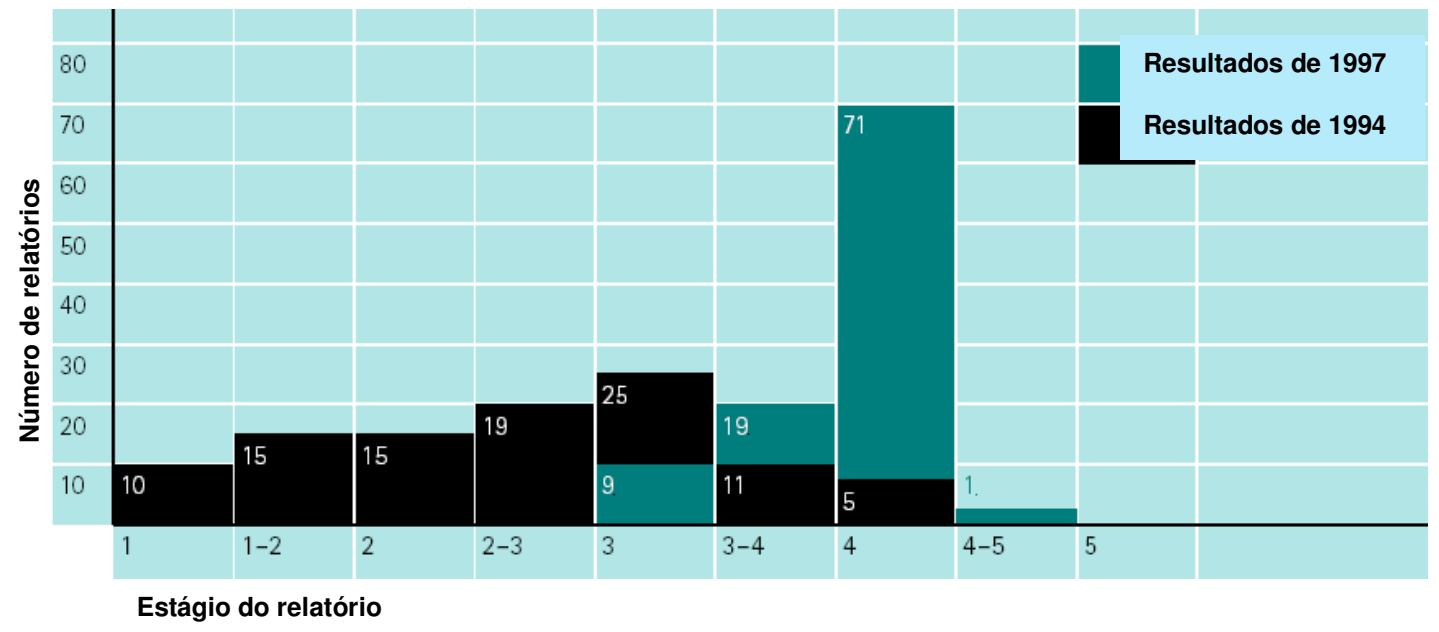

Figura 2 - Modelo de cinco estágios - Resultados de 1994 e 1997 Fonte: Sustainability e UNEP (1997)

Os resultados da pesquisa de 1997, segundo o modelo de cinco estágios revisado (Figura 3), mostram que a maior parte das empresas estava entre os níveis 3 (Descritivo) e 4.1 (Quantitativo). Havia indícios de progresso mas as empresas estavam falhando em comparabilidade. Os relatórios subseqüentes (2000, 2002 e 2004) não voltaram a utilizar esse modelo.

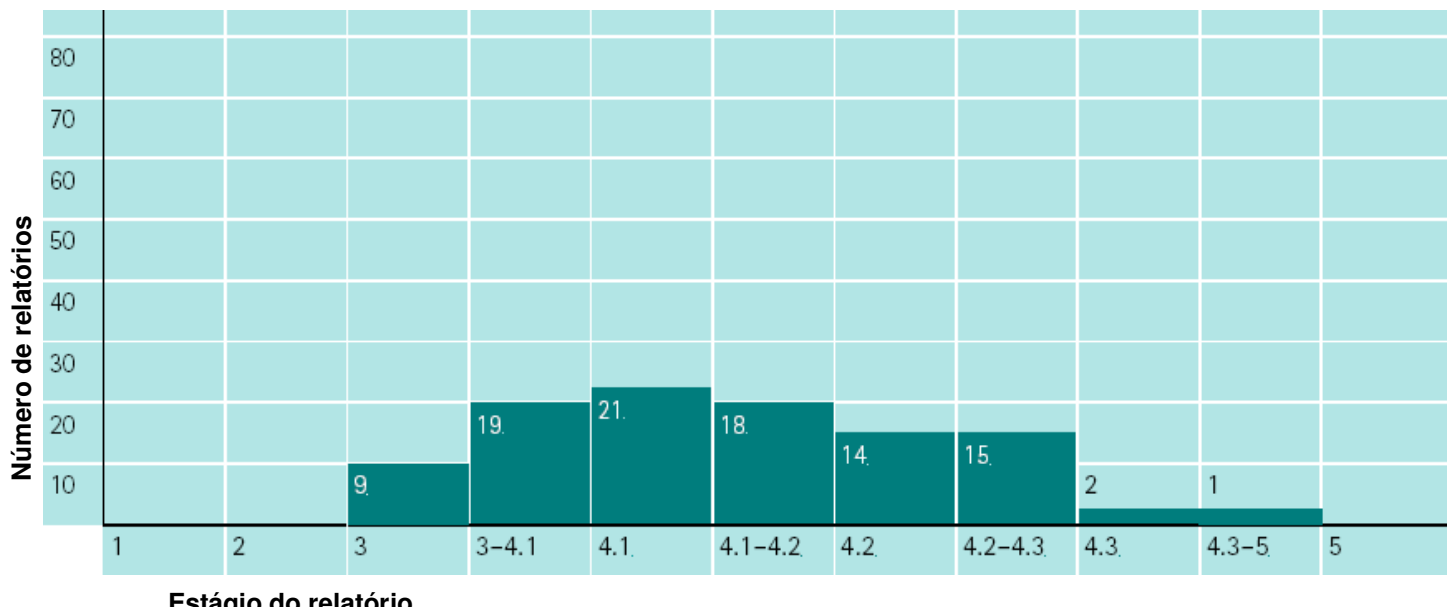

Figura 3 - Modelo de cinco estágios revisado - Resultados de 1997 Fonte: Sustainability e UNEP (1997) 
Uma questão a ser melhorada nos relatórios de sustentabilidade é a cobertura de todas as operações da empresa. Com poucas exceções, os relatórios das empresas multinacionais não incluem de maneira sistematizada os países não desenvolvidos. $\mathrm{Na}$ Ásia, o foco tende a ser exclusivamente em relatórios ambientais, enquanto que na América Latina o relatório social é mais comum. Dado que os países em desenvolvimento serão importantes em termos de população e expansão econômica no futuro, suas questões de sustentabilidade devem ser entendidas e refletidas nos relatórios corporativos de sustentabilidade (SUSTAINABILITY; UNEP, 2000).

Grande parte das empresas falha em tratar as maiores questões de sustentabilidade relacionadas às suas atividades, como a dependência de combustíveis fósseis para uma empresa do setor, a destruição de ecossistemas na extração de matérias primas para uma empresa de mineração, entre outros. Essas questões são de grande importância para as partes interessadas e portanto devem ser tratadas apropriadamente nos relatórios de sustentabilidade, independente do controle individual da empresa sobre elas (SUSTAINABILITY; UNEP, 2000).

$\mathrm{Na}$ pesquisa de 2004, ao aplicar uma regra para considerar a materialidade (relacionada à adequada identificação de questões) as empresas perderam em média $9 \%$ da sua pontuação total. Por exemplo, duas empresas com alta pontuação Rio Tinto e Anglo American caíram consideravelmente - 8 lugares (17\%) para a Rio Tinto, e 10 lugares (16\%) para a Anglo American. Um erro comum é publicar detalhadamente muitos aspectos do desempenho, sem dar ao leitor as ferramentas para avaliá-los (SUSTAINABILITY; UNEP; STANDARD \& POOR'S, 2004).

Analisando especificamente 0 desempenho do setor de mineração nessas avaliações, resumido na Tabela 3, observa-se que mais empresas fazem parte do grupo dos 50 melhores relatórios, mas a maioria delas está piorando a sua posição relativa a cada ano. 
Tabela 3 - Desempenho do setor de mineração nos relatórios "Global Reporters"

\begin{tabular}{llll}
\hline Ano & \multicolumn{1}{c|}{ Posição } & \multicolumn{1}{c|}{ Empresa } \\
\hline 1997 & Pouco acima da média geral & Noranda, Posco, WMC e Danish Steel Works \\
\hline 2000 & $7^{\circ}$ & WMC \\
\hline 2002 & $5^{\circ}$ & Rio Tinto \\
& $12^{\circ}$ & WMC \\
\hline \multirow{2}{*}{2004} & $8^{\circ}$ & Rio Tinto \\
& $12^{\circ}$ & Anglo American \\
& $16^{\circ}$ & BHP Billiton \\
& $21^{\circ}$ & Lafarge \\
\hline \multirow{2}{*}{2006} & $4^{\circ}$ & Anglo Platinun \\
& $12^{\circ}$ & BHP Billiton \\
& $17^{\circ}$ & Rio Tinto \\
& $29^{\circ}$ & Anglo American \\
\hline
\end{tabular}

Fonte: Adaptado de Sustainability e UNEP (1997, 2000, 2002, 2004, 2006)

Em 1998, um estudo feito pela Mining and Environment Research Network (MERN) concluiu que havia um número crescente de relatórios ambientais mas poucos publicavam informações sociais ou sobre a comunidade. embora o setor de mineração estivesse trabalhando para melhorar suas práticas de responsabilidade social e ambiental (MERN, 1998). Scott (2000) analisou empresas de mineração e concluiu que o setor produzia alguns dos relatórios mais abrangentes e que a qualidade dos relatórios aumentava a cada ano. Era esperado que o foco recente em informações sociais, sustentabilidade e relatórios específicos para cada site se expandisse rapidamente.

O estudo sobre relatórios de sustentabilidade de empresas de mineração feito pela empresa de auditoria e consultoria Deloitte (2007b), observou que $44 \%$ das trinta e seis empresas analisadas declararam publicar de acordo as diretrizes GRI, sendo que $25 \%$ usaram o suplemento especialmente desenvolvido para a mineração e $38 \%$ apresentaram algum tipo de verificação externa. Archel, Fernández e Larrinaga (2008) observaram que relatórios declarados pelas empresas como "de acordo com" ("in accordance") as diretrizes GRI - que deveriam apresentar todos os indicadores essenciais - não apresentavam $64 \%$ da informação requerida. 
78\% das 18 empresas que produzem relatórios de sustentabilidade são grandes empresas. As pequenas não publicam relatórios ou publicam de uma maneira limitada, possivelmente por pouca pressão externa, reflexo do nível de relatórios produzidos na região geográfica, custos de publicação dos relatórios ou visão de que os impactos em desenvolvimento sustentável não são significativos para as partes interessadas (DELOITTE, 2007b) .

Ainda segundo a Deloitte (2007b), questões sobre direitos humanos e envolvimento das comunidades têm sido tratadas proativamente, mas o impacto nas comunidades (como perda da propriedade e impacto na estrutura social local) nem sempre está claro na leitura dos relatórios. A declaração sobre influência e posição da empresa quanto a políticas públicas é uma área a ser melhorada. Os indicadores de impacto ambiental são as informações mais apresentadas pela maioria das empresas (em média $70 \%$ ), enquanto as práticas laborais são as menos apresentadas (48\%).

Analisando relatórios de grandes empresas de vários setores, Kolk (2003) concluiu que houve um aumento na quantidade de empresas que publicam relatórios de sustentabilidade e na quantidade de relatórios com verificação. Entre 1998 e 2001, o conteúdo puramente ambiental diminuiu para dar espaço a informações econômicas e sociais. No entanto $40 \%$ dos relatórios ainda não traziam indicadores econômicos. As maiores pontuações são para os temas mais tradicionais, tendência que se observa também nos indicadores sociais (acidentes - presente em 92\% dos relatórios e filantropia - presente em $97 \%$ dos relatórios). O desempenho econômico se restringe a informações básicas vindas do relatório anual.

Peck e Sinding (2003) concluiram que os relatórios ambientais estavam se tornando bem definidos em termos de conteúdo e de atendimento a diretrizes, como as da GRI e de empresas de verificação externa. Jenkins e Yakovleva (2006) concluíram que, apesar de haver evidência do aumento da sofisticação no desenvolvimento da divulgação do desempenho social e ambiental, há uma variação considerável na maturidade do conteúdo e estilo dos relatórios entre as empresas analisadas.

Morhardt, Baird e Freeman (2002) consideram que um dos principais problemas da avaliação de pontuação de relatórios é uma pontuação poder ser alcançada de 
diversas maneiras. Dependendo da definição das categorias pode ser inapropriado somar, calcular médias ou aplicar estatísticas. Por outro lado, se pontuações similares podem não ter o mesmo significado, altas pontuações representam um relatório mais completo, mesmo que não nos mesmos assuntos. Além disso, o autor comenta que outra desvantagem desse tipo de avaliação é empresas ambientalmente corretas poderem ter baixas pontuações por restringir as discussões a tópicos relevantes, enquanto empresas que queiram melhorar sua pontuação simplesmente adicionariam um determinado tópico, independente da qualidade do seu desempenho.

Daub (2007) apresenta algumas desvantagens dos processos de avaliação:

- Freqüentemente, são avaliadas apenas grandes empresas e multinacionais, que têm meios financeiros adequados à disposição para desenhar relatórios detalhados em termos de conteúdo e design. Não se deve assumir que empresas pequenas e médias estejam em condições de usar esse tipo de relatórios como modelo

- Estudos como os realizados pela UNEP e pelo Canadá buscam identificar e classificar as melhores práticas em relatórios de sustentabilidade. Assim, a avaliação da situação atual das práticas não está em primeiro plano.

Mesmo considerando suas eventuais deficiências, os estudos que avaliam e comparam os relatórios de sustentabilidade têm seu valor pois informam sobre as práticas existentes nas empresas e permitem que sejam descobertas oportunidades de melhoria. 


\section{METODOLOGIA}

\subsection{Modalidade de pesquisa}

As pesquisas sobre o emprego de ferramentas de gestão ambiental e sua eficácia podem adotar diversos enfoques, como um estudo de caso, uma análise regional ou setorial, a definição do estado da arte ou uma comparação extensiva de práticas. A pesquisa quanto à sua natureza foi de abordagem qualitativa, pois foi desenvolvida com base em dedução por raciocínio e interpretação do significado das informações qualitativas coletadas, a partir de uma amostra reduzida.

Segundo Gil (1999) uma pesquisa pode ser classificada com base em seus objetivos (exploratória, explicativa ou descritiva) e nos procedimentos técnicos adotados (bibliográfica, experimental ou documental).

Esta pesquisa, quanto aos objetivos, se caracteriza como descritiva, pois tem como objetivo a descrição de um fenômeno (a evolução dos relatórios), com uma técnica padronizada de coleta de dados, a partir do estudo das características de um grupo, sem explicar a natureza desse fenômeno. Quanto aos procedimentos de investigação, a pesquisa tem o caráter documental, uma vez que as fontes investigadas para a coleta de dados serão documentos que não receberam ainda um tratamento analítico (os relatórios corporativos não-financeiros das empresas). (GIL, 1999).

Uma pesquisa documental tem as seguintes fases de desenvolvimento: determinação dos objetivos, elaboração do plano de trabalho, identificação das fontes, localização das fontes e obtenção do material, tratamentos dos dados, confecção das fichas e redação do trabalho (GIL, 1999). Considerando que os objetivos e o plano de trabalho já foram apresentados anteriormente, os capítulos a seguir detalham as demais fases da metodologia. 
A fase de confecção de fichas na pesquisa documental será substituída pela elaboração de tabelas que depois de analisadas e interpretadas permitirão a redação das conclusões.

\subsection{Identificação e localização das fontes}

Em uma pesquisa documental é necessário identificar as fontes capazes de fornecer as respostas adequadas à solução do problema proposto (GIL, 1999).

Assim, a pesquisa documental foi feita em relatórios corporativos não-financeiros, denominados "relatórios de sustentabilidade" (ou relatórios separados denominados ambientais, de saúde e segurança, sociais, para a comunidade, entre outros). Não foram analisadas outras publicações e/ou informações eventualmente disponibilizadas no website das empresas, a não ser quando referenciadas explicitamente no texto do relatório.

Para investigar a evolução dessa prática, optou-se pela análise da totalidade de relatórios publicados pelas empresas selecionadas, para que haja um horizonte temporal significativo e para detectar os avanços recentes nessa área. Esses documentos são públicos (a maioria deles publicados na Internet), portanto não se faz necessário um consentimento das empresas pesquisadas. Foi analisado somente o conteúdo das versões impressas (ou similares disponíveis para download) e não as versões on-line dos relatórios, que podem conter informação mais detalhada.

\subsection{Leitura e coleta de dados}

Os dados foram coletados por meio da leitura dos relatórios. Essa leitura foi analítica e teve como objetivo a identificação das informações constantes no material e o 
estabelecimento de relações entre as informações e o problema proposto. A leitura analítica tem como fim ordenar e resumir as informações contidas nas fontes (GIL, 1999).

Para que a leitura dos relatórios e a coleta de dados fossem objetivas e imparciais, e para facilitar a tomada de apontamentos, optou-se por utilizar a técnica de análise de conteúdo por meio de um instrumento de coleta de dados.

\subsubsection{Análise de conteúdo}

A análise de conteúdo é uma técnica de pesquisa para fazer inferências válidas e replicáveis a partir de textos (KRIPPENDORFF, 2004). Essa técnica tem sido freqüentemente utilizada para avaliar relatórios sociais e ambientais (MILNE; ADLER, 1999).

Utilizando a definição de White e Marsh (2006) para definir os elementos da pesquisa, a unidade de amostra é o relatório de sustentabilidade (que identifica a população e determina as bases para amostragem), as unidades de coletas de dados (para medir as variáveis) são as frases, gráficos ou tabelas contendo certa informação e a unidade de análise (base da análise) é o critério de avaliação, organizado em categorias de avaliação. Segundo Marconi e Lakatos (2001), na análise de conteúdo, o conteúdo das comunicações é analisado por meio de categorias sistemáticas, previamente determinadas, que levam a resultados quantitativos.

\subsubsection{Instrumento de coleta de dados (roteiro de avaliação)}

Para esta análise, foi previamente preparado um roteiro que contemplou a investigação a ser feita, englobando os possíveis estágios de evolução das empresas na utilização de relatórios de sustentabilidade e que permitiu a posterior análise e comparação dos dados. Para tanto foi feita uma pesquisa bibliográfica em artigos e estudos atuais sobre relatórios de sustentabilidade, que contribui para a credibilidade da análise incorporando melhores práticas e recomendações derivadas de diferentes fontes. 
O roteiro de avaliação é composto por:

- Categorias analíticas para as questões, a fim de organizar e enriquecer o processo posterior de análise. As categorias foram criadas no curso da revisão bibliográfica (modelo aberto), agrupando as questões elaboradas por parentesco de sentido (categorias de matéria). As categorias são mutuamente exclusivas e colaboram com a análise, em um número reduzido. Essas categorias representam as diferentes dimensões de análise da evolução dos relatórios.

- Requisitos ou tópicos baseados nas diretrizes e recomendações resgatadas da revisão bibliográfica. Todos os requisitos têm igual peso para a avaliação total do relatório.

- Resposta aos requisitos, considerando uma escala de intensidade que vai de 0 a 1, conforme o Quadro 8. Não foi prevista a alternativa "Não aplicável" pois os requisitos considerados devem ser aplicáveis a todos os relatórios. Optou-se pela utilização de dois conceitos somente para tornar a avaliação a mais objetiva possível, minimizando avaliações inválidas ou inconsistentes. Critérios com conceitos mais sofisticados ou subjetivos requerem mais de um avaliador ou um comitê de partes interessadas.

Quadro 8 - Conceitos de avaliação dos requisitos

\begin{tabular}{|c|c|c|}
\hline Conceito & Pontos & Grau de atendimento \\
\hline Atende & 1 & $\begin{array}{l}\text { O relatório atende completamente a esse requisito. A } \\
\text { informação é apresentada no relatório. }\end{array}$ \\
\hline Não atende & 0 & $\begin{array}{l}\text { Não foi encontrada no relatório nenhuma informação } \\
\text { relevante ou significativa que comprove atendimento a } \\
\text { esse requisito. }\end{array}$ \\
\hline
\end{tabular}

- Colunas para o levantamento de dados em cada relatório anual. A pontuação total do relatório é a soma simples dos conceitos obtidos em cada requisito.

O teste do roteiro valida-o para o levantamento e visa avaliar o instrumento. Devemse selecionar os indivíduos típicos para o teste, em número restrito (GIL, 1999). O teste deste instrumento de pesquisa foi a aplicação a um único relatório específico, a fim de verificar a validade ou a relevância dos requisitos. A escolha do relatório 
escolhido representa a média dos relatórios, em número de páginas e estágio de evolução. O roteiro foi aperfeiçoado segundo os resultados do teste.

\subsubsection{Seleção da amostra}

O universo de pesquisa seria a totalidade dos relatórios não-financeiros, publicados pela totalidade de empresas do setor de mineração no mundo. No entanto, como este universo comporta uma população muito grande para um trabalho individual, faz-se necessário limitar a coleta de dados a uma amostra, selecionada com um critério específico.

O trabalho não pretendeu fazer um estudo localizado em uma região ou país, de uma empresa ou se limitar a um tipo determinado de bem mineral. $O$ objetivo tampouco foi analisar a prática em todo o setor mineral, mas sim escolher casos entre 0 universo das maiores empresas, justamente onde se concentra $\circ$ maior número de empresas que produzem relatórios de sustentabilidade.

Usualmente é nas práticas das grandes empresas que há maior probabilidade de identificação de melhores práticas, devido aos recursos de que dispõem essas empresas, como maior acesso a instituições de pesquisa, financiamentos, recursos financeiros para a aplicação dos conceitos de sustentabilidade, desenvolvimento de indicadores e publicação de relatórios. Jenkins e Yakovleva (2006) citam quatro estudos que concluíram terem grandes empresas publicado mais informações sociais e ambientais do que empresas pequenas. Kolk (2003) também conclui que as maiores empresas multinacionais são as mais ativas na publicação do desempenho ambiental e social.

Segundo Daub (2007), é sabido que uma porção maior da responsabilidade pelos impactos globais, como poluição do meio ambiente e desigualdade social, é colocada nos ombros das grandes empresas e, portanto, elas são mais pressionadas por suas partes interessadas. Em linha com essa idéia, espera-se que melhores práticas sejam adotadas mais freqüentemente por empresas de grande porte e também que a identificação e disponibilidade dos relatórios em websites seja mais fácil. 
Considerando o acima exposto, a amostragem será não-probabilística, por quotas classificação da população mediante uso de propriedades pertinentes e determinação do tamanho da amostra dentro de uma classe (MARCONI; LAKATOS, 2001) - segundo os seguintes critérios de inclusão e exclusão:

- $\quad$ Critérios de inclusão:

Uma vez definido que seriam pesquisadas empresas multinacionais de grande porte, postulou-se que, para selecionar as empresas a serem incluídas no estudo, deveria ser considerado o porte da empresa, segundo uma avaliação econômico-financeira reconhecida mundialmente (por exemplo, rankings mundiais, como os publicados pelas revistas de grande circulação Fortune, Forbes etc.). Com esta finalidade, deveriam ser utilizadas as listas mais atuais e/ou mais completas, porque é um tema recente e em evolução. Pode-se incluir intencionalmente uma empresa de um determinado país ou subsetor da mineração, caso essa inclusão enriqueça o trabalho.

- Critérios de exclusão:

Dadas as particularidades do setor de extração mineral e de seus impactos ambientais, postulou-se que deveriam ser excluídas do estudo empresas de grande porte que, mesmo que classificadas sob a categoria "mineração" ou correlata nos rankings mundiais acima referidos, tivessem a maior parte do seu faturamento devido a outros setores da economia como metalúrgico, petrolífero etc.

Por outro lado, foi também estabelecido que não seriam selecionadas mais que cinco empresas, pois limitando a extensão da amostra, permite-se o aprofundamento da análise. Assim, a pesquisa se restringirá ao máximo de cinco grandes empresas do setor de mineração no âmbito mundial. 


\subsubsection{Coleta de dados}

$\mathrm{Na}$ fase da pesquisa é feita a aplicação dos instrumentos elaborados a fim de se efetuar a coleta dos dados prevista (MARCONI; LAKATOS, 2001). Os dados da pesquisa serão coletados através da leitura e interpretação dos relatórios selecionados (interpretação do conteúdo dos relatórios de forma a codificar as respostas em uma das alternativas definidas). As respostas serão compiladas no próprio roteiro de avaliação, para cada empresa selecionada.

\subsection{Tratamento de dados}

Segundo Marconi e Lakatos (2001), após a coleta de dados devem ser feitas a seleção, codificação e tabulação dos dados. Essas etapas serão parcialmente feitas pelo preenchimento do roteiro de avaliação, que evitará coleta excessiva ou insuficiente de dados, classificará os dados em categorias e irá dispor os dados em forma de uma tabela inicial, que será utilizada na análise.

Adicionalmente serão elaborados tabelas e gráficos para melhor disponibilização dos dados para análise com as seguintes informações:

- $\quad$ Subtotal por categoria (absoluto e porcentual)

- $\quad$ Pontuação total por relatório (absoluta e porcentual)

- Pontuação média em cada categoria e total (soma das pontuações de cada relatório dividida pela quantidade de relatórios)

- Evolução (pontuação do último relatório menos a pontuação do primeiro relatório)

- Gráficos pontuação total por ano por categoria e por empresa

- $\quad$ Tabelas dos resultados de todas as empresas (nos anos comparáveis) 


\subsection{Análise e interpretação dos dados}

A análise de dados tenta evidenciar as relações existentes entre os dados obtidos e as hipóteses formuladas. A interpretação procura dar um significado mais amplo às respostas, vinculando-as a outros conhecimentos (MARCONI; LAKATOS, 2001).

A análise dos dados será feita de maneira individual (por empresa, por ano) ou sintética (evolução de uma empresa, evolução de uma categoria, evolução média das empresas). Serão verificadas as relações existentes entre o fenômeno estudado e outros fatores, por meio de avaliações e generalizações, a fim de extrair as respostas para os problemas propostos.

Posteriormente os dados serão interpretados para determinar evidências encontradas, aplicabilidade dos resultados, informações relevantes e limitações. A interpretação procura um sentido mais amplo nas respostas, estabelecendo uma rede de ligações entre os resultados e outros conhecimentos adquiridos anteriormente.

A desvantagem da comparação de pontuações similares observada por Morhardt, Baird e Freeman (2002) não se aplica a este trabalho, pois o objetivo não foi comparar ou classificar as empresas e sim observar a evolução dos relatórios e as características dessa evolução, analisando também a evolução das categorias e dos requisitos. O viés de penalizar empresas com bom desempenho ou dar crédito àquelas com mau desempenho tampouco se aplica ao método empregado nesta pesquisa, porque o objetivo não foi avaliar o desempenho em sustentabilidade e sim o grau de completude dos relatórios.

A partir dos dados analisados e interpretados, serão apresentadas conclusões apoiadas no desenvolvimento da matéria e também a reorganização das informações discutidas durante o desenvolvimento do texto, de forma a funcionar como um fechamento. Os objetivos inicialmente propostos serão comparados com os resultados da pesquisa para verificar (ou não) a comprovação da hipótese. 


\section{RESULTADOS E DISCUSSÃO}

\subsection{Roteiro de avaliação}

\subsubsection{Roteiro de avaliação}

Como categorias para o roteiro foram utilizadas algumas das categorias da metodologia da SustainAbility de 2006:

- Contexto e Compromissos;

- Qualidade da Gestão;

- Desempenho Econômico;

- Desempenho Social;

- Desempenho Ambiental e

- Acessibilidade e Garantia.

Após a elaboração das questões/requisitos não houve necessidade de eliminar ou de criar uma nova categoria.

De acordo com revisão bibliográfica inicial feita, foi possível identificar várias recomendações, traduzidas em 62 requisitos de informação ou subcategorias. As principais referências consultadas foram GRI (2005, 2006), Sustainability e UNEP (2006), International Institute for Environment and Development (2002), Azapagic (2002) e ICMM (2002). A freqüência de utilização de cada referência no roteiro está descrita na Tabela 27 do apêndice $A$.

Embora as diretrizes GRI sejam consideradas abrangentes e serem amplamente adotadas, optou-se por não utilizar integralmente os tópicos recomendados pelas seguinte razões:

- Alguns tópicos similares foram agregados em um único requisito mais genérico

- A diretriz indica que cada empresa deve identificar os tópicos relevantes e apropriados para o relatório. Para este estudo foram considerados mais 
apropriados os tópicos que permitissem uma avaliação objetiva e que não tornassem o método muito complexo ou extenso.

- O desenvolvimento método deveria incluir outras diretrizes e recomendações para que a avaliação não se tornasse uma auditoria de conformidade com a diretriz GRI

Não foram incluídos os modelos especializados em indicadores de sustentabilidade pois estas fontes trazem recomendações mais abrangentes, para avaliação de sustentabilidade a nível regional, não necessariamente no contexto de publicação de relatórios corporativos.

\subsubsection{Teste do roteiro}

O roteiro foi aplicado satisfatoriamente no relatório da Anglo American de 2002. Os textos do roteiro foram aperfeiçoados para dar maior clareza aos requisitos. $O$ roteiro final encontra-se no apêndice $A$.

Para enriquecer o resultado da pesquisa, notou-se a necessidade de levantar informações que não serão consideradas para a pontuação dos relatórios e sim para descrição do cenário, como:

- O relatório é feito com base em algum padrão ou diretriz? Qual?

- Qual a freqüência de apresentação das informações recomendadas especificamente para o setor de mineração?

- O relatório é verificado com base em algum padrão ou norma? Qual? Qual a empresa que fez a verificação/garantia?

- Quantas páginas tem cada relatório? 


\subsection{Seleção das empresas}

\subsubsection{Rankings}

Os cinco rankings utilizados para fazer a seleção das grandes empresas do setor de mineração são: Covalence Ethical Ranking 2006 (base 2005), Raw Materials Group Top 10 companies 2004 (base 2003), Financial Times (FT) Global 5002006 (base 2005), Fortune Global 5002006 (base 2005) e The World's 2000 Largest Public Companies 2006 (base 2005).

A seguir serão apresentados resumidamente os critérios utilizados pelos rankings e as empresas ou instituições que os calculam.

\section{- $\quad$ Covalence Ethical Ranking}

Covalence é uma empresa suíça que monitora a reputação ética de empresas multinacionais, criada em 2001. A empresa desenvolveu um sistema de informação chamado EthicalQuote, que coleta as informações das diversas fontes (universidades, consultorias, empresas, governo, organizações internacionais, imprensa, ONGs e sindicatos).

O índice utilizado no ranking é formado por 45 critérios de contribuição do negócio ao desenvolvimento humano, incluindo condições de trabalho, impacto ambiental da produção, impacto do produto e impacto institucional (COVALENCE, 2006). As indústrias do ramo de minerais industriais e materiais de construção são consideradas no setor "Construção e Materiais". No entanto, os dados para esse setor não foram compilados para nenhum ano (COVALENCE, 2006). O ranking Covalence Ethical Ranking 2006 completo está no Anexo B.

\section{- $\quad$ Raw Materials Group Top 10 companies}

Raw Materials Group (RMG) é uma consultoria sueca fundada há 20 anos, que compila e analisa dados de mineração. Possui a base de dados Raw Materials Data, 
com dados de produção de bens minerais. Para elaboração do ranking são calculados os valores totais de todos os minerais e metais produzidos no estágio de mina, incluindo metais e minerais industriais. A classificação final é obtida pela participação no valor total de produção de minerais não-combustíveis no ano base (RMG, 2006).

As indústrias do ramo de minerais industriais/materiais de construção não são consideradas no levantamento de dados. Não foi encontrada a publicação da classificação para os anos de 2005 (base 2004) e 2006 (base 2005). Essa informação foi solicitada por correio eletrônico ao endereço de contato indicado no site, mas não houve resposta. O ranking Raw Materials Group Top 10 companies 2004 completo está no Anexo B.

\section{- $\quad$ FT Global 500}

O grupo europeu Financial Times, que entre outros veículos de informação publica o jornal de negócios homônimo, divulga anualmente o ranking FT Global 500, com as 500 maiores empresas do mundo segundo seu valor de mercado. Também é publicado o capital de giro e valor das ações dessas empresas (THE FINANCIAL TIMES, 2006).

As empresas de mineração aparecem distribuídas entre três setores: Mineração, Metais industriais e Construção\&Materiais. O ranking FT Global 5002006 completo está no Anexo B.

\section{- $\quad$ Fortune Global 500}

A Time Warner é uma empresa americana de comunicação e mídia que publica, entre outros, as revistas de negócios Fortune e Money. Anualmente também publica o ranking Fortune Global 500, uma lista das 500 maiores empresas do mundo, segundo suas receitas (CABLE NEWS NETWORK, 2006). 
As empresas de mineração aparecem distribuídas em três setores: Mineração/Óleo, Materiais de construção e Metais. O ranking Fortune Global 5002006 completo está no Anexo B.

- $\quad$ The World's 2000 Largest Public Companies

Forbes é uma empresa de publicações e mídia de sede americana que publica, entre outros, a revista de negócios Forbes Magazine. Anualmente também publica o ranking The World's 2000 Largest Public Companies, uma lista das 2000 maiores e mais poderosas empresas do mundo, medidas por um índice composto pelos valores de vendas, lucros, ativos e valor de mercado (FORBES.COM, 2006).

As empresas de mineração aparecem distribuídas em dois setores: Construção e Materiais. O ranking The World's 2000 Largest Public Companies 2006 completo está no Anexo B.

A lista das cinco primeiras empresas em cada um dos rankings é apresentada no Quadro 9.

\begin{tabular}{|c|c|c|c|c|c|}
\hline \# & $\begin{array}{l}\text { Empresas } \\
\text { Covalence }\end{array}$ & $\begin{array}{c}\text { Empresas } \\
\text { RMG }\end{array}$ & $\begin{array}{c}\text { Empresas } \\
\text { FT }\end{array}$ & $\begin{array}{c}\text { Empresas } \\
\text { Fortune }\end{array}$ & $\begin{array}{c}\text { Empresas } \\
\text { Forbes }\end{array}$ \\
\hline 1 & Anglo American & Anglo American & BHP Billiton & BHP Billiton & BHP Billiton \\
\hline 2 & Rio Tinto & BHP Billiton & Rio Tinto & Anglo American & Anglo American \\
\hline 3 & BHP Billiton & Rio Tinto & Anglo American & RAG Coal & Rio Tinto \\
\hline 4 & Falconbridge & Norilsk Nickel & Vale do Rio Doce & Rio Tinto & Cemex \\
\hline 5 & Gold Fields & Vale do Rio Doce & Cemex & Lafarge & Lafarge \\
\hline
\end{tabular}

Fonte: adaptado de Covalence (2006), RMG (2006), The Financial Times (2006), Cable News Network (2006)e Forbes.com (2006)

\footnotetext{
${ }^{10}$ Para análise dos rankings foram excluídas as empresas cujo faturamento vem principalmente da metalurgia como Alcoa, Alcan, Posco, Nippon Steel, Mittal Steel, Norsk Hydro, JFE Holdings, Baosteel, Arcelor e ThyssenKrupp Group. Também foram excluídas as empresas Saint Gobain e Bouygues, pois sua principal área de atuação é a fabricação de vidros e construção civil, respectivamente.
} 


\subsubsection{Análise dos rankings}

Comparando os rankings apresentados no Quadro 9, observa-se que não existe uma classificação idêntica entre eles. No entanto duas empresas apresentam a maior colocação em primeiro e segundo lugares: BHP Billiton e Anglo American.

Se, como critério de seleção, forem consideradas somente as empresas que mais aparecem nos rankings apresentados, o setor de minerais industriais/materiais de construção não seria representado. Minerais do setor de construção representam com grande vantagem o maior volume de materiais extraídos, com produção anual estimada de 15 bilhões de toneladas por ano (INTERNATIONAL INSTITUTE FOR ENVIRONMENT AND DEVELOPMENT, 2002).

Para que o estudo seja representativo desse subsetor da mineração, serão consideradas intencionalmente as duas primeiras empresas do setor "Construção": Cemex e Lafarge (segundo os rankings Fortune, FT e Forbes, conforme apresentado no Quadro 10), grandes produtores de cimento e minerais industriais, excluídas empresas dos setores de fabricação de vidro e construção civil como Asahi Glass, Vinci e Bouygues, que são principalmente consumidoras de matérias-primas minerais.

Quadro 10 - Ranking (Materiais de Construção)

\begin{tabular}{|lllll|}
\hline$\#$ & Empresas - Fortune & Empresas - FT & Empresas - Forbes \\
\hline 1 & Lafarge & Cemex & Cemex \\
\hline 2 & CRH & Lafarge & Lafarge \\
\hline 3 & Cemex & CRH & CRH \\
\hline 4 & Holcim & Holcim & Holcim \\
\hline
\end{tabular}

Fonte: adaptado de The Financial Times (2006), Cable News Network (2006) e Forbes.com (2006)

Considera-se interessante, para fins de comparação, que o estudo inclua uma empresa brasileira. A primeira grande empresa brasileira listada nos rankings é a Companhia Vale do Rio Doce, hoje renomeada Vale. No entanto, essa empresa não publica relatórios de sustentabilidade e sim algumas páginas sobre o tema nos relatórios anuais. 
Sendo assim, seleciona-se intencionalmente a Samarco, por ser uma referência no setor para a publicação de relatórios não-financeiros. A empresa ganhou pelo segundo ano consecutivo o Prêmio Balanço Social, promovido pelo Instituto Ethos, e Ibase, entre outros. A premiação foi concedida ao relatório de 2005, escolhido como Destaque Nacional, dentre 69 empresas que participaram com seus balanços (BRASIL MINERAL, 2006). A Samarco é constituída por associação entre a BHP Billiton e a Vale, de modo que deve aplicar os princípios de gestão da BHP Billiton.

As cinco empresas a serem consideradas neste estudo são apresentadas no Quadro 11:

Quadro 11 - Empresas selecionadas

\begin{tabular}{|c|ll|}
\hline Posição & \multicolumn{1}{c}{ Empresa } & \multicolumn{1}{c|}{ País (sede) } \\
\hline 1 & BHP Billiton & Austrália \\
2 & Anglo American & Inglaterra \\
3 & Cemex & México \\
4 & Lafarge & França \\
5 & Samarco & Brasil \\
\hline
\end{tabular}

\subsection{Levantamento dos relatórios publicados}

A seguir são apresentadas uma visão geral das empresas selecionadas e a lista dos relatórios não-financeiros coletados para a pesquisa.

\subsubsection{BHP Billiton}

\section{$\underline{\text { Visão geral }}$}

BHP Billiton foi criada em 2001 com a fusão das empresas BHP Limited (atualmente BHP Billiton Limited) e Billiton PIc (agora BHP Billiton PIc). Tem ao redor de 35.000 empregados trabalhando em mais de 100 operações e escritórios em 26 países, com sede em Melbourne, Austrália. Seu faturamento entre julho de 2004 e junho de 2005 foi de U\$31.804 milhões (BHP, 2005). 
Segundo o site corporativo (BHP, 2007a), é líder no fornecimento de matérias primas para aço, segunda maior produtora mundial de cobre e exportadora de carvão para energia, terceira maior produtora de níquel metálico, quarta maior produtora de urânio e sexta maior produtora de alumínio primário. Também produz óleo e gás.

\section{$\underline{\text { Relatórios }}$}

A empresa publica relatórios de sustentabilidade globais anualmente. $\mathrm{O}$ desempenho não-financeiro é publicado desde 1997, mas o primeiro relatório específico relacionado a meio ambiente e comunidade foi publicado em 2000. Também estão disponíveis relatórios de sustentabilidade (ou "Saúde, Segurança, Meio ambiente e Comunidade") para cada site ou linha de negócios. Existe um endereço eletrônico para solicitação de cópias impressas e questões gerais relativas a sustentabilidade.

Os relatórios disponíveis são apresentados na Tabela 4. Foi feita uma consulta por correio eletrônico, mas a empresa não se pronunciou sobre relatórios anteriores.

Tabela 4 - Relatórios levantados (BHP)

\section{No Ano de referência Título}

\begin{tabular}{cc|lcc} 
No & Ano de referência & Título & Páginas \\
\hline 1 & $07 / 2000$ a 06/2001 & Health Safety Environment and Community (HSEC) Report 2001 & 75 \\
\hline 2 & $07 / 2001$ a 06/2002 & Health Safety Environment and Community (HSEC) Report 2002 & 66 \\
\hline 3 & $07 / 2002$ a 06/2003 & Health Safety Environment and Community (HSEC) Report 2003 & 117 \\
\hline 4 & $07 / 2003$ a 06/2004 & Health Safety Environment and Community (HSEC) Report 2004 & 164 \\
\hline 5 & $07 / 2004$ a 06/2005 & Sustainability Report 2005 & 384 \\
\hline 6 & $07 / 2005$ a 06/2006 & Sustainability Report 2006 & 522 \\
\hline 7 & $07 / 2006$ a 06/2007 & Sustainability Report 2007 & 315
\end{tabular}

Todos os relatórios (com exceção do relatório de 1999/2000) estão disponíveis em versão interativa (web) e arquivo para download. Além dos relatórios, para cada ano também está disponível a lista dos indicadores GRI. 


\subsubsection{Anglo American}

\section{Visão geral}

Anglo American é uma empresa britânica, que tem operações de mineração no Brasil, Chile, Irlanda, Namíbia, África do Sul, Venezuela, Austrália e Zimbábue (ANGLO AMERICAN, 2007a).

Segundo seu último relatório anual, apresentou faturamento de $U \$ 29,4$ bilhões em 2005. Produz platina, ouro, diamantes, carvão, metais de base e ferrosos, minerais industriais. Também produz papéis e embalagens. (ANGLO AMERICAN, 2006).

\section{$\underline{\text { Relatórios }}$}

A empresa publica relatórios de sustentabilidade (ou de saúde, segurança e meio ambiente) anualmente, desde 2000. Também estão disponíveis relatórios para algumas minas e por país, além de outros relatórios sobre temas específicos. Existe um formulário para solicitação de cópias impressas e endereços para questões relativas à responsabilidade corporativa.

Os relatórios disponíveis na internet são apresentados na Tabela 5. Em consulta por correio eletrônico a empresa declarou não ter relatórios anteriores.

Tabela 5 - Relatórios levantados (Anglo American)

\begin{tabular}{l|lll}
\hline No & Ano de referência & Nome & Páginas \\
\hline 1 & 2000 & Safety, Health and Environment Report 2000 & 58 \\
\hline 2 & 2001 & Safety, Health and Environment Report 2001 & 54 \\
\hline 3 & 2002 & Report to Society 2002 & 66 \\
\hline 4 & 2003 & Report to Society 2003 & 72 \\
\hline 5 & 2004 & Report to Society 2004 & 74 \\
\hline 6 & 2005 & Report to Society 2005 & 71 \\
\hline 7 & 2006 & Report to Society 2006 & 68 \\
\hline
\end{tabular}

Fonte: adaptado de Anglo American (2007a) 
Somente o relatório de 2005 está disponível em versão interativa (web) e os relatórios de todos os anos estão disponíveis para download. Além dos relatórios, a partir do ano de 2003 também está disponível o índice para os indicadores GRI.

\subsubsection{Cemex}

\section{$\underline{\text { Visão geral }}$}

Cemex é uma empresa com sede no México, que opera em mais de 50 países nas Américas, Europa, África, Oriente Médio e Ásia. Além de cimento, concreto readymix e agregados, produz materiais de construção. Seu faturamento em 2005 foi de U\$ 15.321 milhões (CEMEX, 2006).

\section{$\underline{\text { Relatórios }}$}

A empresa publica relatórios anuais de saúde, segurança e meio ambiente desde 1997 e de sustentabilidade desde 2003. Os relatórios disponíveis na internet são apresentados na Tabela 6. Foi feita uma consulta por correio eletrônico, mas a empresa não se pronunciou sobre relatórios anteriores.

Tabela 6 - Relatórios levantados (Cemex)

\begin{tabular}{l|l|ll} 
No & Ano de referência & Nome & Páginas \\
\hline 1 & 1997 & Environmental, Health and Safety Report 1997 & 18 \\
\hline 2 & 1998 & 1998 Environmental, Health and Safety Report & 7 \\
\hline 3 & 1999 & Environmental, Health and Safety Report 1999 & 16 \\
\hline 4 & 2000 & 2000 Environmental, Health and Safety Report & 27 \\
\hline 5 & 2001 & Environmental, Health and Safety 2001 Progress Report & 16 \\
\hline 6 & 2002 & Environmental, Health and Safety 2002 Progress Report & 14 \\
\hline 7 & 2003 & 2003 Sustainability Report & 36 \\
\hline 8 & 2004 & 2004 Sustainability Report & 36 \\
\hline 9 & 2005 & 2005 Sustainable Development Interim Report & 8 \\
\hline 10 & 2006 & 2006 Sustainable Development Report & 42 \\
\hline
\end{tabular}

A partir de 2000 os relatórios estão disponíveis em versão interativa (web) e os relatórios de todos os anos estão disponíveis para download. 


\subsubsection{Lafarge}

\section{$\underline{\text { Visão geral }}$}

Lafarge é uma empresa francesa fundada em 1833. Tem 80.000 empregados e operações em 76 países, no setor de materiais de construção (cimentos, agregados, concreto ready-mix, etc.). Suas vendas são da ordem de 16 bilhões de euros, vindas principalmente do cimento (48\%) (LAFARGE, 2006).

\section{$\underline{\text { Relatórios }}$}

A empresa publica relatórios anuais de sustentabilidade desde 2001, além de relatórios financeiros semestrais. Os relatórios disponíveis na internet são apresentados na Tabela 7. Em consulta por correio eletrônico a empresa declarou não ter relatórios anteriores.

Tabela 7 - Relatórios levantados (Lafarge)

\section{No Ano de referência Nome}

\begin{tabular}{cclcc}
1 & 2001 & $\begin{array}{l}\text { A First Report on our Economic, Social and Environmental } \\
\text { Performance 2001 }\end{array}$ & 60 \\
\hline 2 & 2002 & 2002 Sustainability Report & 62 \\
\hline 3 & 2003 & 2003 Sustainability Report & 25 \\
\hline 4 & 2004 & Sustainability Report 2004 & 33 \\
\hline 5 & 2005 & Sustainability Report 2005 & 52 \\
\hline 6 & 2006 & Sustainability Report 2006 & 64 \\
\hline
\end{tabular}

Fonte: adaptado de Lafarge (2007a)

Os relatórios não estão disponíveis em versão interativa (web) e os relatórios de todos os anos estão disponíveis para download. 


\subsubsection{Samarco}

\section{Visão geral}

Samarco é uma empresa brasileira de mineração de ferro, com sede em Belo Horizonte e tem aproximadamente 1300 empregados. O faturamento bruto em 2005 foi de $\mathrm{R} \$ 2,6$ bilhões (SAMARCO, 2006).

\section{$\underline{\text { Relatórios }}$}

A empresa publica relatórios anuais desde 2002. Para cada ano também estão disponíveis os indicadores de balanço social lbase. Os relatórios são apresentados na Tabela 8. Foi feita uma consulta por correio eletrônico, mas a empresa não se pronunciou sobre relatórios anteriores.

Tabela 8 - Relatórios levantados (Samarco)

\begin{tabular}{llll} 
No & Ano de referência & Nome & Páginas \\
\hline 1 & 2002 & Relatório anual 2002 & 101 \\
\hline 2 & 2003 & Relatório anual Samarco 2003 & 74 \\
\hline 3 & 2004 & Relatório anual Samarco 2004 & 147 \\
\hline 4 & 2005 & Relatório anual Samarco 2005 & 145 \\
\hline 5 & 2006 & Relatório anual Samarco 2006 & 156 \\
\hline
\end{tabular}

Fonte: adaptado de Samarco (2007a)

Considerando o levantamento apresentado, o trabalho avaliou um total de $\underline{35}$ relatórios. 


\subsection{Levantamento de dados dos relatórios}

\subsubsection{Anglo American}

A Tabela 9 sintetiza as porcentagens obtidas pela avaliação dos relatórios da Anglo American para cada uma das categorias e no total. O roteiro com a avaliação completa de todos os relatórios está apresentado no Apêndice B.

Tabela 9 - Porcentagens obtidas (Anglo American)

\begin{tabular}{lcccc|cc|ccc}
\hline Categoria & $\begin{array}{c}\text { Ano 1 } \\
\mathbf{2 0 0 0}\end{array}$ & $\begin{array}{c}\text { Ano 2 } \\
\mathbf{2 0 0 1}\end{array}$ & $\begin{array}{c}\text { Ano 3 } \\
\mathbf{2 0 0 2}\end{array}$ & $\begin{array}{c}\text { Ano 4 } \\
\mathbf{2 0 0 3}\end{array}$ & $\begin{array}{c}\text { Ano 5 } \\
\mathbf{2 0 0 4}\end{array}$ & $\begin{array}{c}\text { Ano 6 } \\
\mathbf{2 0 0 5}\end{array}$ & $\begin{array}{c}\text { Ano 7 } \\
\mathbf{2 0 0 6}\end{array}$ & Média & Evolução. \\
\hline Contexto & $71 \%$ & $57 \%$ & $71 \%$ & $86 \%$ & $86 \%$ & $100 \%$ & $100 \%$ & $82 \%$ & $29 \%$ \\
\hline Gestão & $70 \%$ & $70 \%$ & $70 \%$ & $60 \%$ & $80 \%$ & $100 \%$ & $90 \%$ & $77 \%$ & $20 \%$ \\
\hline Econômico & $38 \%$ & $50 \%$ & $75 \%$ & $100 \%$ & $88 \%$ & $88 \%$ & $75 \%$ & $73 \%$ & $37 \%$ \\
\hline Social & $58 \%$ & $83 \%$ & $92 \%$ & $75 \%$ & $83 \%$ & $92 \%$ & $83 \%$ & $81 \%$ & $25 \%$ \\
\hline Ambiental & $73 \%$ & $73 \%$ & $80 \%$ & $80 \%$ & $80 \%$ & $87 \%$ & $87 \%$ & $80 \%$ & $14 \%$ \\
\hline Acessibilidade & $40 \%$ & $60 \%$ & $60 \%$ & $70 \%$ & $60 \%$ & $60 \%$ & $60 \%$ & $59 \%$ & $20 \%$ \\
\hline Total & $60 \%$ & $68 \%$ & $76 \%$ & $77 \%$ & $79 \%$ & $87 \%$ & $82 \%$ & $76 \%$ & $22 \%$ \\
\hline
\end{tabular}

O relatório do ano 2005 foi o melhor avaliado. A categoria que teve melhor avaliação média no período analisado foi "Contexto e compromissos". A categoria melhor avaliada em cada ano variou, sendo "Desempenho ambiental" no primeiro ano, "Desempenho social" nos dois anos seguintes, "Desempenho econômico" nos anos 4 e 5, "Contexto e compromissos" e "Gestão" no penúltimo ano e 'Contexto e compromissos" no último ano (com atendimento a $100 \%$ dos tópicos relacionados nessa categoria). A pior categoria em quatro anos foi "Acessibilidade e garantia".

No último ano, as duas melhores categorias foram "Contexto e compromissos" e "Gestão" e a pior categoria no último ano e em média foi "Acessibilidade e garantia". A maior evolução foi da categoria "Desempenho econômico" (37\%) e a menor da categoria "Desempenho ambiental" (14\%). A diferença porcentual entre o primeiro relatório e o último foi de $22 \%$. A diferença entre o pior e o melhor relatório foi de $27 \%$. 
Um trecho de um relatório foi destacado por representar o adequado atendimento ao requisito "Atendimento a requisitos legais":

"As mudanças de legislação e regulamentos continuam a ser uma preocupação em muitas regiões em que operamos. Na África do Sul, algumas operações estão esperando a emissão de licenças para o uso da água. Mudanças esperadas na legislação do Reino Unido terão implicações nos resíduos de Tarmac. Além disso, o efeito de algumas novas diretrizes da União Européia terá que ser investigado." (ANGLO AMERICAN, 2007b, tradução nossa).

A Figura 4 mostra a evolução temporal das pontuações porcentuais obtidas pelos relatórios de 2000 a 2006 para os relatórios da Anglo American.

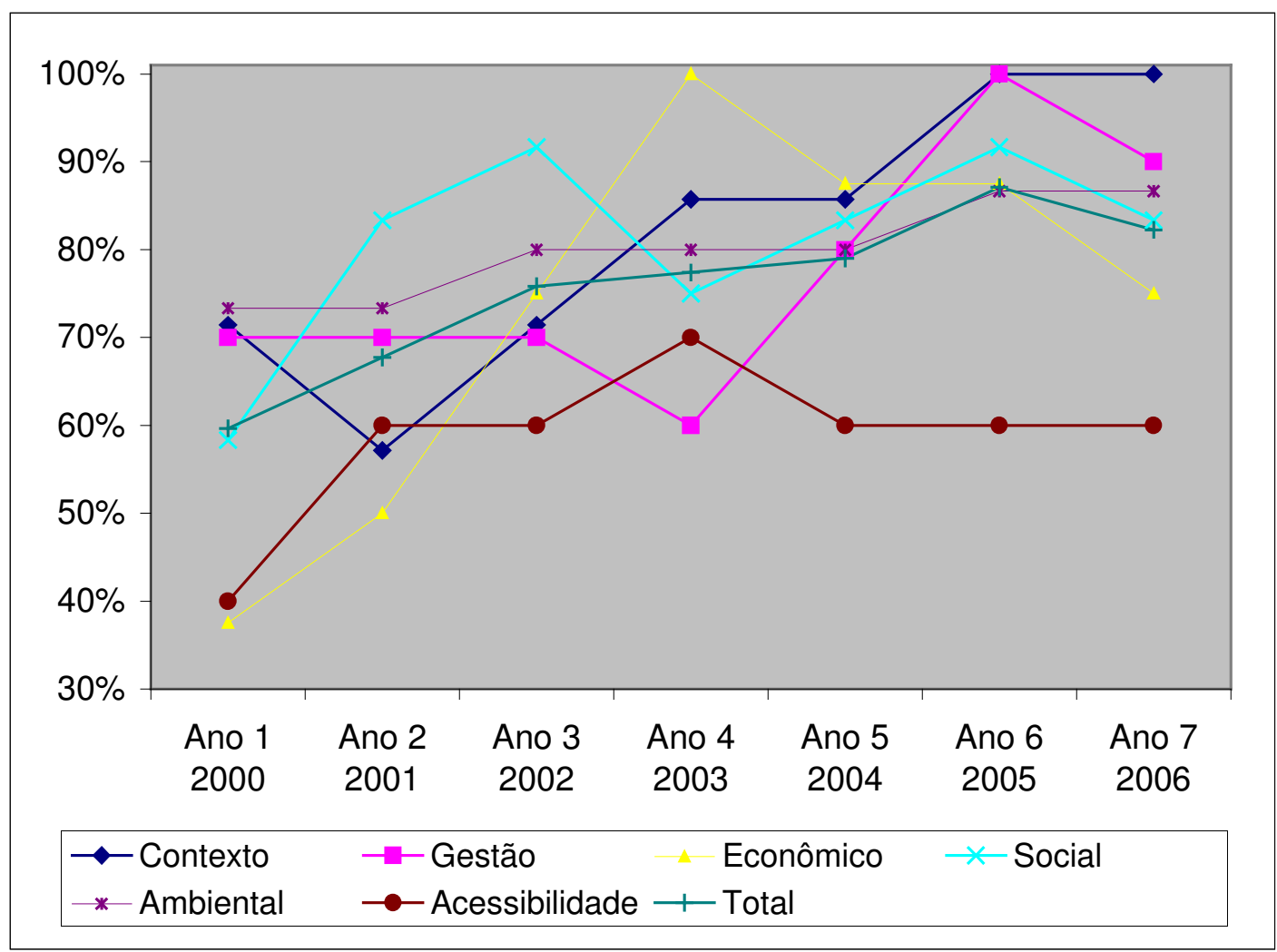

Figura 4 - Evolução temporal (Anglo American)

Os relatórios apresentam um aumento na quantidade de tópicos apresentados. Entretanto, houve um decréscimo no último relatório disponível (2006), causado pelo decréscimo nas categorias "Gestão", "Desempenho social" e "Desempenho econômico".

Após uma queda no primeiro ano, a categoria "Contexto e compromissos" teve evolução constante até alcançar e manter $100 \%$ nos últimos dois anos. A categoria 
"Desempenho ambiental" também apresentou evolução constante, porém pequena. "Acessibilidade e garantia" evoluiu inicialmente e depois se manteve constante, "Desempenho econômico" evoluiu até o ano 4 e depois decresceu. A categoria "Gestão" evoluiu somente nos últimos anos e em 2006 teve uma queda. "Desempenho social" teve comportamento irregular.

A Tabela 10 apresenta as informações adicionais identificadas após exploração dos relatórios.

Tabela 10 - Informações adicionais (Anglo American)

\begin{tabular}{|c|c|c|c|c|c|c|c|}
\hline Informação & $\begin{array}{l}\text { Ano } 1 \\
2000\end{array}$ & $\begin{array}{l}\text { Ano } 2 \\
2001\end{array}$ & $\begin{array}{l}\text { Ano } 3 \\
2002\end{array}$ & $\begin{array}{l}\text { Ano } 4 \\
2003\end{array}$ & $\begin{array}{l}\text { Ano } 5 \\
2004\end{array}$ & $\begin{array}{l}\text { Ano } 6 \\
2005\end{array}$ & $\begin{array}{l}\text { Ano } 7 \\
2006\end{array}$ \\
\hline $\begin{array}{l}\text { Padrão para } \\
\text { Relatório }\end{array}$ & Não & Não & GRI 2002 & GRI 2002 & GRI 2002 & $\begin{array}{l}\text { GRI } 2002 ; \\
\text { GRI Mining }\end{array}$ & $\begin{array}{l}\text { GRI } 2002 ; \\
\text { ICMM e } \\
\text { GRI Mining }\end{array}$ \\
\hline $\begin{array}{l}\text { Apresentação de } \\
\text { informações da } \\
\text { mineração }\end{array}$ & $64 \%$ & $76 \%$ & $85 \%$ & $79 \%$ & $82 \%$ & $91 \%$ & $85 \%$ \\
\hline $\begin{array}{l}\text { Padrão para } \\
\text { verificação }\end{array}$ & Não & Não & Não & Não & ISAE 3000 & ISAE 3000 & Não \\
\hline $\begin{array}{l}\text { Empresa de } \\
\text { auditoria }\end{array}$ & KPMG & KPMG & KPMG & KPMG & KPMG & KPMG & KPMG \\
\hline $\begin{array}{l}\text { Número de } \\
\text { páginas }\end{array}$ & 58 & 54 & 66 & 72 & 74 & 71 & 70 \\
\hline Pontuação total & $60 \%$ & $68 \%$ & $76 \%$ & $77 \%$ & $79 \%$ & $87 \%$ & $82 \%$ \\
\hline
\end{tabular}

Os últimos quatro relatórios seguiram como padrão as diretrizes GRI 2002, entre outras. Nos dois últimos anos foi usado suplemento GRI Mining. O relatório de 2005 foi o que mais apresentou as informações recomendadas especificamente para o setor de mineração (91\%). Todos os relatórios divulgados foram verificados por terceira parte, que somente em dois anos usou um padrão para essa verificação. Houve um acréscimo no número de páginas, embora a melhor pontuação não tenha sido obtida pelo maior relatório, assim como o menor relatório não obteve a menor pontuação.

\subsubsection{BHP Billiton}

BHP é a única empresa analisada que apresenta seus dados referentes ao período de 1 de Julho a 30 de Junho. A Tabela 11 sintetiza as porcentagens obtidas pela avaliação dos relatórios da BHP Billiton para cada uma das categorias e no total. $\mathrm{O}$ 
roteiro com a avaliação completa de todos os relatórios está apresentado no Apêndice C.

Tabela 11 - Porcentagens obtidas (BHP Billiton)

\begin{tabular}{lcc|ccccccc}
\hline Categoria & $\begin{array}{l}\text { Ano 1 } \\
\mathbf{0 0 / 0 1}\end{array}$ & $\begin{array}{c}\text { Ano } 2 \\
\mathbf{0 1 / 0 2}\end{array}$ & $\begin{array}{c}\text { Ano } 3 \\
\mathbf{0 2 / 0 3}\end{array}$ & $\begin{array}{c}\text { Ano } 4 \\
\mathbf{0 3 / 0 4}\end{array}$ & $\begin{array}{c}\text { Ano } 5 \\
\mathbf{0 4 / 0 5}\end{array}$ & $\begin{array}{c}\text { Ano } 6 \\
\mathbf{0 5 / 0 6}\end{array}$ & $\begin{array}{c}\text { Ano } 7 \\
\mathbf{0 6 / 0 7}\end{array}$ & Média & Evolução \\
\hline Contexto & $100 \%$ & $100 \%$ & $86 \%$ & $100 \%$ & $100 \%$ & $100 \%$ & $100 \%$ & $98 \%$ & $0 \%$ \\
\hline Gestão & $60 \%$ & $70 \%$ & $80 \%$ & $90 \%$ & $90 \%$ & $100 \%$ & $100 \%$ & $84 \%$ & $40 \%$ \\
\hline Econômico & $50 \%$ & $63 \%$ & $75 \%$ & $63 \%$ & $75 \%$ & $88 \%$ & $88 \%$ & $71 \%$ & $38 \%$ \\
\hline Social & $92 \%$ & $92 \%$ & $92 \%$ & $92 \%$ & $100 \%$ & $100 \%$ & $100 \%$ & $95 \%$ & $8 \%$ \\
\hline Ambiental & $67 \%$ & $73 \%$ & $80 \%$ & $80 \%$ & $87 \%$ & $93 \%$ & $93 \%$ & $82 \%$ & $26 \%$ \\
\hline Acessibilidade & $50 \%$ & $60 \%$ & $60 \%$ & $80 \%$ & $80 \%$ & $80 \%$ & $80 \%$ & $70 \%$ & $30 \%$ \\
\hline Total & $69 \%$ & $76 \%$ & $79 \%$ & $84 \%$ & $89 \%$ & $94 \%$ & $94 \%$ & $83 \%$ & $25 \%$ \\
\hline
\end{tabular}

O relatório dos dois últimos anos foram melhor avaliados. A categoria que teve melhor avaliação média no período analisado foi "Contexto e compromissos". A categoria melhor avaliada em cada ano foi "Contexto e compromissos", seguida por "Desempenho social" nos dois últimos anos. As categorias "Contexto e compromissos", "Gestão" e "Desempenho social" atingiram 100\% de atendimento aos tópicos relacionados nessas categorias. A pior categoria em quatro anos foi "Acessibilidade e garantia".

No último ano, as duas melhores categorias foram "Contexto e compromissos" e "Desempenho social", e a pior categoria no último ano, e em média, foi "Acessibilidade e garantia". A maior evolução foi da categoria "Gestão" (40\%) e a menor das categorias "Contexto e compromissos" e "Desempenho social". A diferença porcentual entre o primeiro relatório e o último foi de $25 \%$, que coincide com a diferença entre o pior e o melhor relatório. Nos últimos dois anos, todas as categorias obtiveram pontuações maiores ou iguais a $80 \%$.

Um trecho de um relatório foi destacado por representar o adequado atendimento ao requisito "Considerações sobre a cadeia de suprimentos":

"Nossas operações de suprimentos buscam garantir que a contratação de services, compras, ou aluguel de equipamentos e materiais, e atividades com parceiros seja executada de maneira que minimize qualquer consequência adversa em meio ambienta e segurança. Nós também, sempre que possível, colaboramos com nossos fornecedores para otimizar o uso de consumíveis" (BHP, 2007b, tradução nossa). 
A Figura 5 mostra a evolução temporal das pontuações porcentuais obtidas pelos relatórios de 2000/2001 a 2006/2007 para os relatórios da BHP Billiton.

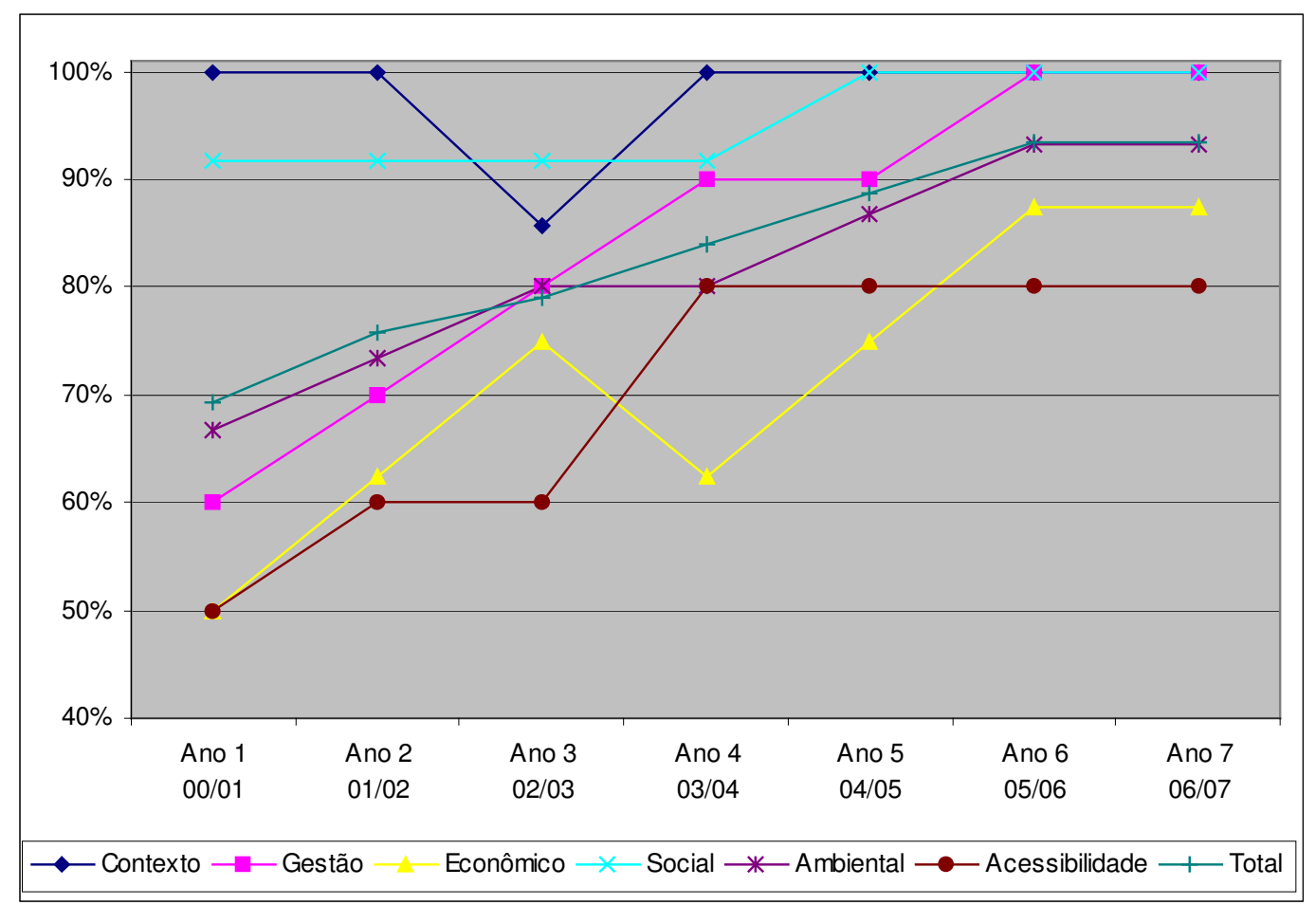

Figura 5 - Evolução temporal (BHP Billiton)

Os relatórios apresentam um sustentado aumento no atendimento aos tópicos do roteiro desenvolvido. Entretanto não houve evolução no último relatório disponível (2006/2007), pois todas as categorias apresentaram a mesma avaliação do período anterior.

A categoria "Contexto e compromisso" teve pontuação máxima constante, com exceção do terceiro relatório. As categorias "Desempenho ambiental" e "Gestão" apresentaram evolução constante, até o penúltimo período. "Acessibilidade e garantia" evoluiu inicialmente mas se manteve constante nos últimos três anos, "Desempenho econômico" evoluiu com exceção do período 2003/2004. A categoria "Desempenho social" teve pontuação constante nos primeiros quatro anos, um período de evolução e mais anos constantes. 
A Tabela 12 apresenta as informações adicionais identificadas após exploração dos relatórios.

Tabela 12 - Informações adicionais (BHP Billiton)

\begin{tabular}{|c|c|c|c|c|c|c|c|}
\hline Informação & $\begin{array}{l}\text { Ano } 1 \\
00 / 01\end{array}$ & $\begin{array}{l}\text { Ano } 2 \\
01 / 02\end{array}$ & $\begin{array}{l}\text { Ano } 3 \\
02 / 03\end{array}$ & $\begin{array}{l}\text { Ano } 4 \\
03 / 04\end{array}$ & $\begin{array}{l}\text { Ano } 5 \\
04 / 05\end{array}$ & $\begin{array}{l}\text { Ano } 6 \\
05 / 06\end{array}$ & $\begin{array}{l}\text { Ano } 7 \\
06 / 07\end{array}$ \\
\hline Padrão para relatório & Não & GRI 2002 & GRI 2002 & GRI 2002 & GRI 2002 & GRI G3 & $\begin{array}{c}\text { GRI G3 } \\
\text { e GRI } \\
\text { Mining } \\
\end{array}$ \\
\hline $\begin{array}{l}\text { Apresentação de } \\
\text { informações da } \\
\text { Mineração }\end{array}$ & $73 \%$ & $79 \%$ & $82 \%$ & $82 \%$ & $91 \%$ & $97 \%$ & $97 \%$ \\
\hline Padrão para verificação & Não & Não & Não & AA1000 & AA1000 & AA1000 & $\begin{array}{l}\text { ISAE } 3000 \\
\text { e AA } 1000\end{array}$ \\
\hline Empresa auditora & KPMG & ERM & ERM & URS & URS & URS & $\begin{array}{l}\text { Ernst \& } \\
\text { Young }\end{array}$ \\
\hline Número de páginas & 75 & 66 & 117 & 164 & 384 & 522 & 315 \\
\hline Pontuação total & $69 \%$ & $76 \%$ & $79 \%$ & $84 \%$ & $89 \%$ & $94 \%$ & $94 \%$ \\
\hline
\end{tabular}

Com exceção do primeiro ano, todos os relatórios seguiram as diretrizes GRI (G3 nos dois últimos relatórios). Os dois últimos relatórios apresentaram a maior quantidade de informações recomendadas para a mineração (97\%). Todos os relatórios divulgados foram verificados por terceira parte, que nos últimos quatro relatórios usou um padrão para essa verificação. Houve um acréscimo significativo no número de páginas havendo, porém, três casos em que o aumento do número de páginas não teve relação com o aumento na pontuação do relatório.

\subsubsection{Cemex}

A Cemex é a empresa analisada que apresenta o maior histórico disponível de relatórios. A Tabela 13 sintetiza as porcentagens obtidas pela avaliação dos relatórios da Cemex para cada uma das categorias e no total. O roteiro com a avaliação completa de todos os relatórios está apresentado no Apêndice D. 
Tabela 13 - Porcentagens obtidas (Cemex)

\begin{tabular}{lccccccccccccc}
\hline & Ano 1 Ano 2 & Ano 3 & Ano 4 & Ano 5 & Ano 6 & Ano 7 & Ano 8 & Ano 9 & Ano 10 & \\
Categoria & 1997 & 1998 & 1999 & 2000 & 2001 & 2002 & 2003 & 2004 & 2005 & 2006 & & \\
\hline Contexto & $57 \%$ & $29 \%$ & $57 \%$ & $57 \%$ & $57 \%$ & $57 \%$ & $86 \%$ & $86 \%$ & $43 \%$ & $86 \%$ & $61 \%$ & $29 \%$ \\
\hline Gestão & $40 \%$ & $30 \%$ & $30 \%$ & $40 \%$ & $20 \%$ & $30 \%$ & $60 \%$ & $60 \%$ & $40 \%$ & $80 \%$ & $43 \%$ & $40 \%$ \\
\hline Econômico & $0 \%$ & $0 \%$ & $13 \%$ & $13 \%$ & $13 \%$ & $13 \%$ & $13 \%$ & $13 \%$ & $0 \%$ & $63 \%$ & $14 \%$ & $63 \%$ \\
\hline Social & $33 \%$ & $25 \%$ & $33 \%$ & $50 \%$ & $25 \%$ & $25 \%$ & $58 \%$ & $58 \%$ & $58 \%$ & $92 \%$ & $46 \%$ & $59 \%$ \\
\hline Ambiental & $13 \%$ & $13 \%$ & $27 \%$ & $60 \%$ & $27 \%$ & $33 \%$ & $33 \%$ & $40 \%$ & $47 \%$ & $60 \%$ & $35 \%$ & $47 \%$ \\
\hline Acessibilidade & $10 \%$ & $10 \%$ & $10 \%$ & $30 \%$ & $20 \%$ & $20 \%$ & $40 \%$ & $30 \%$ & $30 \%$ & $40 \%$ & $24 \%$ & $30 \%$ \\
\hline Total & $24 \%$ & $18 \%$ & $27 \%$ & $44 \%$ & $26 \%$ & $29 \%$ & $47 \%$ & $47 \%$ & $39 \%$ & $69 \%$ & $37 \%$ & $45 \%$ \\
\hline
\end{tabular}

O relatório do último ano foi o melhor avaliado. A categoria que teve melhor avaliação média no período analisado foi "Contexto e compromissos". A categoria com a pior média foi "Desempenho econômico". A categoria melhor avaliada em cada ano foi "Contexto e compromissos", seguida por "Desempenho social" nos dois últimos anos. A pior categoria em oito anos foi "Desempenho econômico".

No último ano, as duas melhores categorias foram "Contexto e commpromissos" e "Desempenho social" e a pior categoria no último ano foi "Acessibilidade e garantia". A maior evolução foi da categoria "Desempenho social" (59\%) e a menor da categoria "Contexto e compromissos", seguida por "Acessibilidade e garantia". A diferença porcentual entre o primeiro relatório e o último foi de $45 \%$, e a diferença entre o pior e o melhor relatório foi de $51 \%$.

Um trecho de um relatório foi destacado por representar o adequado atendimento ao requisito "Perfil do relatório":

\begin{abstract}
"Bem vindo ao nosso relatório de desenvolvimento sustentável do ano-calendário 2006. Este relatório cobre nossas operações globais de cimento, concreto e agregados, N'so publicamos nosso primeiro relatório ambiental em 1995, e produzimos nosso primeiro relatório de sustentabilidade em 2003. Em abril de 2006 nós publicamos um relatório de desenvolvimento sustentável interino para o ano-calendário 2005. No futuro iremos publicar relatórios completes a cada dois anos. [...] Nós usamos as diretrizes G3 da Global Reporting Initiative para produzir esse documento. Nosso relatório atende ao nível B de aplicação" (Cemex, 2007b, tradução nossa).
\end{abstract}

\footnotetext{
${ }^{11}$ Em 2005 Cemex publicou somente um relatório interino (interin report), o que pode justificar a baixa pontuação do relatório desse ano.
} 
A Figura 6 mostra a evolução temporal das pontuações porcentuais obtidas pelos relatórios de 1997 a 2006 para os relatórios da Cemex.

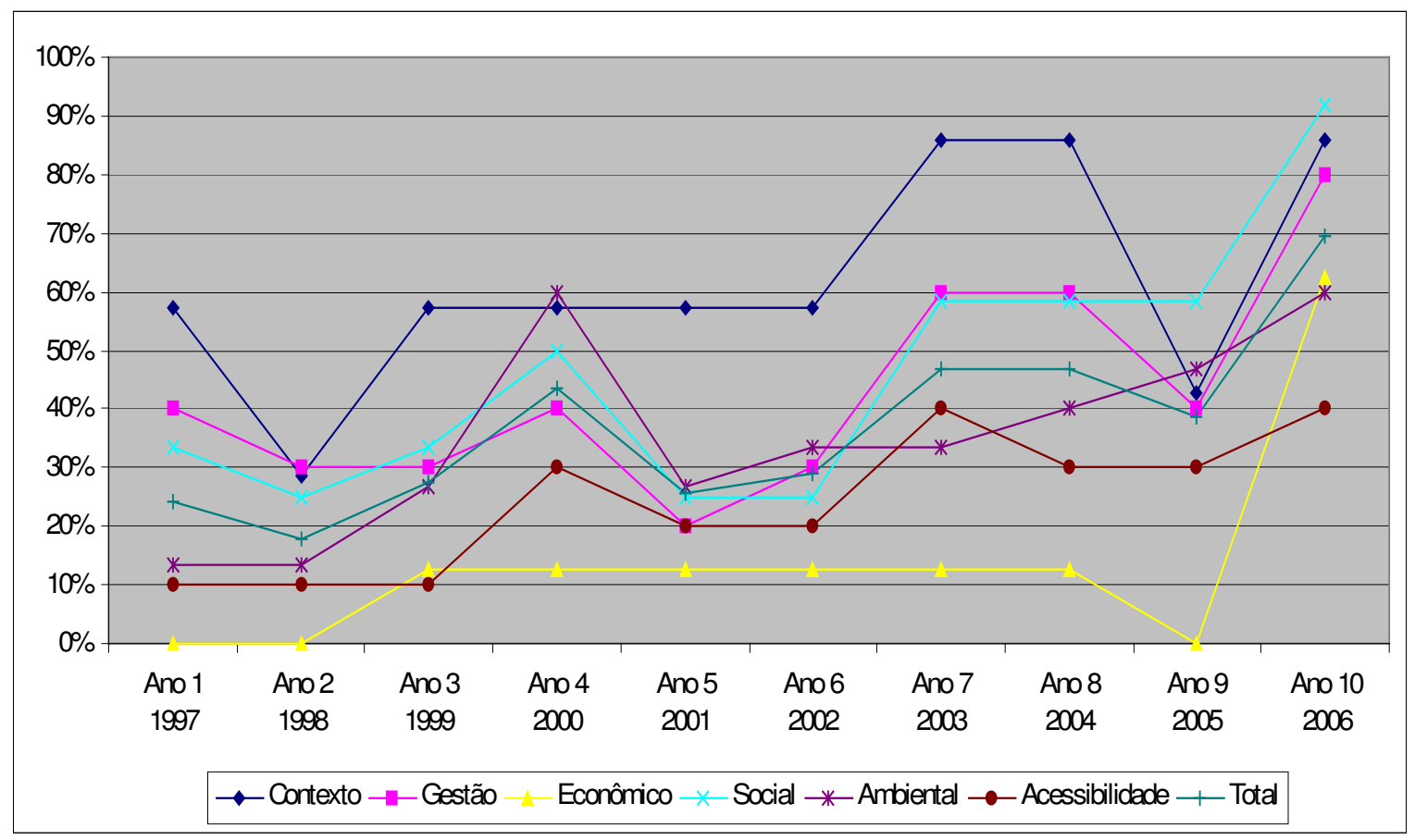

Figura 6 - Evolução temporal (Cemex)

Em termos absolutos houve evolução, mas não há uma tendência clara. Somente o último relatório apresentou uma evolução significativa. As categorias "Acessibilidade e garantia", "Contexto e compromissos" e "Gestão" tiveram pontuação irregular. As categorias "Desempenho social" e "Desempenho ambiental" apresentaram evolução constante somente a partir do sexto período. A categoria "Desempenho econômico" se manteve praticamente constante, evoluindo significativamente somente no último período.

A Tabela 14 apresenta as informações adicionais identificadas após exploração dos relatórios. 
Tabela 14 - Informações adicionais (Cemex)

\begin{tabular}{|c|c|c|c|c|c|c|c|c|c|c|}
\hline Informação & $\begin{array}{l}\text { Ano } 1 \\
1997 \\
\end{array}$ & $\begin{array}{l}\text { Ano } 2 \\
1998 \\
\end{array}$ & $\begin{array}{l}\text { Ano } 3 \\
1999 \\
\end{array}$ & $\begin{array}{l}\text { Ano } 4 \\
2000 \\
\end{array}$ & $\begin{array}{l}\text { Ano } 5 \\
2001 \\
\end{array}$ & $\begin{array}{c}\text { Ano } 6 \\
2002 \\
\end{array}$ & $\begin{array}{l}\text { Ano } 7 \\
2003 \\
\end{array}$ & $\begin{array}{l}\text { Ano } 8 \\
2004 \\
\end{array}$ & $\begin{array}{l}\text { Ano } 9 \\
2005 \\
\end{array}$ & $\begin{array}{l}\text { Ano } 10 \\
2006\end{array}$ \\
\hline $\begin{array}{l}\text { Padrão para } \\
\text { relatório }\end{array}$ & Não & Não & Não & Não & Não & Não & $\begin{array}{l}\text { GRI } \\
2002\end{array}$ & $\begin{array}{l}\text { GRI } \\
2002 ; \\
\text { Cement } \\
\text { Sust. } \\
\text { Initiative }\end{array}$ & Não & $\begin{array}{l}\text { GRI G3 } \\
\text { Nível B }\end{array}$ \\
\hline $\begin{array}{l}\text { Apresentação de } \\
\text { informações da } \\
\text { Mineração }\end{array}$ & $18 \%$ & $18 \%$ & $24 \%$ & $45 \%$ & $15 \%$ & $24 \%$ & $33 \%$ & $36 \%$ & $33 \%$ & $70 \%$ \\
\hline $\begin{array}{l}\text { Padrão para } \\
\text { verificação } \\
\text { Empresa que fez } \\
\text { a verificação }\end{array}$ & Não & Não & Não & Não & Não & Não & Não & Não & Não & Não \\
\hline $\begin{array}{l}\text { Número de } \\
\text { páginas }\end{array}$ & 18 & 7 & 16 & 27 & 16 & 14 & 36 & 36 & 8 & 42 \\
\hline Pontuação total & $24 \%$ & $18 \%$ & $27 \%$ & $44 \%$ & $26 \%$ & $29 \%$ & $47 \%$ & $47 \%$ & $39 \%$ & $69 \%$ \\
\hline
\end{tabular}

Somente a partir de 2003 a Cemex adotou um padrão para o relatório (diretrizes GRI). O relatório de 2006 foi o que apresentou maior quantidade de informações recomendadas para a mineração $(70 \%)$. Nenhum relatório divulgado foi verificado por terceira parte, mas o relatório de 2006 traz uma declaração de que a empresa apresentará essa verificação nos próximos relatórios. Houve uma variação no número de páginas, apesar de não haver indícios de que o aumento do número de páginas tenha relação com o aumento de pontuação do relatório.

\subsubsection{Lafarge}

A Tabela 15 sintetiza as porcentagens obtidas pela avaliação dos relatórios da Lafarge para cada uma das categorias e no total. O roteiro com a avaliação completa de todos os relatórios está apresentado no Apêndice $\mathrm{E}$. 
Tabela 15 - Porcentagens obtidas (Lafarge)

\begin{tabular}{lcccccccc}
\hline Categoria & $\begin{array}{c}\text { Ano 1 } \\
\mathbf{2 0 0 1}\end{array}$ & $\begin{array}{c}\text { Ano 2 } \\
\mathbf{2 0 0 2}\end{array}$ & $\begin{array}{c}\text { Ano 3 } \\
\mathbf{2 0 0 3} \mathbf{1 2}^{12}\end{array}$ & $\begin{array}{c}\text { Ano 4 } \\
\mathbf{2 0 0 4}\end{array}$ & $\begin{array}{c}\text { Ano 5 } \\
\mathbf{2 0 0 5}\end{array}$ & $\begin{array}{c}\text { Ano 6 } \\
\mathbf{2 0 0 6}\end{array}$ & Média & Evolução \\
\hline Contexto & $71 \%$ & $86 \%$ & $71 \%$ & $71 \%$ & $100 \%$ & $71 \%$ & $79 \%$ & $0 \%$ \\
\hline Gestão & $80 \%$ & $80 \%$ & $60 \%$ & $60 \%$ & $80 \%$ & $70 \%$ & $72 \%$ & $-10 \%$ \\
\hline Econômico & $63 \%$ & $63 \%$ & $50 \%$ & $63 \%$ & $50 \%$ & $63 \%$ & $58 \%$ & $0 \%$ \\
\hline Social & $92 \%$ & $83 \%$ & $83 \%$ & $92 \%$ & $83 \%$ & $75 \%$ & $85 \%$ & $-17 \%$ \\
\hline Ambiental & $73 \%$ & $87 \%$ & $67 \%$ & $80 \%$ & $80 \%$ & $80 \%$ & $78 \%$ & $7 \%$ \\
\hline Acessibilidade & $70 \%$ & $60 \%$ & $50 \%$ & $80 \%$ & $80 \%$ & $80 \%$ & $70 \%$ & $10 \%$ \\
\hline Total & $76 \%$ & $77 \%$ & $65 \%$ & $76 \%$ & $79 \%$ & $74 \%$ & $74 \%$ & $-2 \%$ \\
\hline
\end{tabular}

A média das pontuações totais é inferior à pontuação obtida pelo primeiro relatório. O relatório do penúltimo ano foi o melhor avaliado. A categoria que teve melhor avaliação média no período analisado foi "Desempenho social", sendo também a categoria melhor avaliada na metade dos relatórios. A categoria "Contexto e compromissos" atingiu $100 \%$ de conformidade no penúltimo ano, mas depois caiu para $71 \%$.

No último ano, as duas melhores categorias foram "Desempenho ambiental" e "Acessibilidade e garantia". A pior categoria no último ano e em média foi "Desempenho econômico". A maior evolução foi da categoria "Acessibilidade e garantia" (10\%) e a menor foi da "Desempenho social" (decréscimo de 17\%). A diferença porcentual entre o primeiro relatório e o último foi de $-2 \%$, e a diferença entre o pior e o melhor relatório foi de $3 \%$.

Um trecho de um relatório foi destacado por representar o adequado atendimento ao requisito "Consumo de recursos naturais não-renováveis":

\begin{abstract}
"A pedra calcária, os agregados e o gesso - núcleo de nossos produtos - são recursos minerais naturais. Nós extraímos $92 \%$ destas matérias primas com operações em pedreiras. Como exemplo, o consumo anual per capita dos agregados (a areia e o cascalho usados no concreto e estradas) é em média 7 toneladas em Europa, quase 10 nos EUA e perto de 15 no Canadá. Com tão elevada demanda, extrair esses materiais é uma questão importante. As pedreiras criam impactos sociais, econômicos e ambientais, que nós devemos controlar. Como a parte de nosso compromisso com sustentabilidade, nós trabalhamos para conservar recursos naturais operando nossas pedreiras eficientemente e usando substitutos para as matérias primas sempre que possível" (LAFARGE, 2007b, tradução nossa).
\end{abstract}

\footnotetext{
${ }^{12}$ Em 2003 Lafarge publicou somente uma "versão reduzida" (short version) do relatório, o que pode justificar a pontuação baixa nesse ano.
} 
A Figura 7 mostra a evolução temporal das pontuações porcentuais obtidas pelos relatórios de 2001 a 2006 para os relatórios da Lafarge.

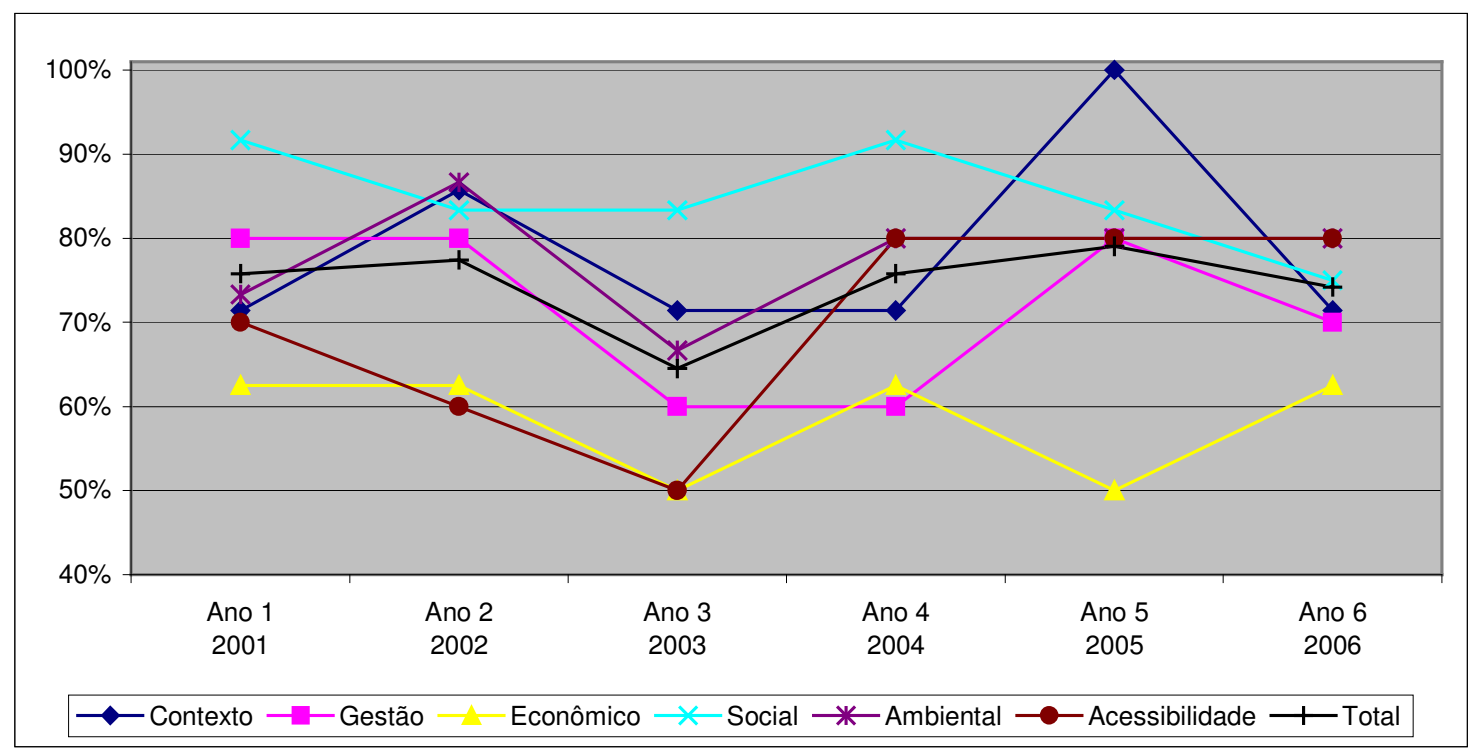

Figura 7 - Evolução temporal (Lafarge)

Os relatórios da Lafarge não mostram uma evolução sistemática, mantendo sua pontuação praticamente constante.

As categorias "Contexto e compromissos", "Gestão" e "Desempenho econômico" tiveram pontuação irregular. "Contexto e compromissos" e "Gestão" evoluíram em 2005 mas caíram em 2006. A pontuação da categoria "Desempenho econômico" oscilou no período analisado. A categoria "Desempenho social" mostra tendência de queda. A categoria "Desempenho ambiental" e "Acessibilidade e garantia" tiveram pontuação constante nos últimos três anos.

A Tabela 16 apresenta as informações adicionais identificadas após exploração dos relatórios. 
Tabela 16 - Informações adicionais (Lafarge)

\begin{tabular}{lccccccc}
\hline \multicolumn{1}{c}{ Informação } & $\begin{array}{c}\text { Ano 1 } \\
2001\end{array}$ & $\begin{array}{c}\text { Ano 2 } \\
2002\end{array}$ & $\begin{array}{c}\text { Ano 3 } \\
2003\end{array}$ & $\begin{array}{c}\text { Ano 4 } \\
2004\end{array}$ & $\begin{array}{c}\text { Ano 5 } \\
2005\end{array}$ & $\begin{array}{c}\text { Ano 6 } \\
2006\end{array}$ \\
\hline Padrão para relatório & GRI 2002 & GRI 2002 & GRI 2002 & GRI 2002 & GRI 2002 & $\begin{array}{c}\text { GRI 2002 } \\
\text { Cement } \\
\text { Sustainable } \\
\text { Initiative } \\
\text { (CSI) }\end{array}$ \\
\hline $\begin{array}{l}\text { Apresentação de } \\
\text { informaçes da } \\
\text { Mineração }\end{array}$ & $76 \%$ & $79 \%$ & $64 \%$ & $73 \%$ & $76 \%$ & $73 \%$ \\
\hline $\begin{array}{l}\text { Padrão para } \\
\text { verificação }\end{array}$ & $\begin{array}{c}\text { Amnesty } \\
\text { International } \\
\text { UK's business } \\
\text { guidelines. } \\
\text { SAM, }\end{array}$ & Não & Não & Não & Não & Não \\
$\begin{array}{l}\text { Empresa que fez a } \\
\text { verificação }\end{array}$ & $\begin{array}{c}\text { Storebrand } \\
\text { ARESE e EIRIS }\end{array}$ & & & & $\begin{array}{c}\text { PriceWaterh } \\
\text { ouseCoopers }\end{array}$ & $\begin{array}{c}\text { Ernst } \\
\text { \&Young }\end{array}$ \\
\hline Número de páginas & 60 & 62 & 25 & 33 & 52 & 64 \\
\hline Pontuação total & $76 \%$ & $77 \%$ & $65 \%$ & $76 \%$ & $79 \%$ & $74 \%$ \\
\hline
\end{tabular}

Todos os relatórios seguiram as diretrizes GRI 2002. O relatório de 2002 foi o que mais apresentou informações recomendadas para a mineração. O primeiro e os dois últimos relatórios foram verificados por terceira parte. Não havendo uma variação significativa no número de páginas. O menor relatório obteve a menor pontuação mas o maior relatório não obteve a maior pontuação.

\subsubsection{Samarco}

A Tabela 17 sintetiza as porcentagens obtidas pela avaliação dos relatórios da Samarco para cada uma das categorias e no total. O roteiro com a avaliação completa de todos os relatórios está apresentado no Apêndice F. 
Tabela 17 - Porcentagens obtidas (Samarco)

\begin{tabular}{lccccccc}
\hline Categoria & $\begin{array}{c}\text { Ano 1 } \\
2002\end{array}$ & $\begin{array}{c}\text { Ano 2 } \\
2003\end{array}$ & $\begin{array}{c}\text { Ano 3 } \\
2004\end{array}$ & $\begin{array}{c}\text { Ano 4 } \\
2005\end{array}$ & $\begin{array}{c}\text { Ano } 5 \\
2006\end{array}$ & Média & Evolução \\
\hline Contexto & $71 \%$ & $71 \%$ & $86 \%$ & $86 \%$ & $100 \%$ & $83 \%$ & $29 \%$ \\
\hline Gestão & $90 \%$ & $90 \%$ & $90 \%$ & $90 \%$ & $90 \%$ & $90 \%$ & $0 \%$ \\
\hline Econômico & $63 \%$ & $75 \%$ & $75 \%$ & $75 \%$ & $75 \%$ & $73 \%$ & $12 \%$ \\
\hline Social & $92 \%$ & $92 \%$ & $92 \%$ & $92 \%$ & $92 \%$ & $92 \%$ & $0 \%$ \\
\hline Ambiental & $53 \%$ & $67 \%$ & $73 \%$ & $73 \%$ & $73 \%$ & $68 \%$ & $20 \%$ \\
\hline Acessibilidade & $10 \%$ & $50 \%$ & $50 \%$ & $50 \%$ & $50 \%$ & $42 \%$ & $40 \%$ \\
\hline Total & $63 \%$ & $74 \%$ & $77 \%$ & $77 \%$ & $79 \%$ & $74 \%$ & $16 \%$ \\
\hline
\end{tabular}

O relatório do último ano foi o melhor avaliado (79\%). A categoria que teve melhor avaliação média no período analisado foi "Desempenho social" (92\%), sendo também a categoria melhor avaliada na maioria dos relatórios. A categoria "Contexto e compromissos" atingiu 100\% de conformidade no último ano. A média mais baixa foi da categoria "Acessibilidade e garantia", recebendo também a pior pontuação em todos os anos.

No último ano, as duas melhores categorias foram "Contexto e compromissos" e "Desempenho social". A pior categoria no último ano foi "Acessibilidade e garantia". A maior evolução foi da categoria "Acessibilidade e garantia' (40\%) e a menor foi das categorias "Gestão" e "Desempenho social" (0\%). A diferença porcentual entre o primeiro relatório e o último foi de $16 \%$, que é a diferença entre o pior e o melhor relatório.

Um trecho de um relatório foi destacado por representar o adequado atendimento ao requisito "Avaliação do relatório": 


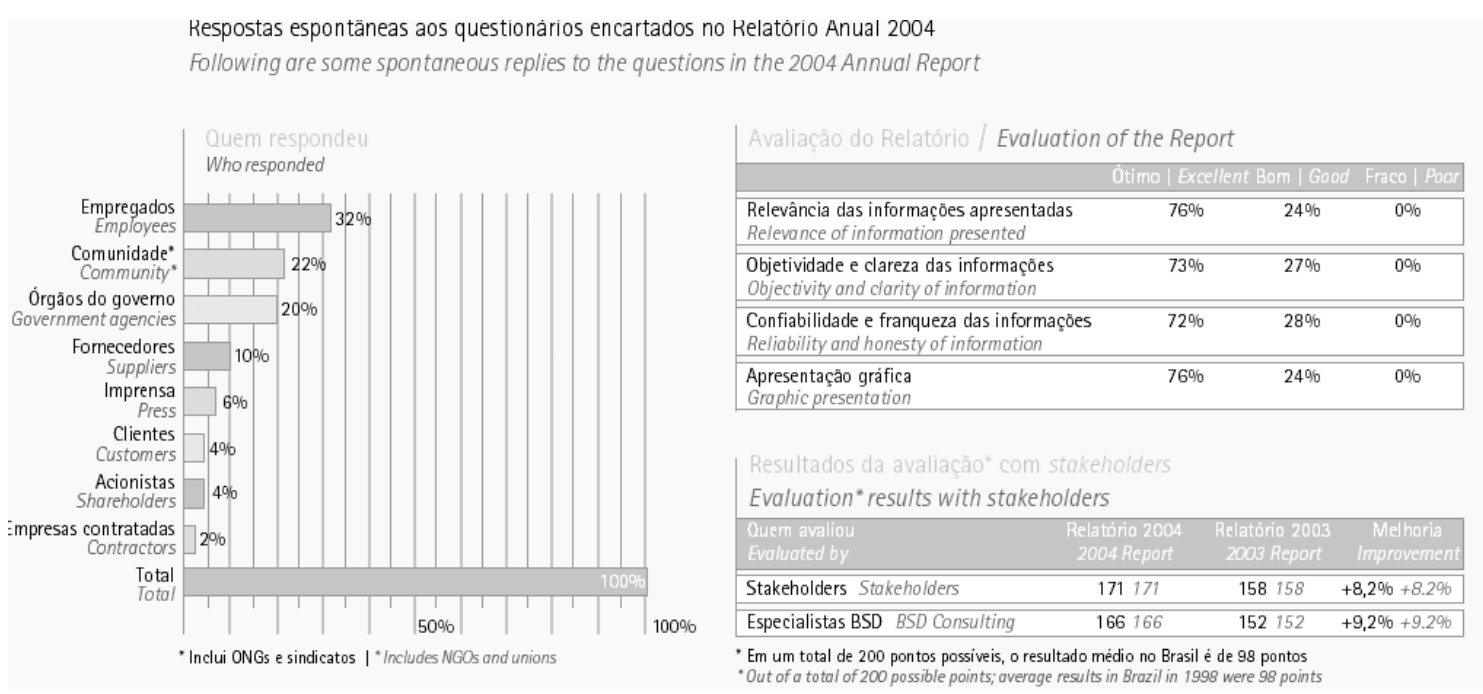

Figura 8 - Avaliação do relatório (Samarco, 2006)

A Figura 8 mostra a evolução temporal das pontuações porcentuais obtidas pelos relatórios de 2002 a 2006 para os relatórios da Samarco.

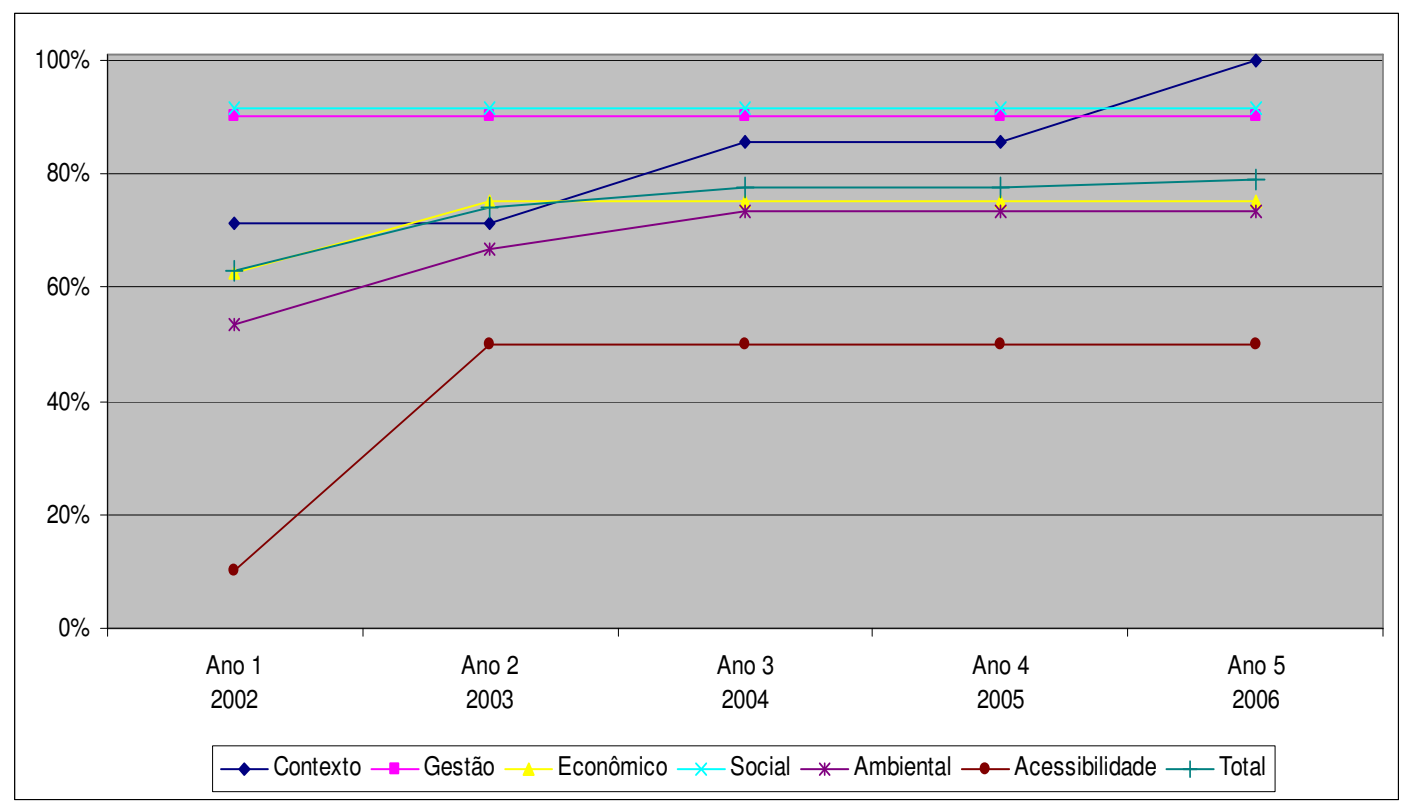

Figura 9 - Evolução temporal (Samarco)

Os relatórios da Samarco mostram uma evolução pequena, pois algumas categorias evoluíram e outras se mantiveram constantes.

As categorias "Gestão" e "Desempenho Social" tiveram pontuação constante no período analisado, assim como a categoria "Desempenho econômico" e 
"Acessibilidade e garantia" a partir do segundo ano. A categoria "Desempenho ambiental" evoluiu até o terceiro relatório e a partir desse ano se manteve constante. Somente a categoria "Contexto e compromisso" evoluiu de maneira mais constante até atingir $100 \%$ no último relatório.

A Tabela 18 apresenta as informações adicionais identificadas após exploração dos relatórios.

\begin{tabular}{lcccccc}
\multicolumn{7}{c}{ Tabela 18 - Informações adicionais (Samarco) } \\
\hline \multicolumn{1}{c}{ Informação } & $\begin{array}{c}\text { Ano 1 } \\
2002\end{array}$ & $\begin{array}{c}\text { Ano 2 } \\
2003\end{array}$ & $\begin{array}{c}\text { Ano 3 } \\
2004\end{array}$ & $\begin{array}{c}\text { Ano 4 } \\
2005\end{array}$ & $\begin{array}{c}\text { Ano 5 } \\
2006\end{array}$ \\
\hline Padrão para relatório & Ibase & $\begin{array}{c}\text { GRI 2002 } \\
\text { Ethos e } \\
\text { lbase }\end{array}$ & $\begin{array}{c}\text { GRI 2002 } \\
\text { Ethos e } \\
\text { lbase }\end{array}$ & $\begin{array}{c}\text { GRI 2002 } \\
\text { Ethos e } \\
\text { lbase }\end{array}$ & $\begin{array}{c}\text { GRI G3 } \\
\text { Ethos }\end{array}$ \\
\hline $\begin{array}{l}\text { Apresentação de informações da } \\
\text { Mineração }\end{array}$ & $67 \%$ & $82 \%$ & $82 \%$ & $82 \%$ & $82 \%$ \\
\hline $\begin{array}{l}\text { Padrão para verificação } \\
\text { Empresa que fez a verificação }\end{array}$ & Não & Não & Não & Não & Não \\
\hline Número de páginas & 101 & 74 & 148 & 139 & 156 \\
\hline Pontuação total & $68 \%$ & $71 \%$ & $77 \%$ & $76 \%$ & $79 \%$ \\
\hline
\end{tabular}

Todos os relatórios seguiram alguma diretriz, sendo que a partir de 2003 foram usadas as diretrizes GRI (G3 no último ano). Os últimos quatro relatórios mostraram o mesmo grau de apresentação das informações recomendadas para a mineração (82\%). Nenhum relatório foi verificado por terceira parte. O relatório com menos páginas não obteve a menor pontuação, mas o maior relatório obteve a maior pontuação.

\subsubsection{Comparação entre empresas}

Para fins de comparação somente serão usados os resultados dos períodos comuns, ou seja de 2002 a 2006. A Tabela 19 apresenta a pontuação porcentual obtida por cada empresa ao longo dos anos. 
Tabela 19 - Porcentagem total dos relatórios por empresa para os mesmos anos

\begin{tabular}{lcccccc}
\hline & Ano 1 & Ano 2 & Ano 3 & Ano 4 & Ano 5 & \\
Empresa & 2002 & 2003 & 2004 & 2005 & 2006 & Evolução \\
\hline Anglo & $76 \%$ & $77 \%$ & $79 \%$ & $87 \%$ & $82 \%$ & $6 \%$ \\
\hline BHP & $76 \%$ & $79 \%$ & $84 \%$ & $89 \%$ & $94 \%$ & $18 \%$ \\
\hline Cemex & $29 \%$ & $47 \%$ & $47 \%$ & $39 \%$ & $69 \%$ & $40 \%$ \\
\hline Lafarge & $77 \%$ & $65 \%$ & $76 \%$ & $79 \%$ & $74 \%$ & $-3 \%$ \\
\hline Samarco & $63 \%$ & $74 \%$ & $77 \%$ & $77 \%$ & $79 \%$ & $16 \%$ \\
\hline
\end{tabular}

Anglo American e BHP - empresas do ramo de minerais metálicos - pontuaram melhor do que as empresas do setor de cimento e minerais industriais (Lafarge e Cemex) e do que a empresa brasileira Samarco. Os relatórios da Cemex tem menor pontuação no método de avaliação desenvolvido, apesar de seu longo histórico de publicações. Em 2002 BHP, Anglo American e Lafarge obtiveram pontuações similares, no entanto BHP melhorou sistematicamente os relatórios a cada ano, obtendo a melhor pontuação entre as cinco empresas nos últimos quatro anos.

A empresa que teve maior evolução foi Cemex (40\%) e a que teve menor evolução foi Lafarge (-3\%). A Figura 10 mostra a evolução temporal de todas as empresas.

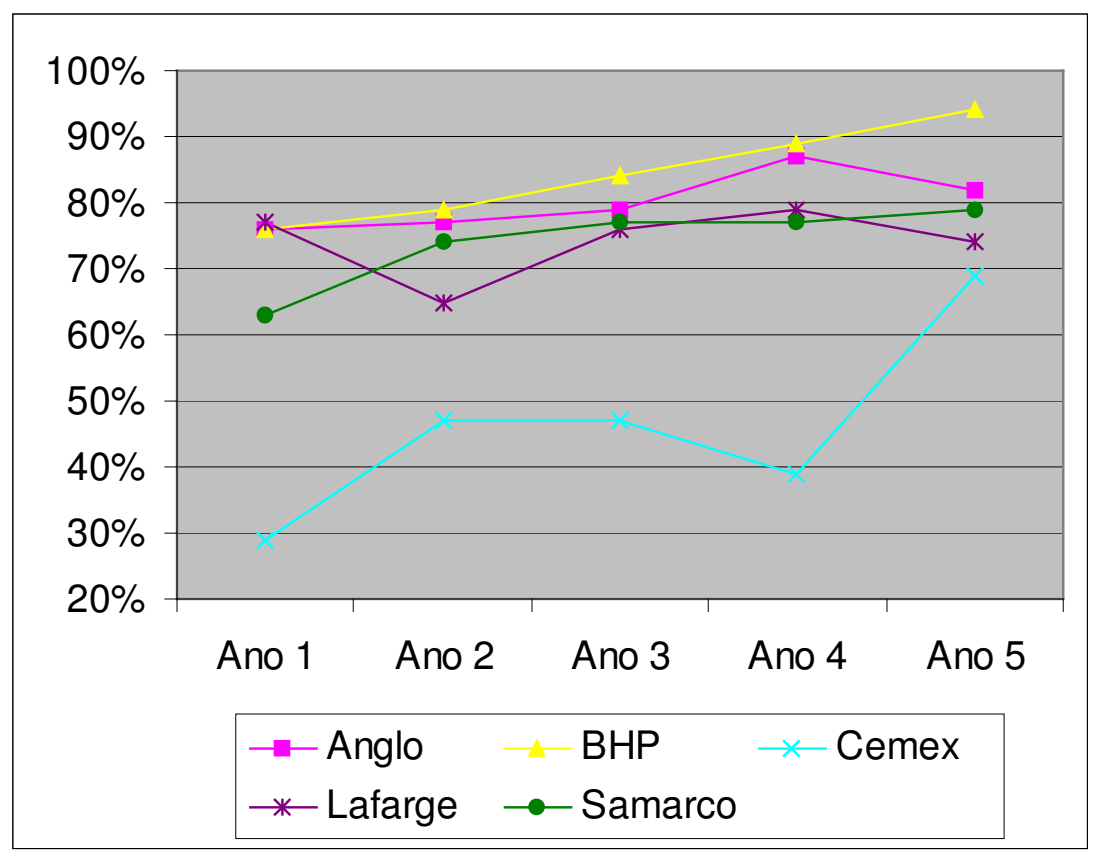

Figura 10 - Evolução temporal (cinco empresas) 
A Tabela 20 apresenta a pontuação média em cada categoria e total para todas as empresas, considerando o período de 2002 a 2006.

Tabela 20 - Pontuação média das empresas entre 2002 e 2006

\begin{tabular}{lccccc}
\hline \multicolumn{1}{c}{ Categoria } & BHP & Anglo & Samarco & Lafarge & Cemex \\
\hline Contexto & $97 \%$ & $89 \%$ & $83 \%$ & $80 \%$ & $71 \%$ \\
\hline Gestão & $92 \%$ & $80 \%$ & $90 \%$ & $70 \%$ & $54 \%$ \\
\hline Econômico & $78 \%$ & $85 \%$ & $73 \%$ & $58 \%$ & $20 \%$ \\
\hline Social & $97 \%$ & $85 \%$ & $92 \%$ & $83 \%$ & $58 \%$ \\
\hline Ambiental & $87 \%$ & $83 \%$ & $68 \%$ & $79 \%$ & $43 \%$ \\
\hline Acessibilidade & $76 \%$ & $62 \%$ & $42 \%$ & $70 \%$ & $32 \%$ \\
\hline Total & $88 \%$ & $80 \%$ & $74 \%$ & $74 \%$ & $46 \%$ \\
\hline
\end{tabular}

BHP tem as melhores pontuações médias em todas as categorias, exceto econômico, em que a Anglo American tem a melhor média. A Tabela 21 apresenta a pontuação em cada categoria e total para o último relatório analisado (2006).

Tabela 21 - Pontuação dos relatórios de 2006

\begin{tabular}{lccccc}
\hline \multicolumn{1}{c}{ Categoria } & BHP & Anglo & Samarco & Lafarge & Cemex \\
\hline Contexto & $100 \%$ & $100 \%$ & $100 \%$ & $71 \%$ & $86 \%$ \\
\hline Gestão & $100 \%$ & $90 \%$ & $90 \%$ & $70 \%$ & $80 \%$ \\
\hline Econômico & $88 \%$ & $75 \%$ & $75 \%$ & $63 \%$ & $63 \%$ \\
\hline Social & $100 \%$ & $83 \%$ & $92 \%$ & $75 \%$ & $92 \%$ \\
\hline Ambiental & $93 \%$ & $87 \%$ & $73 \%$ & $80 \%$ & $60 \%$ \\
\hline Acessibilidade & $80 \%$ & $60 \%$ & $50 \%$ & $80 \%$ & $40 \%$ \\
\hline
\end{tabular}

O relatório da BHP 2006/2007 é o que tem maior pontuação em todas as categorias. Em segundo lugar na maioria das categorias está o relatório de 2006 da Anglo American. Destacam-se as categorias "Contexto e compromisso", "Gestão", "Desempenho econômico" e "Desempenho social" do relatório da Samarco, a categoria "Acessibilidade e Garantia" no relatório da Lafarge e a categoria "Desempenho social" no relatório da Cemex. A Tabela 22 resume o desempenho das categorias para as cinco empresas analisadas: maior e menor pontuação média, maior e menor pontuação em cada ano, maior e menor pontuação no último relatório (2006) e maior e menor evolução. 
Tabela 22 - Desempenho das categorias

\begin{tabular}{lccccc}
\hline \multicolumn{1}{c}{ Resultado } & BHP & Anglo & Samarco & Lafarge & Cemex \\
\hline Melhor média & Contexto & Contexto & Social & Social & Contexto \\
\hline $\begin{array}{l}\text { Melhor em cada } \\
\text { ano }\end{array}$ & $\begin{array}{c}\text { Contexto } \\
\text { Social }\end{array}$ & Várias & Social & Social & $\begin{array}{c}\text { Contexto } \\
\text { Social }\end{array}$ \\
\hline Melhor em 2006 & $\begin{array}{c}\text { Contexto } \\
\text { Social }\end{array}$ & $\begin{array}{c}\text { Contexto } \\
\text { Gestão }\end{array}$ & $\begin{array}{c}\text { Contexto } \\
\text { Social }\end{array}$ & $\begin{array}{c}\text { Ambiental } \\
\text { Acessibilidade }\end{array}$ & $\begin{array}{c}\text { Contexto } \\
\text { Social }\end{array}$ \\
\hline Pior em cada ano & Acessibilidade & Acessibilidade & Econômico & Econômico & Acessibilidade \\
\hline Pior média & Acessibilidade & Acessibilidade & Acessibilidade & Econômico & Econômico \\
\hline Pior em 2006 & Acessibilidade & Acessibilidade & Acessibilidade & Econômico & Acessibilidade \\
\hline Maior evolução & Gestão & Econômico & Acessibilidade Acessibilidade & Social \\
\hline Menor evolução & Contexto & Social & Ambiental & Gestão & Social \\
\hline
\end{tabular}

Nota-se que as categorias "Contexto e compromisso" e "Desempenho social" são as que apresentam melhor pontuação e as categorias "Acessibilidade e garantia" e "Desempenho econômico" são as que têm menor pontuação em todas as empresas. Não há uma categoria comum com maior evolução, e as categorias "Contexto e compromisso" e "Desempenho social" aparecem em algumas empresas como tendo a menor evolução.

Baseada nos gráficos apresentados no Apêndice G, a Tabela 23 compara o comportamento da pontuação dos relatórios ao longo dos anos.

Tabela 23 - Comportamento da pontuação ao longo dos anos

\begin{tabular}{|c|c|c|c|c|c|}
\hline Categoria & Anglo & BHP & Cemex & Lafarge & Samarco \\
\hline Contexto & Evolução & Constante & Oscilação & Oscilação & Evolução \\
\hline Gestão & Evolução e queda & Evolução & Oscilação & Oscilação & Constante \\
\hline Econômico & Evolução e queda & Evolução & Constante & Oscilação & Constante \\
\hline Social & Oscilação & $\begin{array}{c}\text { Evolução e } \\
\text { constante }\end{array}$ & $\begin{array}{c}\text { Oscilação e } \\
\text { evolução }\end{array}$ & Queda & Constante \\
\hline Ambiental & Evolução & Evolução & $\begin{array}{c}\text { Oscilação e } \\
\text { evolução }\end{array}$ & Constante & $\begin{array}{l}\text { Evolução e } \\
\text { constante }\end{array}$ \\
\hline Acessibilidade & $\begin{array}{l}\text { Evolução e } \\
\text { constante }\end{array}$ & $\begin{array}{c}\text { Evolução e } \\
\text { constante }\end{array}$ & Oscilação & Constante & Constante \\
\hline Total & Evolução e queda & $\begin{array}{c}\text { Evolução e } \\
\text { constante }\end{array}$ & $\begin{array}{c}\text { Evolução e } \\
\text { oscilação }\end{array}$ & Constante & Evolução \\
\hline
\end{tabular}

De maneira geral os relatórios de todas as empresas evoluíram no período analisado. Essa evolução, porém, se deu de modo desigual, pois não existe um 
padrão semelhante entre as categorias, com exceção da categoria Acessibilidade, que em geral manteve pontuação constante nas empresas.

A Tabela 24 mostra a porcentagem de informações que cada uma das empresas não apresentou em nenhum relatório no período de 2002 a 2006, quantas informações foram apresentadas em todos os relatórios e também alguns exemplos dessas informações (itens que só essa empresa apresentou em todos os relatórios e itens não apresentados em nenhum relatório).

Tabela 24 - Comparação de tópicos apresentados (2002 a 2006)

\begin{tabular}{|c|c|c|c|c|c|}
\hline & Anglo & BHP & Cemex & Lafarge & Samarco \\
\hline $\begin{array}{l}\text { Quantidade de } \\
\text { tópicos nunca } \\
\text { apresentados }\end{array}$ & $6,5 \%$ & $8,1 \%$ & $32,3 \%$ & $8,1 \%$ & $17,8 \%$ \\
\hline $\begin{array}{l}\text { Quantidade de } \\
\text { tópicos } \\
\text { apresentada em } \\
\text { todos os } \\
\text { relatórios }\end{array}$ & $58,1 \%$ & $72,6 \%$ & $16,1 \%$ & $51,6 \%$ & $56,5 \%$ \\
\hline $\begin{array}{l}\text { Tópicos } \\
\text { apresentados em } \\
\text { todos os } \\
\text { relatórios } \\
\text { (exclusivamente) }\end{array}$ & - & $\begin{array}{l}\text { Identificação de } \\
\text { riscos } \\
\text { Provisões para } \\
\text { reabilitação }\end{array}$ & - & $\begin{array}{l}\text { Consumo de } \\
\text { recursos } \\
\text { naturais não- } \\
\text { renováveis } \\
\text { Resposta às } \\
\text { partes } \\
\text { interessadas }\end{array}$ & $\begin{array}{c}\text { Segurança de } \\
\text { barragens }\end{array}$ \\
\hline $\begin{array}{l}\text { Tópicos não } \\
\text { apresentados no } \\
\text { período }\end{array}$ & $\begin{array}{l}\text { Consumo de } \\
\text { recursos } \\
\text { naturais não- } \\
\text { renováveis, } \\
\text { Plano de } \\
\text { resposta a } \\
\text { emergências, } \\
\text { Comparação - } \\
\text { padrões, } \\
\text { Comparação - } \\
\text { objetivos } \\
\text { amplos }\end{array}$ & $\begin{array}{c}\text { Emissão de } \\
\text { poeiras e } \\
\text { particulados, } \\
\text { Metas } \\
\text { econômicas, } \\
\text { Técnicas de } \\
\text { medição, } \\
\text { Comparação - } \\
\text { objetivos } \\
\text { amplos }\end{array}$ & $\begin{array}{c}\text { Água, } \\
\text { Resíduos, } \\
\text { Técnicas de } \\
\text { medição, } \\
\text { Avaliação do } \\
\text { relatório, } \\
\text { Verificação, } \\
\text { Comparação } \\
\text { e outros } 12 \\
\text { itens }\end{array}$ & $\begin{array}{c}\text { Identificação } \\
\text { das partes } \\
\text { interessadas, } \\
\text { Direitos sobre a } \\
\text { terra, } \\
\text { Segurança de } \\
\text { barragens e } \\
\text { outros, } \\
\text { Área afetada, } \\
\text { Comparação - } \\
\text { padrões }\end{array}$ & $\begin{array}{c}\text { Metas } \\
\text { econômicas, } \\
\text { Combate à } \\
\text { pobreza, } \\
\text { Direitos sobre a } \\
\text { terra, } \\
\text { Plano de } \\
\text { resposta a } \\
\text { emergências, } \\
\text { Técnicas de } \\
\text { medição, } \\
\text { Materialidade, } \\
\text { Verificação de } \\
\text { terceira parte } \\
\text { e outros } 4 \text { itens }\end{array}$ \\
\hline
\end{tabular}

Todas as empresas apresentaram em todos os relatórios de 2002 a 2006 as seguintes informações:

- Perfil da empresa,

- Declaração do executivo,

- Acidentes, 
- Indicadores ambientais,

- Indicadores sociais e

- Projetos comunitários ou fundações.

Não houve um tópico que nenhuma empresa tenha apresentado nos últimos anos (2002-2006). Contudo, todas as empresas tem pelo menos quatro tópicos que nunca mencionaram no mesmo período, conforme a Tabela 24 apresentada anteriormente.

Os itens sistematicamente não apresentados por $60 \%$ das empresas nesse mesmo período são: Técnicas de medição, Plano de resposta a emergências, Metas econômicas, Direitos sobre a terra, Comparação com padrões e Comparação com objetivos amplos.

Não há padronização para apresentação dos indicadores - alguns são apresentados em tabelas consolidadas para o grupo, outros em tabelas por mina/unidade e outros informados ao longo de textos de relatos de casos específicos. De modo geral os relatórios apresentam os dados de maneira não uniforme, às vezes em textos, às vezes em informações quantitativas, em alguns casos para um só site e em outros para todo o grupo. Também são apresentadas declarações genéricas sem exemplos ou ações.

\subsubsection{Comparação das informações adicionais}

A Tabela 25 compara os padrões ou diretrizes usadas em cada relatório. Nota-se a predominância da diretriz GRI em suas duas versões. 
Tabela 25 - Padrão para relatório

\begin{tabular}{lccccc}
\hline Empresa & 2002 & 2003 & 2004 & 2005 & 2006 \\
\hline Anglo & GRI 2002 & GRI 2002 & GRI 2002 & $\begin{array}{c}\text { GRI 2002 ; GRI } \\
\text { Mining }\end{array}$ & $\begin{array}{c}\text { GRI 2002; } \\
\text { ICMM e GRI } \\
\text { Mining }\end{array}$ \\
\hline Cemex & GRI 2002 & GRI 2002 & GRI 2002 & GRI G3 & $\begin{array}{c}\text { GRI G3 (In } \\
\text { accordance) } \\
\text { GRI Mining }\end{array}$ \\
\hline Lafarge & GRI 2002 & GRI 2002 & $\begin{array}{c}\text { GRI 2002; } \\
\text { Cement } \\
\text { Sustainable } \\
\text { Initiative (CSI) }\end{array}$ & Não & $\begin{array}{c}\text { GRI G3 } \\
\text { Nível B }\end{array}$ \\
\hline Samarco & Ibase & $\begin{array}{c}\text { GRI 2002 } \\
\text { Ethos e lbase }\end{array}$ & $\begin{array}{c}\text { GRI 2002 } \\
\text { Ethos e lbase }\end{array}$ & $\begin{array}{c}\text { GRI 2002 } \\
\text { Ethos e lbase }\end{array}$ & $\begin{array}{c}\text { GRI G3 } \\
\text { Ethos }\end{array}$ \\
\hline
\end{tabular}

A Tabela 26 compara a porcentagem de informações recomendadas para a mineração apresentadas em cada relatório. No último ano todas as empresas apresentaram $70 \%$ ou mais dos requisitos específicos da mineração.

Tabela 26 - Apresentação de informações da mineração

\begin{tabular}{llllll}
\hline Empresa & 2002 & 2003 & 2004 & 2005 & 2006 \\
\hline Anglo & $85 \%$ & $79 \%$ & $82 \%$ & $91 \%$ & $85 \%$ \\
\hline BHP & $82 \%$ & $82 \%$ & $91 \%$ & $97 \%$ & $97 \%$ \\
\hline Cemex & $24 \%$ & $33 \%$ & $36 \%$ & $33 \%$ & $70 \%$ \\
\hline Lafarge & $79 \%$ & $64 \%$ & $73 \%$ & $76 \%$ & $73 \%$ \\
\hline Samarco & $67 \%$ & $82 \%$ & $82 \%$ & $82 \%$ & $82 \%$ \\
\hline
\end{tabular}

A Tabela 27 compara o padrão para auditoria e empresa utilizados em cada relatório. No último ano duas empresas não apresentaram verificação externa e somente uma utilizou algum padrão para essa verificação. 
Tabela 27 - Padrão para verificação e auditoria

\begin{tabular}{|c|c|c|c|c|c|}
\hline Empresa & 2002 & 2003 & 2004 & 2005 & 2006 \\
\hline Anglo & $\begin{array}{l}\text { Não - } \\
\text { KPMG }\end{array}$ & $\begin{array}{l}\text { Não - } \\
\text { KPMG }\end{array}$ & $\begin{array}{l}\text { ISAE } 3000 \text { - } \\
\text { KPMG }\end{array}$ & $\begin{array}{l}\text { ISAE } 3000 \text { - } \\
\text { KPMG }\end{array}$ & $\begin{array}{l}\text { Não - } \\
\text { KPMG }\end{array}$ \\
\hline BHP & $\begin{array}{l}\text { Não - } \\
\text { ERM }\end{array}$ & $\begin{array}{l}\text { AA1000 - } \\
\text { URS }\end{array}$ & $\begin{array}{l}\text { AA1000 - } \\
\text { URS }\end{array}$ & $\begin{array}{l}\text { AA1000 - } \\
\text { URS }\end{array}$ & $\begin{array}{c}\text { ISAE } 3000 \text { e } \\
\text { AA1000 - } \\
\text { Ernst \& Young }\end{array}$ \\
\hline Cemex & $\begin{array}{c}\text { Sem } \\
\text { verificação }\end{array}$ & $\begin{array}{c}\text { Sem } \\
\text { verificação }\end{array}$ & $\begin{array}{c}\text { Sem } \\
\text { verificação }\end{array}$ & $\begin{array}{c}\text { Sem } \\
\text { verificação }\end{array}$ & $\begin{array}{c}\text { Sem } \\
\text { verificação }\end{array}$ \\
\hline Lafarge & Não & Não & Não & $\begin{array}{c}\text { Não - } \\
\text { PriceWaterhou } \\
\text { seCoopers }\end{array}$ & $\begin{array}{c}\text { Não - } \\
\text { Ernst \&Young }\end{array}$ \\
\hline Samarco & $\begin{array}{c}\text { Sem } \\
\text { verificação }\end{array}$ & $\begin{array}{c}\text { Sem } \\
\text { verificação }\end{array}$ & $\begin{array}{c}\text { Sem } \\
\text { verificação }\end{array}$ & $\begin{array}{c}\text { Sem } \\
\text { verificação }\end{array}$ & $\begin{array}{c}\text { Sem } \\
\text { verificação }\end{array}$ \\
\hline
\end{tabular}

\subsubsection{Boas práticas}

Além da identificação das boas práticas e recomendações inseridas no roteiro de avaliação desenvolvido, outras boas práticas foram encontradas nos relatórios analisados:

- Menção ao Pacto Global e Objetivos do Milênio

- Participação em associações

- Estudo de caso (business case) para sustentabilidade

- Índices de sustentabilidade e posição em rankings

- Qualidade de vida e pesquisa de satisfação dos funcionários

- Glossário

- Ações de combate à AIDS, gripe aviária, problemas específicos da comunidade ou tragédias locais como tsunami

- Empregos ou ações de inclusão de pessoas com deficiência e minorias étnicas

- Sistemas de gestão e programa de auditorias

- Menção a economias emergentes

- Licenças aplicáveis solicitadas e seu estado

- Ações de voluntariado

- Posição política e contribuição para campanhas

- Evolução da escolaridade

- Consumo de combustíveis fósseis e ações para diminuição do mesmo 
- Bioindicadores (monitoramento das condições de vida de plantas e animais)

- Outros indicadores recomendados pelas diretrizes GRI como comparação dos salários com o salário mínimo, transporte, política de competição, prêmios e reconhecimentos na área ambiental, segurança do trabalho e sustentabilidade e justificativas para não apresentação de alguns indicadores GRI.

\subsection{Análise e interpretação dos dados}

\subsubsection{Evolução dos relatórios}

Assim como nos estudos similares, notou-se a evolução através dos títulos dos relatórios, que nos anos iniciais eram denominados ambientais ou de saúde e segurança e no último ano analisado traziam sempre no título as palavras "sustentabilidade", "desenvolvimento sustentável" ou "sociedade".

Desde o estudo feito pela MERN (1998), houve um avanço na abrangência dos relatórios, que desde 2002 trazem informações sociais, econômicas e sobre a comunidade, além das ambientais. Conforme previsto por Scott (2000) houve uma expansão do foco para sustentabilidade.

Todos os relatórios estavam disponíveis para download de maneira acessível na internet, mostrando um avanço claro na utilização dessa prática desde o estudo feito pela SUSTAINABILITY em 2000 (SUSTAINABILITY; UNEP, 2000).

Verificou-se a premissa de melhoria nos relatórios ao longo do tempo, conforme estudos anteriores já observaram (PECK; SINDING, 2003; JENKINS; YAKOVLEVA, 2006; SCOTT, 2000), sem uma tendência de diminuição da evolução. Mesmo as empresas que começaram a publicar relatórios mais tarde mostraram acompanhar o estado da arte do momento.

Assim como nos resultados obtidos por Jenkins e Yakovleva (2006), observou-se uma variação na maneira como as empresas atendem aos requisitos e no estilo dos 
relatórios. Segundo os mesmos autores, um fator que pode contribuir para essa falta de uniformidade é a limitada colaboração entre as empresas do setor. A Global Mining Initiative seria um bom exemplo caso tivesse maior participação das grandes empresas do setor e caso a iniciativa continuasse até os dias de hoje.

Em 2002 três empresas publicaram relatórios que atendiam a mais de $75 \%$ dos requisitos selecionados para esta pesquisa, estando praticamente no mesmo nível de maturidade. No último ano analisado, a média das pontuações é $80 \%$, com um relatório bem próximo à pontuação máxima, mostrando assim a boa qualidade dos relatórios dessas empresas.

As melhores pontuações foram obtidas pelas duas maiores empresas do setor na época da análise (Anglo American e BHP Billiton), também consideradas por Jenkins e Yakovleva (2006) como "maduras" (mature reporters). Por terem um impacto financeiro e geográfico amplo, o que aumenta seu potencial de impactos sociais e ambientais e essas empresas direcionam mais recursos financeiros para desempenhar bem a divulgação dessas questões.

É interessante observar que em alguns casos houve diminuição da pontuação do relatório com relação ao ano anterior (por exemplo Anglo American e Lafarge em 2006, Cemex em 2001 e categorias "Desempenho econômico" e "Contexto e compromissos" dos relatórios da BHP Billiton de 2003/2004 e 2002/2003, respectivamente). Nesses casos informações presentes em um relatório não foram apresentadas no relatório do ano seguinte. Uma pesquisa específica deveria ser feita para levantar as causas dessa mudança de conteúdo do relatório, mas teoricamente pode-se dizer que possíveis razões são mudança de estratégia (ou falta de estratégia clara), opinião das partes interessadas ou limitação de espaço no relatório.

O fato de uma informação importante ter sido eliminada do relatório seguinte indica que a estrutura do relatório não estava estabelecida e/ou o modelo de gestão não incluía aquela informação. Sendo requisitos recomendados por mais de uma referência, as empresas deveriam manter a mesma informação, talvez adaptando o espaço dado a ela. 
Notou-se que a extensão do relatório nem sempre é garantia da qualidade do mesmo. Relatórios menores atenderam aos requisitos da mesma maneira que aqueles com mais páginas, dependendo da maneira de publicar uma determinada informação. Relatórios muito longos são mais cansativos para o leitor e não necessariamente atendem à necessidade de informação de todas as partes interessadas.

Não seria possível classifica-los em diferentes níveis de maturidade como outros estudos, porque estão todos em níveis muito próximos. Usando a classificações encontradas na literatura podem-se classificar as empresas analisadas em mature (JENKINS; YAKOVLEVA, 2006) e reporters (PECK; SINDING, 2003). Na análise feita por Peck e Sinding (2003) a empresa BHP já aparecia como "reporter" mas a Anglo American foi classificada como iniciante - o que confirma a significativa evolução dessa última empresa identificada nesta pesquisa.

O modelo de cinco estágios proposto pela Sustainability é de aplicação mais complexa. No entanto, em uma análise superficial poderíamos generalizar a classificação das empresas no estágio 4.2 ("Qualidade"), pois o uso de referências, indicadores setoriais e padrões globais não está maduro o suficiente para permitir a comparabilidade. Mesmo com essa breve análise pode-se notar a evolução dos relatórios, pois em 1997 a maioria deles encontrava-se no estágio 4.1 ("Quantitativo").

Deve-se observar, contudo, que a comparabilidade entre empresas do setor de mineração é assunto muito mais complexo que em outros ramos de atividade, devido a características intrínsecas da mineração, à grande variação entre minas e entre as condições ambientais locais. Tais fatores contrastam com empresas que atuam em ramos industriais, financeiro ou de distribuição, cujas atividades guardam mais semelhança entre si e, por extensão, também a tipologia de impactos sócioambientais. 


\subsubsection{Evolução das categorias}

Todas as empresas apresentaram uma alta porcentagem das informações recomendadas para o setor, mostrando seu esforço na identificação de risco e resposta às partes interessadas.

A categoria "Acessibilidade e Garantia" apresentou a menor pontuação em cada ano e em média, apesar de ter grande evolução em duas empresas no período analisado. Esse desempenho se explica principalmente pelas questões relacionadas a comparação do desempenho com padrões legais, regionais ou setoriais.

Em geral não se percebe tendência de evolução dessa categoria, fato que deveria ser analisado pelas empresas devido à grande importância dessas informações para a credibilidade e acessibilidade do relatório, além da comparabilidade do desempenho.

A segunda pior categoria foi "Desempenho econômico" - pelo baixo desempenho dos itens "Metas econômicas", "Combate a pobreza" e "Valor agregado". Segundo Morhardt, Baird e Freeman (2002) a falta de informações econômicas é ocasionada pelo fato de que a maioria das empresas se contenta em deixar esse tipo de informação nos relatórios financeiros anuais.

Somente a Anglo American teve a maior evolução nessa categoria e mostra tendência de melhoria. No geral, parece haver uma tendência a manter-se constante a pontuação nessa categoria, o que também merece atenção das empresas e revisão da estratégia. Os impactos econômicos são parte importante do tripé da sustentabilidade e deixar essa informação somente no relatório financeiro não atinge de forma eficiente algumas partes interessadas.

As melhores pontuações foram obtidas nas categorias "Contexto e compromissos" e "Desempenho social". A análise da característica da evolução na categoria "Contexto e compromissos" não apresentou um padrão nas empresas analisadas, mas não há tendência clara de evolução na categoria "Desempenho social" - talvez pelas 
empresas acreditarem que já estão apresentando essas informações de maneira adequada.

Segundo Morhardt, Baird e Freeman (2002) os pontos nos tópicos de organização geral e desempenho ambiental são maiores porque essas categorias dominam os relatórios ambientais tradicionais. No entanto, contrariando essa explicação, a categoria "Desempenho ambiental" (bem como "Gestão") teve desempenho intermediário, pois muitas das informações não apresentadas pelas empresas se enquadram nessa categoria.

Umas das causas possíveis seria a característica dos impactos ambientais da mineração, em grande parte negativos, e a dificuldade de divulgação e transparência de assuntos complexos e iniciativas recentes como a sustentabilidade dos produtos e o consumo de recursos naturais não-renováveis. Felizmente a categoria "Desempenho ambiental" apresentou uma evolução constante no período analisado e se essa tendência se confirmar, as empresas estarão caminhando no sentido de aperfeiçoar a divulgação do seu desempenho ambiental.

Para que haja mais avanço na divulgação da dimensão ambiental seria necessário que os relatórios tocassem temas mais profundos, como consumo de recursos naturais não-renováveis, ecoeficiência dos produtos e plano de emergência. Podese concluir que as grandes empresas de mineração ainda hesitam em abordar problemas mais complexos do setor, destacando mais os projetos sociais, nos quais podem mais facilmente evidenciar aspectos positivos de sua atividade.

As empresas do setor de minerais industriais apresentam com mais consistência as questões de ecoeficiência dos produtos e do consumo de recursos não-renováveis, talvez por estar mais perto do consumidor final cuja opinião, como parte interessada, tem maior influência sobre a empresa.

Nos últimos dois anos duas das cinco empresas não apresentaram nenhuma forma de verificação de terceira parte (Cemex e Samarco). No último ano somente uma empresa usou um padrão para a verificação de terceira parte (BHP Billiton). Nota-se que a verificação de terceira parte é uma prática vigente, porém a forma de atender 
a esse requisito é variada. A extensão da verificação e a metodologia usada não são similares. Deloitte (2007b) afirma que a variedade de escopo, metodologia e linguagem entre as verificações é fruto do estado emergente dessa prática e da variedade de empresas provendo esse serviço.

Jenkins e Yakovleva (2006) também notaram um aumento gradual nos níveis de verificação, mas que raramente cobrem todos os aspectos do relatório. O mesmo comportamento foi observado no estudo feito por Scott (2000) em que apenas 5\% dos relatórios apresentava uma verificação completa. Este fato foi igualmente notado nas declarações de garantia dos relatórios analisados nesta pesquisa, que tampouco tinham o relatório inteiro como escopo.

\subsubsection{Análise do método}

O método empregado para a avaliação do relatórios mostrou-se eficaz para avaliar a abrangência ou completude dos relatórios. Todavia não se aplica à avaliação do desempenho em sustentabilidade, comparação ou julgamento de valor das empresas analisadas.

A omissão de um tópico no relatório nem sempre é compreendida pelas partes interessadas como um bom desempenho nessa área. Por isso recomenda-se que seja colocada uma menção ao tópico, por mais breve que seja, como por exemplo, no relatório da Samarco (2007):

"Direitos indígenas: Não existem populações indígenas nas áreas onde a Samarco está localizada."

Assim como no estudo de Archel, Fernández e Larrinaga (2008), foi notado que mesmo os relatórios que declararam usar a diretriz GRI não obtiveram pontuações em alguns dos indicadores recomendados por essa diretriz.

Esse fato pode ser explicado por alguns fatores:

- O método desenvolvido para esta pesquisa considera outras recomendações além da diretriz GRI. 
- A diretriz GRI propõe indicadores essenciais e adicionais, diferenciação que não foi feita por este trabalho. Mesmo no caso dos indicadores essenciais a empresa poderia deixar de apresentar a informação desde que justifique sua decisão.

- Ao usar as diretrizes, alguns relatórios focam a adoção dos indicadores de desempenho, e não necessariamente a adoção dos princípios e outros itens gerais.

- Falha na interpretação da diretriz pelas empresas ou falha na interpretação do relatório pela pesquisadora.

Conforme mencionado anteriormente, não é possível o resultado desta pesquisa concluir que relatórios com altas pontuações atendem melhor às expectativas das partes interessadas. Mesmo com uma boa apresentação do tópico "Avaliação do relatório" - conforme ilustração da empresa Samarco - seria necessária uma análise mais profunda dos resultados das avaliações dos relatórios para afirmar as informações são consideradas relevantes pelas partes interessadas.

O método de avaliação aqui adotado foi desenvolvido para minimizar a subjetividade da avaliação, embora possa se notar que alguma subjetividade continua presente, pois a avaliação é baseada unicamente no conhecimento e na capacidade de interpretação do pesquisador.

O resultado do estudo mostra que o método foi eficiente para avaliar um nível básico de divulgação (a apresentação de determinadas informações). As boas pontuações alcançadas pelas empresas são similares ao destaque que essas mesmas empresas tiveram em estudos similares. $O$ próximo passo seria incrementar o método com mais conceitos de avaliação para analisar o grau de atendimento a cada requisito, assim como fizeram outros trabalhos (PECK; SINDING, 2000; DAUB, 2007; SUSTAINABILITY; UNEP, 2002).

Percebe-se que as recomendações e o grau de exigência também mudam ao longo dos anos, fruto da evolução do conceito e do conhecimento. Assim, o método de avaliação desenvolvido vai requerer revisões para que se mantenha atual. 
Para aumentar a completude do relatório e a conformidade segundo o método desenvolvido as empresas podem:

- Atender a todos os requisitos, ou seja apresentar todas as informações que são recomendadas

- Aumentar o grau de exigência, buscando realmente atender ao objetivo de cada requisito, apresentando todas as informações para todas as unidades e de maneira consolidada

- Evidenciar o desempenho com indicadores ou casos, para ir além da declaração de políticas ou intenções

- Estabelecer um processo que garanta que todas as informações estarão presentes em todos os relatórios. Há variação na apresentação de algumas informações indicando que o processo não deve estar suficientemente estabilizado para algumas empresas ou em algumas áreas

- Ampliar as ações de influência e na cadeia de suprimentos

- Comparar seu desempenho com objetivos de sustentabilidade mais amplos (setoriais ou regionais)

Além de indicadores como consumo de recursos ou geração de poluentes, a empresa deve também mostrar suas ações. Segundo DeloiTte (2007), valores de desempenho que aumentam ou diminuem ao longo do tempo contam uma parte da história, mas uma sofisticação maior é necessária para entender o desempenho em sustentabilidade, como o real impacto ambiental e análises de consumo comparadas à disponibilidade de recursos. 


\section{CONCLUSÕES}

Todas as empresas selecionadas publicam algum tipo de relatório não-financeiro, há pelo menos quatro anos. A premissa de evolução foi confirmada, em forma, conteúdo e profundidade, com uma tendência a continuar aumentando aderência a melhores práticas de publicação de relatórios. Os títulos dos relatórios analisados acompanham essa tendência.

O objetivo geral de investigar de que modo se dá a evolução dos relatórios de sustentabilidade pelas principais empresas do setor de mineração foi atingido. As empresas analisadas estão praticamente no mesmo estágio de evolução, no entanto a evolução se dá de maneira diferente em cada dimensão ou categoria de relato. As categorias "Acessibilidade e Garantia" e "Desempenho econômico" obtiveram as menores pontuações segundo os procedimentos empregados nessa pesquisa e não apresentam tendência de evolução ao longo dos últimos anos. As categorias "Contexto" e "Desempenho Social" apresentam os melhores resultados, enquanto a categoria "Desempenho Ambiental", apesar de não ter obtido as maiores pontuações, tem apresentado evolução constante. Outra característica da evolução é que cada empresa atende aos requisitos do método desenvolvido de maneiras diferentes, com práticas de divulgação diversas mas igualmente satisfatórias.

Os seguintes objetivos específicos foram atingidos:

- Foram identificadas várias recomendações da literatura sobre a publicação de relatórios de sustentabilidade, estudadas por pesquisadores, consultorias e entidades voltadas ao estudo desse tipo de relatório

- Foram identificadas várias recomendações da literatura sobre a publicação de relatórios de sustentabilidade, publicadas por pesquisadores, empresas de consultoria e entidades voltadas ao estudo desse tipo de relatório.

- Foi elaborada uma lista de verificação (checklist) para avaliação de relatórios, que pode ser utilizada por diferentes interessados para avaliar relatórios e por outras empresas para apoiar a definição de conteúdo ao iniciar a preparação de tais relatórios. 
- As principais características dos relatórios já publicados foram identificadas, segundo as categorias da lista de verificação e as informações apresentadas com maior ou menor freqüência.

- Os resultados permitiram encontrar oportunidades de melhorias nos relatórios de sustentabilidade: aumento da abrangência e profundidade da apresentação das informações requeridas, na comparabilidade do desempenho, apresentação das ações que possam ter influência sobre outras organizações e na apresentação do desempenho econômico, além de alguns impactos ambientais mais complexos.

A alta aderência ao método de avaliação desenvolvido da maioria dos relatórios e a alta porcentagem de utilização de indicadores especialmente recomendados para a mineração demonstram um bom nível de transparência e maturidade dessa prática nas empresas analisadas. Logicamente há oportunidades de melhoria, mas mesmo nos relatórios com pontuações menores há exemplos de boas práticas que podem ser seguidos por todas as empresas. Nota-se que nessas empresas os processos de processos de publicação estão estabelecidos, e é possível continuar evoluindo com uma orientação a discussões mais profundas.

Verificou-se que os resultados obtidos pela única empresa brasileira analisada (Samarco) são muito próximos em média aos relatórios das grandes empresas como a multinacional Anglo American, e superiores aos resultados alcançados por Lafarge e Cemex. Pode-se concluir que uma empresa de um país em desenvolvimento, que poderia ter menos recursos ou menor pressão das partes interessadas, não necessariamente produz relatórios de menor qualidade.

O estudo apresentou as seguintes limitações:

- As conclusões não podem ser generalizadas para todo o setor, pois o estudo não foi exaustivo e se limitou à análise de uma amostra de cinco empresas

- Os resultados dessa pesquisa não representam os desempenhos ambiental, social e econômico dessas empresas.

Recomenda-se maior desenvolvimento do método, detalhando os conceitos de avaliação de cada requisito para permitir a diferenciação da qualidade do atendimento às recomendações. Outra melhoria do método seria uma adaptação 
para aumentar a quantidade de avaliadores, o que favoreceria a objetividade da avaliação e permitiria considerar o ponto de vista de outras partes interessadas.

Acredita-se que o trabalho pode contribuir para melhorar a percepção do setor e para colaborar com a avaliação e/ou o desenvolvimento dos relatórios de sustentabilidade de outras empresas. Este estudo revelou-se complementar a outros estudos similares, por incluir relatórios de anos mais recentes e analisar a evolução temporal de relatórios das empresas selecionadas.

O resultado da pesquisa mostrou que mesmo as grandes empresas podem aprender umas com as outras, pois há diferentes exemplos positivos entre empresas de setores, tamanhos e países diferentes. Tal fato reforça a sugestão de Jenkins $E$ Yakovleva (2006) de que as empresas com melhores práticas - que têm recursos e experiências para desenvolver estratégias fortes - tenham uma liderança e cooperação maiores para ajudar outras empresas a amadurecer as suas práticas de publicação de relatórios.

Observou-se ser possível que uma empresa de menor porte produza relatórios com um conteúdo que atenda às principais recomendações e diretrizes. As boas práticas de publicação de relatórios avaliadas neste estudo podem ser difundidas em empresas de diversos portes para que a preocupação com o desenvolvimento sustentável seja inserida amplamente no setor e demonstrada às partes interessadas.

Passada a fase inicial de amadurecimento dos relatórios, é momento para as empresas avançarem nas suas práticas de divulgação, buscando atender às melhores práticas e expectativas das partes interessadas de uma maneira mais completa, atingindo o próximo patamar de qualidade em relatórios de sustentabilidade. 


\section{REFERÊNCIAS}

ACCOUNTABILITY. AA1000 Assurance Standard. London, 2003. 36 p. Disponível em:<http://www.accountability21.net/uploadstore/cms/docs/Assurance\%20Standard \%20for\%20Web.pdf. Acesso em: $10 \mathrm{fev} .2008$.

AMARAL, S. P. Estabelecimento de Indicadores e Modelo de Relatório de Sustentabilidade Ambiental, Social e Econômica: Uma Proposta para a Indústria de Petróleo Brasileira. 2003. 250 p. Tese - Universidade Federal do Rio de Janeiro. Rio de Janeiro, nov. 2003.

ANGLO AMERICAN. Anglo American plc Safety, Health and Environment Report 2000. London: Anglo American plc, 2001. 58 p. Disponível em: $<$ http://www.corporateregister.com/a10723/aap00-ehs-usa.pdf>. Acesso em: 22 set. 2006.

ANGLO AMERICAN. Resourcing our future. Anglo American plc Safety, Health and Environment Report 2001. London: Anglo American plc, 2002. 54 p. Disponível em: $<$ http://www.corporateregister.com/a10723/aap01-ehs-usa.pdf>. Acesso em: 22 set. 2006.

ANGLO AMERICAN. Towards Sustainable Development: Report to society 2002. London: Anglo American plc, 2003. 66 p. Disponível em:

<http://www.angloamerican.co.uk/static/uploads/angloshe2002.pdf>. Acesso em: 22 set. 2006.

ANGLO AMERICAN. Working for Sustainable Development: Report to society 2003. London: Anglo American plc, 2004. 72 p. Disponível em:

<http://www.angloamerican.co.uk/static/uploads/SD\%20Report\%202003.pdf>. Acesso em: 22 set. 2006.

ANGLO AMERICAN. Creating Enduring Value: Report to society 2004. London: Anglo American plc, 2005. 74 p. Disponível em:

<http://www.angloamerican.co.uk/static/uploads/RTS\%202004.pdf>. Acesso em: 22 set. 2006. 
ANGLO AMERICAN. A climate of change: Report to society 2005. London: Anglo American plc, 2006. 71 p. Disponível em:

<http://www.angloamerican.co.uk/static/uploads/Anglo\%20American\%202005.pdf>. Acesso em: 22 set. 2006.

ANGLO AMERICAN. Londres. Disponível em: <http://www.angloamerican.co.uk>. Acesso em: 01 nov. 2007.

ANGLO AMERICAN. A climate of change: Report to society 2006. London: Anglo American plc, 2007. 68 p. Disponível em:

$<$ http://www.angloamerican.co.uk/static/uploads/Report\%20to\%20Society\%202007.p df>. Acesso em: 01 nov. 2006.

ARCHEL, P. ; FERNÁNDEZ, M. ; LARRINAGA, C. The Organizational and Operational Boundaries of Triple Bottom Line Reporting: A Survey. Environmental Management, v. 41, n. 1, p. 106-117, janeiro, 2008.

ASSOCIATION OF CHARTERED CERTIFIED ACCOUNTANTS. European Awards Archive. Glasgow, 2006. Disponível em:

<http://www.accaglobal.com/sustainability/awards/esra/>. Acesso em: 10 nov. 2006.

AUSTRALASIAN JOINT ORE RESERVES COMMITTEE. Australasian Code for Mineral Resources and Ore Reserves Reporting of Exploration Results - The JORC Code. Carlton South, 2004. Disponível em:

$<$ http://www.jorc.org/pdf/jorc2004print.pdf>. Acesso em: 18 fev. 2008.

AZAPAGIC, A. Developing a framework for sustainable development indicators for the mining and minerals industry. Journal of Cleaner Production, v. 12., n. 6. p. 639-662, ago. 2004.

BERNARDO, D. et al. Balanço Social Como Ferramenta Estratégica

Empresarial: Um Estudo dos Demonstrativos Sociais das Sociedades Anônimas de Capital Aberto no Brasil. FEA, São Paulo, 2005. 13 p. Disponível em $<$ www.ead.fea.usp.br/Semead/8semead/resultado/trabalhosPDF/163.pdf $>$. Acesso em: 26 nov. 2005.

BHP BILLITON. 2001 Annual Health Safety Environment and Community

Report.. Melbourne: BHP Billiton, 2001. 75 p. Disponível em: 
<http://www.bhpbilliton.com/bbContentRepository/Reports/2001HSECReport.pdf>. Acesso em: 28 jul. 2006.

BHP BILLITON. 2002 Annual Health Safety Environment and Community Report.. Melbourne: BHP Billiton, 2002. 66 p. Disponível em: $<$ http://www.bhpbilliton.com/bbContentRepository/Reports/2002_HSEC_Report.pdf>. Acesso em: 28 jul. 2006.

BHP BILLITON. 2003 Annual Health Safety Environment and Community Report.. Melbourne: BHP Billiton, 2003. 117 p. Disponível em: $<$ http://hsecreport.bhpbilliton.com/2003/downloads/bhpb_hsec_2003_full_report.pdf> . Acesso em: 28 jul. 2006.

\section{BHP BILLITON. 2004 Annual Health Safety Environment and Community}

Report.. Melbourne: BHP Billiton, 2004. 164 p. Disponível em: $<$ http://www.bhpbilliton.com/bbContentRepository/Reports/bhpb full hsec report 04. pdf>. Acesso em: 28 jul. 2006.

BHP BILLITON. BHP Billiton Sustainability Report. Our Health, Safety, Environment and Community Performance. Full Report 2005. Melbourne: BHP Billiton, 2005. 384 p. Disponível em: $<$ http://sustainability.bhpbilliton.com/2005/docs/BHPBillitonSustainabilityReport2005. pdf>. Acesso em: 28 jul. 2006.

BHP BILLITON. BHP Billiton Sustainability Report: Full Report 2006. Melbourne: BHP Billiton, 2006. 522 p. Disponível em: $<$ http://sustainability.bhpbilliton.com/2006/documents/BHPBillitonSustainabilityReport 2006.pdf>. Acesso em: 28 jul. 2006.

BHP BILLITON. Melbourne. Disponível em: <http://www.bhpbilliton.com>. Acesso em: 07 nov. 2007.

BHP BILLITON. BHP Billiton Sustainability Report: Full Report 2007. Melbourne: BHP Billiton, 2007. 315 p. Disponível em: $<$ http://www.bhpbilliton.com/bbContentRepository/200710338624/sustainabilityreport. pdf>. Acesso em: 07 nov. 2007. 
BOSSEL H. Indicators for sustainable development: theory, method, applications. Winnipeg - Canada: International Institutte for Sustainable Development; 1999. 123 p.

BRASIL MINERAL. Samarco ganha Balanço Social pela segunda vez Brasil Mineral OnLine $\mathrm{n}^{\circ} \quad 273,2006.2$ Disponível em: $<$ http://www.brasilmineral.com.br/BM/default.asp?COD=2567\&busca $=\&$ numero $=273$ >. Acesso em: 04 out. 2006.

CABLE NEWS NETWORK. Fortune Global 500 2006. Atlanta, 2006. Disponível em: $<$ http://money.cnn.com/magazines/fortune/global500/2006/full list/index.html>. Acesso em: 01 set. 2006.

CAMBRIDGE UNIVERSITY PRESS. Cambridge Advanced Learner's Dictionary Cambridge, 2006. Disponível em: <http://dictionary.cambridge.org/>. Acesso em: 07 nov. 2006.

CEMEX. Environment Health and Safety Report 1997. México, Cemex: 1998. 18 p. Disponível em: <http://www.cemex.com/pdf/cc/enviro97.pdf>. Acesso em: 22 set. 2006.

CEMEX. 1998 Environment Health and Safety Report. México, Cemex: 1999. 7 p. Disponível em: < http://www.cemex.com/pdf/cc/enviro98.pdf>. Acesso em: 22 set. 2006.

CEMEX. Environment Health and Safety Report 1999. México, Cemex: 2000. 16 p. Disponível em: <http://www.cemex.com/pdf/cc/enviro99.pdf>. Acesso em: 22 set. 2006.

CEMEX. The Ecoeficciency: 2000 Environment Health and Safety Report. México, Cemex: 2001. 27 p. Disponível em: $<$ http://www.cemex.com/pdf/cc/enviro00.pdf>. Acesso em: 22 set. 2006.

CEMEX. Environment Health and Safety 2001 Progress Report. México, Cemex: 2002. 16 p. Disponível em: <http://www.cemex.com/pdf/cc/enviro01.pdf>. Acesso em: 22 set. 2006. 
CEMEX. Environment Health and Safety 2002 Progress Report. México, Cemex: 2003. 14 p. Disponível em: <http://www.cemex.com/pdf/cc/enviro02.pdf>. Acesso em: 22 set. 2006.

CEMEX. Building for Future Generations Cemex 2003 Sustainability Report. México, Cemex: 2004. 36 p. Disponível em:

<http://www.cemex.com/sr2003/eng/pdf/SR03english.pdf>. Acesso em: 22 set. 2006.

CEMEX. Building for Future Generations 2004 Sustainability Report. México, Cemex: 2005. 36 p. Disponível em:

$<$ http://www.cemex.com/sr2004/eng/pdf/SR04english.pdf>. Acesso em: 22 set. 2006.

CEMEX. Moving Forward 2005 Sustainable Development Interim Report. México, Cemex: 2006. 8 p. Disponível em:

<http://www.cemex.com/sr2005/eng/pdf/SR05english.pdf>. Acesso em: 22 set. 2006.

CEMEX. México. Disponível em: <http://www.cemex.com>. Acesso em: 01 nov. 2007.

CEMEX. 2006 Sustainable Development Report. México, Cemex: 2007. 42 p. Disponível em: <http://www.cemex.com/sr2005/eng/pdf/SR05english.pdf >. Acesso em: 01 nov. 2007.

CORPORATE REGISTER. Corporate Register - Search reports. 2008. Disponível em: http://www.corporateregister.com/. Acesso em: 01 de fev. de 2008.

COVALENCE. Covalence Ranking 2005. Geneva, 2006. Disponível em: $<$ http://www.covalence.ch/docs/results CovalenceRanking2005.xls $>$. Acesso em: 28 jul. 2006.

$\mathrm{DAUB}, \mathrm{C}$. Assessing the quality of sustainability reporting: an alternative methodological approach. Journal of Cleaner Production, Amsterdam, v. 15, n. 1, p. 75-85, 2007.

DELOITTE TOUCHE TOHMATSU. A deeper level of detail. Improving the reporting of mining closure liabilities. London, 2007. 12 p. Disponível em: 
$<$ http://www.deloitte.com/dtt/cda/doc/content/UK_EIU_ImprovingtheReportingofMine ClosureLiiabilities.pdf>. Acesso em: 30 jan. 2008.

DELOITTE TOUCHE TOHMATSU. A mine of information. An analysis of sustainable reporting in the mining industry. London, 2007. 12 p. Disponível em:

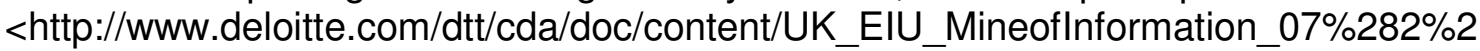
9.pdf>. Acesso em: 30 jan. 2008.

ELKINTON, J. Canibais com Garfo e Faca. São Paulo: Makron Books, 2001. 444 p.

EXTRACTIVE INDUSTRIES REVIEW. Reporting Guidelines for the mining sector - Draft for consultation. 2003. 22 p. Disponível em:

<http://www.justiceinitiative.org/db/resource2/fs/?file_id=15665>. Acesso em: 21 nov. 2006.

EXTRACTIVE INDUSTRIES TRANSPARENCY INITIATIVE. Reporting Guidelines for the mining sector - Draft for consultation. 2003. 22 p. Disponível em:

<http://www.justiceinitiative.org/db/resource2/fs/?file_id=15665>. Acesso em: 21 nov. 2006.

FINANCIAL TIMES STOCK EXCHANGE. Ground Rules For The Management Of The FTSE4good Index Series. London, 2005. Disponível em:

$<$ http://www.ftse.com/indices marketdata/ground rules/ftse4good-ground-rules.pdf $>$. Acesso em: 27, nov. 2005.

FORBES.COM INC. The World's 2000 Largest Public Companies New York, 2006. Disponível em: <http://www.forbes.com/2006/03/29/06f2k worlds-largestpublic-companies land.html>. Acesso em: 04 ago. 2006.

GIL, A.C. Como elaborar projetos de pesquisa. 3. ed. São Paulo: Editora Atlas, 1999. $159 \mathrm{p}$.

GLOBAL REPORTING INITIATIVE. GRI Mining and Metals Sector Supplement Pilot Version 1.0. Amsterdam: Global Reporting Initiative, 2005. 45 p. Disponível em: <http://www.globalreporting.org/NR/rdonlyres/25EEF0C7-F050-48CA-9FF5C79F359D9976/0/SS MiningMetals ENG.pdf>. Acesso em: 18 out. 06. 
GLOBAL REPORTING INITIATIVE. The G3 Application Levels. Amsterdam: Global Reporting Initiative, 2006. 4 p. Disponível em:

$<$ http://www.globalreporting.org/NR/rdonlyres/FB8CB16A-789B-454A-BA52-

993C9B755704/0/ApplicationLevels.pdf>. Acesso em: 01 fev. 08.

GLOBAL REPORTING INITIATIVE. Sustainability Reporting Guidelines Version 3.0 Amsterdam: Global Reporting Initiative, 2006. 44 p.

INNOVEST STRATEGIC VALUE ADVISORS. Corporate Environmental

Performance: A study into the influence of Environmental Governance and Financial Performance full report. Bristol: Environment Agency, 2004. Disponível em: $<$ http://www.innovestgroup.com/pdfs/2004-11-09-Environmental_Governance.pdf>. Acesso em: 14 nov. 2006.

INSTITUTO BRASILEIRO DE ANÁLISES ECONÔMICAS E SOCIAIS. Balanço Social. Rio de Janeiro. Disponível em: < http://www.balancosocial.org.br/cgi/cgilua.exe/sys/start.htm>. Acesso em: 25 nov. 2005.

INSTITUTO ETHOS. Indicadores Ethos Setoriais de Responsabilidade Social Empresarial - Mineração. Disponível em:

$<$ http://www.ethos.org.br/docs/conceitos_praticas/indicadores/questionario/mineraca o.pdf>. Acesso em: 06 ago. 2005.

INTERNATIONAL COUNCIL ON MINING AND METALS. ICMM Sustainable Development Framework - ICMM Principles. London, 2002. 2 p. Disponível em: $<$ http://www.icmm.com/publications/lCMM Principles en.pdf >. Acesso em: 16 mar. 07.

INTERNATIONAL COUNCIL ON MINING AND METALS. Global Mining Initiative. London, 2006. Disponível em: <http://www.icmm.com/gmi.php>. Acesso em: 01 fev. 08.

INTERNATIONAL FEDERATION OF ACCOUNTANTS. International Standard on Assurance Engagements 3000 (ISAE 3000). New York: IFAC, 2004. 20 p. Disponível em: http://www.accountability21.net/uploadedFiles/lssues/ISAE 3000.pdf. Acesso em: 10 fev. 2008. 
INTERNATIONAL INSTITUTE FOR ENVIRONMENT AND DEVELOPMENT. Breaking new ground : mining, minerals, and sustainable development : the report of the MMSD project. London: Earthscan Publications, 2002. 441 p.

JENKINS, H.; YAKOVLEVA, N. Corporate social responsibility in the mining industry: Exploring trends in social and environmental disclosure. Journal of Cleaner Production, v. 14, n. 3-4, p. 271-284, 2006.

KOLK, A. Trends in sustainability reporting by the Fortune Global 250 . Business Strategy and the Environment, v. 12, n. 5, p. 279-291, setembro, 2003.

KPMG INTERNATIONAL. Mining - A Survey of Global Reporting Trends 2003. South Africa, 2003. 97 p. Disponível em: $<$ http://www.kpmg.ca/en/industries/enr/mining/documents/MiningSurvey.pdf>. Acesso em: 25 out. 2006.

KPMG INTERNATIONAL. Global Mining Reporting Survey 2006. Melbourne, 2006. 101 p. Disponível em: <http://www.kpmg.com/NR/rdonlyres/00E35F14-2A1E474C-B0D4-00F03AB14C72/0/GlobalMiningReportingSurvey2006.pdf >. Acesso em: 25 out. 2006.

KPMG; WETENSCHAPPELIJK INSTITUUT VOOR MILIEUMANAGEMENT. KPMG international survey of corporate sustainability reporting 2002. Amsterdam: Graduate Business School; 2002. Disponível em: <http://www.gppi.net/fileadmin/gppi/KPMG2002.pdf>. Acesso em: 25 out. 2006.

KRIPPENDORFF, K. Content analysis: An introduction to its methodology. $2^{\text {nd }}$ ed. Thousand Oaks: Sage. 2004. 413 p.

LAFARGE. A First Report on our Economic, Social and Environmental Performance 2001. Paris: Lafarge, 2002. 60 p. Disponível em: <http://www.lafarge.com/09222004-publication_sustainableSustainability_report_2001_041501-uk.pdf>. Acesso em: 22 set. 2006.

LAFARGE. 2002 Sustainability Report. Paris: Lafarge, 2003. 62 p. Disponível em: <http://www.lafarge.com/09222004-publication_sustainableSustainability_report_2002_051503-uk.PDF>. Acesso em: 22 set. 2006. 
LAFARGE. 2003 Sustainability Report. Paris: Lafarge, 2004. 25 p. Disponível em: $<$ http://www.lafarge.com/09212004-publication_sustainable-

Sustainability_report_2003-uk.pdf>. Acesso em: 22 set. 2006.

LAFARGE. Sustainability Report 2004. Paris: Lafarge, 2005. 33 p. Disponível em: <http://www.lafarge.com/06142005-publications_sustainable_developmentLafarge_sustainable_report_2004-uk.pdf>. Acesso em: 22 set. 2006.

LAFARGE. Sustainability Report 2005. Paris: Lafarge, 2006. 52 p. Disponível em: $<$ http://www.lafarge.com/07052006-publication_sustainable_developmentreport2005-uk.pdf>. Acesso em: 22 set. 2006.

LAFARGE. Paris. Disponível em: <http://www.lafarge.com>. Acesso em: 01 nov. 2007.

LAFARGE. Sustainability Report 2006. Paris: Lafarge, 2007. 64 p. Disponível em: $<$ http://www.lafarge.com/05032007-publication_sustainable_developmentreport2006-uk.pdf>. Acesso em: 01 nov. 2007.

MARCONI, M.A. ; LAKATOS, E.M. Técnicas de pesquisa. 5. ed. São Paulo: Editora Atlas, 2002. 282 p.

MEADOWS, D. Indicators and information systems for sustainable development. Hartland: The Sustainability Institute; 1998. 78 p.

MILNE M.J.; ADLER, R. W. Exploring the reliability of social and environmental disclosures content analysis. Accounting, Auditing \& Accountability Journal, v. 12, n. 2, p. 237-256, 1999.

MINING AND ENVIRONMENT RESEARCH NETWORK. Corporate Social Responsibility and the Mining Industry: Presentation to Euromines.

Coventry,1998. Disponível em: <http://www.mineralresourcesforum.org/docs/pdfs/merncsr.pdf>. Acesso em: $01 \mathrm{fev}$. 2008. 
MINING, MINERALS, AND SUSTAINABLE DEVELOPMENT PROJECT. Minería, minerales y desarrollo sustentable en América del Sur Santiago:

MMSD/CIPMA/IDRC/CRDI, 2002. 623 p.

MINISTÉRIO DO MEIO AMBIENTE. Agenda 21 Global - Conferência das Nações Unidas sobre Meio Ambiente e Desenvolvimento. Rio de Janeiro, 1992. Disponível em: <http://www.mma.gov.br/estruturas/agenda21/_arquivos/ag21.zip>. Acesso em: 01 fev. 2008.

MONEVA, J.M. ; ARCHEL, P. ; CORREA, C. GRI and the camouflaging of corporate unsustainability. Accounting Forum, v. 30, n. 2, p. 121-137, junho, 2006.

MONSANTO COMPANY. 1996 Environmental Annual Review - Pursuing Sustainability. St Louis: Monsanto, 1997. 29 p. Disponível em: http://www.corporateregister.com/a10723/mon96-env-usa.pdf. Acesso em: 01 fev. 2008.

MORHARDT, J.E. ; BAIRD, S.; FREEMAN, K. Scoring Corporate Environmental and Sustainability Reports using GRI 2000, ISO 14031 and Other Criteria.

Corporate Social Responsibility and Environmental Management, v. 9, n. 4, p. 215233, novembro, 2002.

PARK, J. ; BRORSON, T. Experiences of and views on third-party assurance of corporate environmental and sustainability reports. Journal of Cleaner Production, v. 3, n. 10-11, p. 1095-1106, agosto, 2005.

PEARSON EDUCATION. Longman Dictionary Of Contemporary English Online. London, 2006. Disponível em: <http://www.ldoceonline.com>. Acesso em: 07 novt. 2006.

PECK, P.; SINDING, K. Environmental and social disclosure and data richness in the mining industry. Business Strategy and the Environment, v. 2, n. 3, p. 131146, maio 2003.

PROGRAMA DAS NAÇÕES UNIDAS PARA O DESENVOLVIMENTO. Pacto GIobal - Brasil. Disponível em: http://www.pactoglobal.org.br/pg principio.php. Acesso em: 02 mar. 2008. 
RAW MATERIALS GROUP. Raw Materials Group Top 10 companies in world metal mining in 2003 Stockholm, 2006. Disponível em: <www.rmg.se/DocPDF/RMGTop10b.doc>. Acesso em: 04 ago. 2006.

RENDU, J. M. ; MISKELLY, N. Mineral Resources and Mineral Reserves:

Progress on International Definitions and Reporting Standards. Mining Technology, v. 110, n. 3, p. 133-138, dezembro, 2001. Disponível em:

<http://www.jorc.org/pdf/rendu2.pdf>. Acesso em: 18 fev. 2008.

SAMARCO. Belo Horizonte. Disponível em: <http://www.samarco.com>. Acesso em: 01 de nov. 2007.

SAMARCO. Relatório Anual 2002. Belo Horizonte: Samarco, 2003. 101 p. Disponível em: <http://www.samarco.com/uploads/3flrkjwz2vlf9uw.pdf>. Acesso em: 22 set. 2006.

SAMARCO. Relatório Anual Samarco 2003. Belo Horizonte: Samarco, 2004. 74 p. Disponível em: <http://www.samarco.com/uploads/p30ht08lh56q7b.pdf>. Acesso em: 22 set. 2006.

SAMARCO. Relatório Anual Samarco 2004. Belo Horizonte: Samarco, 2005. 147 p. Disponível em: <http://www.samarco.com/uploads/f1dbzjymqqzu9.pdf>. Acesso em: 22 set. 2006.

SAMARCO. Relatório Anual Samarco 2005. Belo Horizonte: Samarco, 2006. 145 p. Disponível em: <http://www.samarco.com/uploads/53x3lwv97l.pdf>. Acesso em: 22 set. 2006.

SAMARCO. Relatório Anual Samarco 2006. Belo Horizonte: Samarco, 2007. 156 p. Disponível em: <http://www.samarco.com/uploads/53×3lwv97l.pdf>. Acesso em: 01 nov. 2007.

SAM INDEXES GMBH. Dow Jones Sustainability World Indexes Guide - English Version 7.0. Zurich: SAM Indexes $\mathrm{GmbH}$, 2005. Disponível em: $<$ http://www.sustainabilityindex.com/djsi pdf/publications/DJSI WORLD Guidebooks/DJSI World Guidebook 70.pdf>. Acesso em: 26 nov. 2005. 
SÁNCHEZ, L.E. Industry response to the challenge of sustainability: The case of Canadian nonferrous mining sector. Environmental Management, New York, v. 22, n. 4, p. 521-531, fevereiro, 1998.

SCOTT, P. Reporting in the mining sector. Mining Environmental Management, v. 8, n. 2, p. 10-12, março, 2000.

STRATOS INC. Stepping forward: corporate sustainability reporting in Canada. Ottawa: Stratos, 2001.

SUSTAINABILITY. Mudanças no Conceito de Responsabilidade Civil Um Guia Corporativo sobre tendências de Responsabilidade Ambiental, Social e Econômica. London: SustainAbility, 2004. Disponível em: <http://www.cebds.org.br/cebds/pubdocs/pub-la-mudancas-conceito-resp.pdf $>$. Acesso em: 26 nov. 2005. 4p.

SUSTAINABILITY. Report Assessment Methodology - Global Reporters 2006. London: $\quad$ SustainAbility; $2006 . \quad$ Disponível em: <http://www.sustainability.com/downloads_public/insight_reports/GR06_methodology .pdf>. Acesso em: 10 nov. 2006.

SUSTAINABILITY; DELOITTE TOUCHE TOHMATSU INTERNATIONAL; INTERNATIONAL INSTITUTE FOR SUSTAINABLE DEVELOPMENT. Coming Clean: Corporate Environmental Reporting. London: Sustainability, 1993. 63 p.

SUSTAINABILITY; UNITED NATIONS ENVIRONMENT PROGRAMME. The 1997 Benchmark Survey: The Third International Progress Report on Company Environmental Reporting. 40 p. London: SustainAbility, 1997. Disponível em: $<$ http://www.sustainability.com/downloads_public/insight_reports/97_benchmark.pdf> . Acesso em: 18 out. 2006.

SUSTAINABILITY; UNITED NATIONS ENVIRONMENT PROGRAMME. The Global Reporters: The First International Benchmark Survey of Corporate Sustainability Reporting. London: SustainAbility, 2000. 60 p. Disponível em: $<$ http://www.sustainability.com/downloads_public/insight_reports/global_reporters.pdf >. Acesso em: 18 out. 2006. 
The Global Reporters 2002 Study of Corporate Sustainability. London: SustainAbility, 2002. 66 p. Disponível em:

$<$ http://www.sustainability.com/downloads_public/insight_reports/trust_us.pdf>.

Acesso em: 18 out. 2006.

SUSTAINABILITY; UNITED NATIONS ENVIRONMENT PROGRAMME; STANDARD \& POOR'S. Risk \& Opportunity: Best practice in Non-Financial Reporting The Global Reporters 2004 Survey of Corporate Sustainability Reporting. London: Sustainability, 2004. 52 p. Disponível em:

$<$ http://www.sustainability.com/downloads_public/insight_reports/R\&O2004.pdf>. Acesso em: 18 out. 2006.

THE FINANCIAL TIMES LTD. Global 5002006 London, 2006. Disponível em: $<$ http://media.ft.com/cms/adb61f66-f7bf-11da-9481$0000779 \mathrm{e} 2340$,dwp uuid=5a16620a-f178-11da-940b-0000779e2340.pdf $>$. Acesso em: 04 ago. 2006.

UNITED NATIONS. Millennium Development Goals. 2000. Disponível em: <http://www.un.org/millenniumgoals/>. Acesso em: 01 fev. 2008.

WHITE, M. D.; MARSH, E. E. Content Analysis: A Flexible Methodology. Library Trends, v. 55, n. 1, p. 22-45, 2006.

WORD BUSINESS COUNCIL FOR SUSTAINABLE DEVELOPMENT. Sustainable development reporting: striking the balance. WBCSD: Geneva, 2002. 60 p.

WORLD BUSINESS COUNCIL FOR SUSTAINABLE DEVELOPMENT. Beyond Reporting: Creating business value and accountability. Geneva: WBCSD, 2005. Disponível em:

$<$ http://www.wbcsd.org/DocRoot/Jjn1cB29B0UG90dx0RMZ/Beyond_rep_final_press v.pdf>. Acesso em: 4 jul. 2006.

WORLD COMISSION ON ENVIRONMENT AND DEVELOPMENT. Nosso futuro comum. Rio de Janeiro: Editora da Fundação Getulio Vargas, 1988. 430 p. 


\section{APÊNDICES}

\section{APÊNDICE A - Roteiro de avaliação}

\begin{tabular}{|c|c|c|c|c|}
\hline No & $\begin{array}{l}\text { Categoria } \\
\text { Informação }\end{array}$ & Instruções & Aplicação ${ }^{13}$ & Ref. $^{14}$ \\
\hline 1 & Contexto e Compromissos & & & \\
\hline 1.1 & Perfil da empresa & $\begin{array}{l}\text { Natureza e escala das atividades da empresa, } \\
\text { produtos/serviços e contexto em que opera }\end{array}$ & G & a;e;f;g \\
\hline 1.2 & Visão de sustentabilidade & $\begin{array}{l}\text { Visão de sustentabilidade adotada pela empresa } \\
\text { (ou valores, princípios, políticas, códigos de } \\
\text { conduta) }\end{array}$ & G & $a ; e ; g$ \\
\hline 1.3 & Declaração do principal executivo & $\begin{array}{l}\text { Declaração do principal executivo sobre a } \\
\text { relevância da sustentabilidade para a empresa }\end{array}$ & G & a;e;f;g \\
\hline 1.4 & Identificação dos riscos & $\begin{array}{l}\text { Processo ou método de identificação dos riscos } \\
\text { ou avaliação dos impactos }\end{array}$ & G & $e ; g$ \\
\hline 1.5 & Conformidade legal & Cumprimento de requerimentos legais aplicáveis & $\mathrm{M}$ & $\mathrm{h} ; \mathrm{i}$ \\
\hline 1.6 & Governança & Processos ou estrutura de governança & $\mathrm{G}$ & $e ; f ; h$ \\
\hline 1.7 & Influência & $\begin{array}{l}\text { Estratégia ou exemplos da influência sobre } \\
\text { políticas públicas, setor, fornecedores e/ou } \\
\text { clientes }\end{array}$ & G & $e ; g ; h$ \\
\hline 2 & Gestão & & & \\
\hline 2.1 & Cadeia de suprimentos & $\begin{array}{l}\text { Considerações sobre sustentabilidade na cadeia } \\
\text { de suprimentos (de fornecedores a clientes) }\end{array}$ & $\mathrm{G}$ & e \\
\hline 2.2 & Partes interessadas & $\begin{array}{l}\text { Lista genéricas ou específicas das partes } \\
\text { interessadas (stakeholders) }\end{array}$ & G & $e ; f ; g$ \\
\hline 2.3 & Identificação das partes interessadas & $\begin{array}{l}\text { Processos para identificação e seleção das } \\
\text { partes interessadas }\end{array}$ & G & $e ; f$ \\
\hline 2.4 & $\begin{array}{l}\text { Envolvimento das partes } \\
\text { interessadas }\end{array}$ & $\begin{array}{l}\text { Processos para o envolvimento das partes } \\
\text { interessadas }\end{array}$ & G & a;e;f;g;h \\
\hline 2.5 & Resposta às partes interessadas & $\begin{array}{l}\text { Processos de resposta às expectativas, } \\
\text { interesses e demandas das partes interessadas }\end{array}$ & G & $e ; f ; g$ \\
\hline 2.6 & Envolvimento da comunidade local & $\begin{array}{l}\text { Envolvimento e apoio das comunidades locais } \\
\text { (política, abordagem, mecanismos, etc.) }\end{array}$ & $\mathrm{M}$ & $\mathrm{d} ; \mathrm{h}$ \\
\hline 2.7 & Multas e penalidades & $\begin{array}{l}\text { Multas, penalidades ou termos de ajustes de } \\
\text { conduta }\end{array}$ & G & g \\
\hline 2.8 & Acidentes & $\begin{array}{l}\text { Acidentes do trabalho, acidentes ambientais, } \\
\text { passivos e/ou outros eventos negativos }\end{array}$ & G & $c ; i$ \\
\hline 2.9 & Investimentos & $\begin{array}{l}\text { Investimentos em meio ambiente e/ou segurança } \\
\text { do trabalho }\end{array}$ & $\mathrm{M}$ & $\mathrm{b}$ \\
\hline 2.10 & Treinamento & $\begin{array}{l}\text { Treinamentos para os empregados em algumas } \\
\text { das três dimensões da sustentabilidade }\end{array}$ & M & b;e;h;i \\
\hline 3 & Desempenho Econômico & & & \\
\hline 3.1 & Indicadores econômicos & $\begin{array}{l}\text { Indicadores econômicos (impactos positivos ou } \\
\text { negativos da organização sobre as } \\
\text { circunstâncias econômicas das partes } \\
\text { interessadas e sobre o sistema econômico) }\end{array}$ & G & $a ; f$ \\
\hline 3.2 & Metas econômicas & Metas econômicas & $\mathrm{G}$ & $e ; f$ \\
\hline 3.3 & Benefícios & $\begin{array}{l}\text { Valores de salários e/ou benefícios concedidos } \\
\text { aos empregados }\end{array}$ & M & $b ; i$ \\
\hline 3.4 & $\begin{array}{l}\text { Retorno financeiro para as } \\
\text { comunidades }\end{array}$ & $\begin{array}{l}\text { Retorno financeiro (ou distribuição de receitas) } \\
\text { para as comunidades locais }\end{array}$ & M & $b ; i$ \\
\hline 3.5 & Contribuição econômica local & $\begin{array}{l}\text { Utilização de fornecedores ou de mão de obra } \\
\text { local }\end{array}$ & M & $b ; d ; i$ \\
\hline
\end{tabular}

${ }^{13}$ Aplicação do requisito ao setor de mineração (M) ou geral $(G)$

${ }^{14}$ Referência onde foi encontrada essa recomendação: a = DAUB (2007) ; b = AZAPAGIC (2002) ; c $=\mathrm{GRI}(2005) ; \mathrm{d}=$ Instituto Ethos (2005) $; \mathrm{e}=$ SUSTAINABILITY (2006) $\mathrm{f}=\mathrm{GRI}(2006 \mathrm{~b}) ; \mathrm{g}=\mathrm{Stratos}$ (2001) $; \mathrm{h}=\mathrm{ICMM}(2003) ; \mathrm{i}=$ International Institute for Environment and Development (2002); $\mathrm{j}=$ Extractive Industries Transparency Initiative (2003) ; k = Extractive Industries Review (2003) 
continuação

\begin{tabular}{|c|c|c|c|c|}
\hline No & $\begin{array}{l}\text { Categoria } \\
\text { Informação }\end{array}$ & Instruções & Aplicação & Ref. ${ }^{15}$ \\
\hline 3.6 & Valor agregado & $\begin{array}{l}\text { Valor agregado/adicionado (receitas totais menos } \\
\text { o custo total das aquisições) }\end{array}$ & M & C \\
\hline 3.7 & Combate à pobreza & Contribuição no combate à pobreza & $\mathrm{M}$ & $\mathrm{H} ; \mathrm{k}$ \\
\hline 3.8 & Pagamentos ao Governo & $\begin{array}{l}\text { Pagamento de taxas referentes a licenças e } \\
\text { concessões e/ou pagamentos ao Governo }\end{array}$ & $M$ & $\mathrm{~J}$ \\
\hline 4 & Desempenho Social & & & \\
\hline 4.1 & Indicadores sociais & $\begin{array}{l}\text { Indicadores sociais (impactos positivos ou } \\
\text { negativos da organização sobre os sistemas } \\
\text { sociais nos quais opera) }\end{array}$ & G & $a ; f$ \\
\hline 4.2 & Metas sociais & Metas sociais & $\mathrm{G}$ & $e ; f$ \\
\hline 4.3 & Direitos Humanos & Política de direitos humanos da empresa & $\mathrm{M}$ & $c ; i$ \\
\hline 4.4 & $\begin{array}{l}\text { Liberdade de associação e trabalho } \\
\text { infantil }\end{array}$ & $\begin{array}{l}\text { Conformidade com as convenções } 87 / 98 \text { da OIT } \\
\text { (Right to Organize) e } 138 \text { (Child Labour) }\end{array}$ & M & $f ; i$ \\
\hline 4.5 & Projetos comunitários ou fundações & $\begin{array}{l}\text { Projetos comunitários, fundos ou fundações nos } \\
\text { quais a empresa esteve envolvida }\end{array}$ & M & $b ; i$ \\
\hline 4.6 & Direitos sobre a terra & $\begin{array}{l}\text { Política de proteção de direitos sobre a terra e de } \\
\text { compensação }\end{array}$ & M & $c ; i$ \\
\hline 4.7 & Impactos nas comunidades & $\begin{array}{l}\text { Gerenciamento de impactos nas comunidades } \\
\text { das áreas afetadas }\end{array}$ & M & $\mathrm{C}$ \\
\hline 4.8 & Mulheres empregadas & $\begin{array}{l}\text { Quantidade de mulheres empregadas e/ou em } \\
\text { posições de liderança }\end{array}$ & M & $b ; i$ \\
\hline 4.9 & $\begin{array}{l}\text { Desenvolvimento das partes } \\
\text { interessadas }\end{array}$ & $\begin{array}{l}\text { Treinamento e desenvolvimento da comunidade } \\
\text { e/ou outras partes interessadas }\end{array}$ & M & $\mathrm{D} ; \mathrm{h}$ \\
\hline 4.10 & Empregos diretos & Número de empregos diretos & $\mathrm{M}$ & $\mathrm{b} ; \mathrm{i}$ \\
\hline 4.11 & $\begin{array}{l}\text { Segurança e meio ambiente para } \\
1 \text { terceirizados }\end{array}$ & $\begin{array}{l}\text { Abordagem para assegurar padrões em } \\
\text { segurança e meio ambiente para terceirizados }\end{array}$ & M & $\mathrm{D}$ \\
\hline 4.12 & Combate a corrupção e propina & $\begin{array}{l}\text { Códigos de conduta ou políticas para o combate } \\
\text { à corrupção e propina }\end{array}$ & M & I \\
\hline 5 & Desempenho Ambiental & & & \\
\hline 5.1 & Indicadores ambientais & $\begin{array}{l}\text { Indicadores ambientais (impactos positivos ou } \\
\text { negativos da organização sobre sistemas } \\
\text { naturais vivos ou não, incluindo ecossistemas, } \\
\text { terra, ar e água) }\end{array}$ & G & $a ; f$ \\
\hline 5.2 & Metas ambientais & Metas ambientais & $\mathrm{G}$ & $e ; f$ \\
\hline 5.3 & Reabilitação & $\begin{array}{l}\text { Política de fechamento de minas e reabilitação de } \\
\text { áreas degradadas }\end{array}$ & M & $\mathrm{d} ; \mathrm{i}$ \\
\hline 5.4 & Provisões para reabilitação & $\begin{array}{l}\text { Provisões financeiras ou contábeis para } \\
\text { fechamento e reabilitação de minas }\end{array}$ & M & $b$ \\
\hline 5.5 & Segurança de barragens e outros & $\begin{array}{l}\text { Medidas adotadas para prevenção de falhas e } \\
\text { desastres ambientais em barragens de rejeitos, } \\
\text { maciços e/ou solo (erosão) }\end{array}$ & M & $\mathrm{c} ; \mathrm{d}$ \\
\hline 5.6 & Resíduos & $\begin{array}{l}\text { Gerenciamento de resíduos, estéreis e rejeitos, } \\
\text { incluindo avaliação de riscos }\end{array}$ & M & $\mathrm{c} ; \mathrm{h}$ \\
\hline 5.7 & Ecoeficiência dos produtos & $\begin{array}{l}\text { Políticas para avaliar a ecoeficiência e atributos } \\
\text { de sustentabilidade dos produtos (reciclagem, } \\
\text { uso de material e energia, toxicidade, etc.) }\end{array}$ & M & $\mathrm{c} ; \mathrm{h}$ \\
\hline 5.8 & Emissão de poeiras e particulados & Emissão de poeiras e particulados & $\mathrm{M}$ & $\mathrm{b} ; \mathrm{c}$ \\
\hline 5.9 & Emissão de gases & $\begin{array}{l}\text { Emissão de gases controlados pelos protocolos } \\
\text { de Quioto e/ou Montreal (efeito estufa e camada } \\
\text { de ozônio) }\end{array}$ & M & $b ; f$ \\
\hline 5.10 & $\begin{array}{l}\text { Consumo de recursos naturais não- } \\
\text { renováveis }\end{array}$ & $\begin{array}{l}\text { Abordagem para minimização de consumo de } \\
\text { recursos naturais não-renováveis. Eficiência no } \\
\text { uso de recursos minerais. }\end{array}$ & M & $\begin{array}{c}\mathrm{b} \\
\text { ntinua }\end{array}$ \\
\hline
\end{tabular}

${ }^{15}$ Referência onde foi encontrada essa recomendação: a = DAUB (2007) ; b = AZAPAGIC (2002) ; c $=\mathrm{GRI}(2005) ; \mathrm{d}=$ Instituto Ethos (2005) $; \mathrm{e}=$ SUSTAINABILITY (2006) $\mathrm{f}=\mathrm{GRI}(2006 \mathrm{~b}) ; \mathrm{g}=\mathrm{Stratos}$ (2001) $; \mathrm{h}=$ ICMM (2003) $; \mathrm{i}$ = International Institute for Environment and Development (2002); $\mathrm{j}=$ Extractive Industries Transparency Initiative (2003) ; k = Extractive Industries Review (2003) 
conclusão

\begin{tabular}{|c|c|c|c|c|}
\hline & & & & \\
\hline No & $\begin{array}{l}\text { Categoria } \\
\text { Informação }\end{array}$ & Instruções & Aplicação & Ref. $^{16}$ \\
\hline 5.11 & Área afetada & $\begin{array}{l}\text { Área necessária para atividades de produção } \\
\text { e/ou extração }\end{array}$ & M & $\mathrm{C}$ \\
\hline 5.12 & Energia & Consumo de energia & $\mathrm{M}$ & $b ; i$ \\
\hline 5.13 & Biodiversidade & $\begin{array}{l}\text { Impactos na biodiversidade, planos ou } \\
\text { gerenciamento }\end{array}$ & $\mathrm{M}$ & c;d;h;i \\
\hline 5.14 & Água & Uso e/ou reciclagem de água & $\mathrm{M}$ & $\mathrm{d}$ \\
\hline 5.15 & Plano de resposta a emergências & $\begin{array}{l}\text { Desenvolvimento, manutenção e teste de } \\
\text { plano(s) e procedimento(s) de resposta a } \\
\text { emergências }\end{array}$ & M & $\mathrm{c} ; \mathrm{h}$ \\
\hline 6 & Acessibilidade e Garantia & & & \\
\hline 6.1 & Perfil do relatório & $\begin{array}{l}\text { Período de relato, data do relatório anterior e } \\
\text { freqüência de relato }\end{array}$ & $\mathrm{G}$ & $a ; f ; g$ \\
\hline 6.2 & Técnicas de medição & $\begin{array}{l}\text { Descrição das técnicas de medição dos dados e } \\
\text { bases de cálculo }\end{array}$ & G & $f$ \\
\hline 6.3 & Comparação - períodos & $\begin{array}{l}\text { Indicadores para o período de relato atual e pelo } \\
\text { menos um período anterior }\end{array}$ & G & $f$ \\
\hline 6.4 & Comparação - padrões & $\begin{array}{l}\text { Comparação do desempenho com padrões e/ou } \\
\text { referências }\end{array}$ & G & $a ; e ; f$ \\
\hline 6.5 & Comparação - objetivos amplos & $\begin{array}{l}\text { Comparação do desempenho com referência a } \\
\text { condições e objetivos de desenvolvimento } \\
\text { sustentável amplos (setoriais, locais, regionais } \\
\text { e/ou globais) }\end{array}$ & G & $e ; f$ \\
\hline 6.6 & Contato & $\begin{array}{l}\text { Ponto de contato para questões relativas ao } \\
\text { relatório e seu conteúdo ou para obtenção de } \\
\text { informações adicionais }\end{array}$ & G & $\mathrm{e}$ \\
\hline 6.7 & Fronteiras do relatório & $\begin{array}{l}\text { Países, divisões, subsidiárias, joint ventures, } \\
\text { fornecedores, etc. incluídas no relatório }\end{array}$ & G & $f$ \\
\hline 6.8 & Materialidade & $\begin{array}{l}\text { Métodos ou processos para avaliar materialidade } \\
\text { (importância relativa dos temas) }\end{array}$ & G & $f$ \\
\hline 6.9 & Verificação de terceira parte & $\begin{array}{l}\text { Verificação de terceira parte ou garantia (para } \\
\text { parte do relatório ou o todo) }\end{array}$ & G & $e ; f ; g$ \\
\hline 6.10 & Avaliação do relatório & $\begin{array}{l}\text { Processo e/ou resultados da avaliação do } \\
\text { relatório pelas partes interessadas }\end{array}$ & $\mathrm{G}$ & $\mathrm{e}, \mathrm{h}$ \\
\hline
\end{tabular}

Tabela 28 - Freqüência de uso das referências no roteiro de coleta de dados

\begin{tabular}{clc}
\hline Legenda & Referência & $\begin{array}{c}\text { freqüência de uso } \\
\text { no roteiro (em n\% } \\
\text { de requisitos) }\end{array}$ \\
\hline F & GRI G3 & $37 \%(23)$ \\
\hline E & SUSTAINABILITY & $32 \%(20)$ \\
\hline I & IIED - Breaking New Ground & $26 \%(16)$ \\
\hline H & ICMM & $21 \%(13)$ \\
\hline B & AZAPAGIC & $21 \%(13)$ \\
\hline C & GRI - Mining and Metals & $19 \%(12)$ \\
\hline G & Stratos & $18 \%(11)$ \\
\hline A & DAUB & $14 \%(9)$ \\
\hline D & Ethos - Mineração & $13 \%(8)$ \\
\hline I & Extractive Ind. Transparency Initiative & $2 \%(1)$ \\
\hline K & Extractive Industries Review & $2 \%(1)$ \\
\hline
\end{tabular}

${ }^{16}$ Referência onde foi encontrada essa recomendação: $a=$ Daub (2007); b = Azapagic (2002) ; c = GRI (2005) ; d = Instituto Ethos (2005) ; e = Sustainability (2006) ; $f=$ GRI (2006b) ; g = Stratos (2001) $; \mathrm{h}=\mathrm{ICMM}(2003) ; \mathrm{i}=$ International Institute for Environment and Development (2002); $\mathrm{j}=$ Extractive Industries Transparency Initiative (2003) ; k = Extractive Industries Review (2003) 


\section{APÊNDICE B - Roteiro completo - Anglo American}

\begin{tabular}{|c|c|c|c|c|c|c|c|c|c|}
\hline No & $\begin{array}{c}\text { Categoria } \\
\text { Informação }\end{array}$ & $A p$ & \begin{tabular}{|l|} 
Ano 1 \\
2000
\end{tabular} & $\begin{array}{l}\text { Ano } 2 \\
2001\end{array}$ & \begin{tabular}{|l|} 
Ano 3 \\
2002 \\
\end{tabular} & \begin{tabular}{|l|} 
Ano 4 \\
2003 \\
\end{tabular} & \begin{tabular}{|l|} 
Ano 5 \\
2004 \\
\end{tabular} & \begin{tabular}{|l|} 
Ano 6 \\
2005
\end{tabular} & $\begin{array}{l}\text { Ano } 7 \\
2006\end{array}$ \\
\hline 1 & Contexto e Compromissos & G & 5 & 4 & 5 & 6 & 6 & 7 & 7 \\
\hline 1.1 & Perfil da empresa & $G$ & 1 & 1 & 1 & 1 & 1 & 1 & 1 \\
\hline 1.2 & Visão de sustentabilidade & $G$ & 1 & 1 & 1 & 1 & 1 & 1 & 1 \\
\hline 1.3 & Declaração do principal executivo & $G$ & 1 & 1 & 1 & 1 & 1 & 1 & 1 \\
\hline 1.4 & Identificação dos riscos & $G$ & 0 & 0 & 0 & 1 & 1 & 1 & 1 \\
\hline 1.5 & Conformidade legal & $M$ & 1 & 1 & 1 & 0 & 0 & 1 & 1 \\
\hline 1.6 & Governança & $G$ & 1 & 0 & 1 & 1 & 1 & 1 & 1 \\
\hline 1.7 & Influência & $G$ & 0 & 0 & 0 & 1 & 1 & 1 & 1 \\
\hline 2 & Gestão & G & 7 & 7 & 7 & 6 & 8 & 10 & 9 \\
\hline 2.1 & Cadeia de suprimentos & $G$ & 0 & 0 & 0 & 0 & 1 & 1 & 1 \\
\hline 2.2 & Partes interessadas & $G$ & 0 & 1 & 1 & 0 & 1 & 1 & 1 \\
\hline 2.3 & Identificação das partes interessadas & $G$ & 0 & 0 & 0 & 0 & 0 & 1 & 0 \\
\hline 2.4 & Envolvimento das partes interessadas & $G$ & 1 & 1 & 1 & 1 & 1 & 1 & 1 \\
\hline 2.5 & Resposta às partes interessadas & $G$ & 1 & 0 & 0 & 0 & 0 & 1 & 1 \\
\hline 2.6 & Envolvimento da comunidade local & $\mathrm{M}$ & 1 & 1 & 1 & 1 & 1 & 1 & 1 \\
\hline 2.7 & Multas e penalidades & $G$ & 1 & 1 & 1 & 1 & 1 & 1 & 1 \\
\hline 2.8 & Acidentes & $G$ & 1 & 1 & 1 & 1 & 1 & 1 & 1 \\
\hline 2.9 & Investimentos & $\mathrm{M}$ & 1 & 1 & 1 & 1 & 1 & 1 & 1 \\
\hline 2.10 & Treinamento & $\mathrm{M}$ & 1 & 1 & 1 & 1 & 1 & 1 & 1 \\
\hline 3 & Desempenho Econômico & G & 3 & 4 & 6 & 8 & 7 & 7 & 6 \\
\hline 3.1 & Indicadores econômicos & $G$ & 1 & 1 & 1 & 1 & 1 & 1 & 1 \\
\hline 3.2 & Metas econômicas & $G$ & 0 & 0 & 0 & 1 & 0 & 0 & 0 \\
\hline 3.3 & Benefícios & $\mathrm{M}$ & 0 & 0 & 1 & 1 & 1 & 1 & 1 \\
\hline 3.4 & $\begin{array}{l}\text { Retorno financeiro para as } \\
\text { comunidades }\end{array}$ & $M$ & 0 & 1 & 1 & 1 & 1 & 1 & 1 \\
\hline 3.5 & Contribuição econômica local & $M$ & 1 & 1 & 1 & 1 & 1 & 1 & 1 \\
\hline 3.6 & Valor agregado & $M$ & 0 & 0 & 1 & 1 & 1 & 1 & 1 \\
\hline 3.7 & Combate à pobreza & $\mathrm{M}$ & 0 & 0 & 0 & 1 & 1 & 1 & 0 \\
\hline 3.8 & Pagamentos ao Governo & $M$ & 1 & 1 & 1 & 1 & 1 & 1 & 1 \\
\hline 4 & Desempenho Social & G & 7 & 10 & 11 & 9 & 10 & 11 & 10 \\
\hline 4.1 & Indicadores sociais & $G$ & 1 & 1 & 1 & 1 & 1 & 1 & 1 \\
\hline 4.2 & Metas sociais & $G$ & 1 & 1 & 1 & 1 & 1 & 1 & 1 \\
\hline 4.3 & Direitos Humanos & $\mathrm{M}$ & 0 & 1 & 1 & 1 & 1 & 1 & 1 \\
\hline 4.4 & $\begin{array}{l}\text { Liberdade de associação e trabalho } \\
\text { infantil }\end{array}$ & $M$ & 0 & 1 & 1 & 0 & 0 & 1 & 0 \\
\hline 4.5 & Projetos comunitários ou fundações & $\mathrm{M}$ & 1 & 1 & 1 & 1 & 1 & 1 & 1 \\
\hline 4.6 & Direitos sobre a terra & $\mathrm{M}$ & 0 & 0 & 0 & 1 & 0 & 0 & 0 \\
\hline 4.7 & Impactos nas comunidades & $\mathrm{M}$ & 1 & 1 & 1 & 1 & 1 & 1 & 1 \\
\hline 4.8 & Mulheres empregadas & $M$ & 0 & 0 & 1 & 1 & 1 & 1 & 1 \\
\hline 4.9 & $\begin{array}{l}\text { Desenvolvimento das partes } \\
\text { interessadas }\end{array}$ & $M$ & 1 & 1 & 1 & 1 & 1 & 1 & 1 \\
\hline 4.10 & Empregos diretos & $M$ & 1 & 1 & 1 & 1 & 1 & 1 & 1 \\
\hline 4.11 & $\begin{array}{l}\text { Segurança e meio ambiente para } \\
\text { terceirizados }\end{array}$ & $M$ & 1 & 1 & 1 & 0 & 1 & 1 & 1 \\
\hline
\end{tabular}




\begin{tabular}{|c|c|c|c|c|c|c|c|c|c|}
\hline \begin{tabular}{|l|} 
No \\
\end{tabular} & $\begin{array}{l}\text { Categoria } \\
\text { Informação }\end{array}$ & Ap & $\begin{array}{l}\text { Ano } 1 \\
2000 \\
\end{array}$ & $\begin{array}{c}\text { Ano } 2 \\
2001\end{array}$ & \begin{tabular}{|l|} 
Ano 3 \\
2002
\end{tabular} & $\begin{array}{l}\text { Ano } 4 \\
2003 \\
\end{array}$ & $\begin{array}{l}\text { Ano } 5 \\
2004 \\
\end{array}$ & \begin{tabular}{|c|} 
Ano 6 \\
2005
\end{tabular} & $\begin{array}{l}\text { Ano } 7 \\
2006 \\
\end{array}$ \\
\hline 4.12 & Combate a corrupção e propina & $\mathrm{M}$ & 0 & 1 & 1 & 0 & 1 & 1 & 1 \\
\hline 5 & Desempenho Ambiental & G & 11 & 11 & 12 & 12 & 12 & 13 & 13 \\
\hline 5.1 & Indicadores ambientais & $\mathrm{G}$ & 1 & 1 & 1 & 1 & 1 & 1 & 1 \\
\hline 5.2 & Metas ambientais & G & 0 & 0 & 1 & 1 & 1 & 1 & 1 \\
\hline 5.3 & Reabilitação & $\mathrm{M}$ & 1 & 1 & 1 & 1 & 1 & 1 & 1 \\
\hline 5.4 & Provisões para reabilitação & $\mathrm{M}$ & 1 & 0 & 0 & 1 & 1 & 1 & 1 \\
\hline 5.5 & Segurança de barragens e outros & $\mathrm{M}$ & 1 & 1 & 1 & 0 & 1 & 1 & 1 \\
\hline 5.6 & Resíduos & $\mathrm{M}$ & 1 & 1 & 1 & 1 & 1 & 1 & 1 \\
\hline 5.7 & Ecoeficiência dos produtos & $\mathrm{M}$ & 0 & 0 & 1 & 1 & 0 & 1 & 1 \\
\hline 5.8 & Emissão de poeiras e particulados & $\mathrm{M}$ & 1 & 1 & 1 & 1 & 1 & 1 & 1 \\
\hline 5.9 & Emissão de gases & $\mathrm{M}$ & 1 & 1 & 1 & 1 & 1 & 1 & 1 \\
\hline 5.10 & $\begin{array}{l}\text { Consumo de recursos naturais não- } \\
\text { renováveis }\end{array}$ & $\mathrm{M}$ & 0 & 0 & 0 & 0 & 0 & 0 & 0 \\
\hline 5.11 & Área afetada & $\mathrm{M}$ & 1 & 1 & 1 & 1 & 1 & 1 & 1 \\
\hline 5.12 & Energia & $\mathrm{M}$ & 1 & 1 & 1 & 1 & 1 & 1 & 1 \\
\hline 5.13 & Biodiversidade & $\mathrm{M}$ & 1 & 1 & 1 & 1 & 1 & 1 & 1 \\
\hline 5.14 & Água & $\mathrm{M}$ & 1 & 1 & 1 & 1 & 1 & 1 & 1 \\
\hline 5.15 & Plano de resposta a emergências & $\mathrm{M}$ & 0 & 1 & 0 & 0 & 0 & 0 & 0 \\
\hline $6:$ & acessibilidade e Garantia & G & 4 & 6 & 6 & 7 & 6 & 6 & 6 \\
\hline 6.1 & Perfil do relatório & $\mathrm{G}$ & 0 & 1 & 1 & 1 & 0 & 0 & 0 \\
\hline 6.2 & Técnicas de medição & G & 0 & 0 & 0 & 1 & 0 & 0 & 0 \\
\hline 6.3 & Comparação - períodos & $G$ & 0 & 1 & 1 & 1 & 1 & 1 & 1 \\
\hline 6.4 & Comparação - padrões & $G$ & 0 & 0 & 0 & 0 & 0 & 0 & 0 \\
\hline 6.5 & Comparação - objetivos amplos & $\mathrm{G}$ & 0 & 0 & 0 & 0 & 0 & 0 & 0 \\
\hline 6.6 & Contato & $\mathrm{G}$ & 1 & 1 & 1 & 1 & 1 & 1 & 1 \\
\hline 6.7 & Fronteiras do relatório & G & 1 & 1 & 1 & 1 & 1 & 1 & 1 \\
\hline 6.8 & Materialidade & G & 0 & 0 & 0 & 0 & 1 & 1 & 1 \\
\hline 6.9 & Verificação de terceira parte & $\mathrm{G}$ & 1 & 1 & 1 & 1 & 1 & 1 & 1 \\
\hline 6.10 & Avaliação do relatório & $G$ & 1 & 1 & 1 & 1 & 1 & 1 & 1 \\
\hline \multirow{2}{*}{62} & \multirow{2}{*}{$\begin{array}{l}\text { Total (absoluto) } \\
\text { (porcentagem) }\end{array}$} & & 37 & 42 & 47 & 48 & 49 & 54 & 51 \\
\hline & & & $60 \%$ & $68 \%$ & $76 \%$ & $77 \%$ & $79 \%$ & $87 \%$ & $82 \%$ \\
\hline
\end{tabular}




\section{APÊNDICE C - Roteiro completo - BHP Billiton}

\begin{tabular}{|c|c|c|c|c|c|c|c|c|c|}
\hline No & $\begin{array}{l}\begin{array}{l}\text { Categoria } \\
\text { Informação }\end{array} \\
\end{array}$ & Ap & \begin{tabular}{|l|} 
Ano 1 \\
$00 / 01$ \\
\end{tabular} & $\begin{array}{l}\text { Ano } 2 \\
01 / 02 \\
\end{array}$ & \begin{tabular}{|l|} 
Ano 3 \\
02/03 \\
\end{tabular} & \begin{tabular}{|l|} 
Ano 4 \\
$03 / 04$ \\
\end{tabular} & $\begin{array}{l}\text { Ano } 5 \\
04 / 05 \\
\end{array}$ & \begin{tabular}{|l|} 
Ano 6 \\
$05 / 06$ \\
\end{tabular} & $\begin{array}{l}\text { Ano } 7 \\
06 / 07 \\
\end{array}$ \\
\hline 1 & Contexto e Compromissos & G & 7 & 7 & 6 & 7 & 7 & 7 & 7 \\
\hline 1.1 & Perfil da empresa & $G$ & 1 & 1 & 1 & 1 & 1 & 1 & 1 \\
\hline 1.2 & Visão de sustentabilidade & G & 1 & 1 & 1 & 1 & 1 & 1 & 1 \\
\hline 1.3 & Declaração do principal executivo & $G$ & 1 & 1 & 1 & 1 & 1 & 1 & 1 \\
\hline 1.4 & Identificação dos riscos & $G$ & 1 & 1 & 1 & 1 & 1 & 1 & 1 \\
\hline 1.5 & Conformidade legal & $M$ & 1 & 1 & 0 & 1 & 1 & 1 & 1 \\
\hline 1.6 & Governança & $G$ & 1 & 1 & 1 & 1 & 1 & 1 & 1 \\
\hline 1.7 & Influência & $G$ & 1 & 1 & 1 & 1 & 1 & 1 & 1 \\
\hline 2 & Gestão & G & 6 & 7 & 8 & 9 & 9 & 10 & 10 \\
\hline 2.1 & Cadeia de suprimentos & $G$ & 0 & 0 & 0 & 1 & 1 & 1 & 1 \\
\hline 2.2 & Partes interessadas & $G$ & 1 & 1 & 1 & 1 & 1 & 1 & 1 \\
\hline 2.3 & Identificação das partes interessadas & $G$ & 0 & 0 & 0 & 0 & 1 & 1 & 1 \\
\hline 2.4 & Envolvimento das partes interessadas & $G$ & 0 & 1 & 1 & 1 & 1 & 1 & 1 \\
\hline 2.5 & Resposta às partes interessadas & $G$ & 0 & 0 & 1 & 1 & 0 & 1 & 1 \\
\hline 2.6 & Envolvimento da comunidade local & $M$ & 1 & 1 & 1 & 1 & 1 & 1 & 1 \\
\hline 2.7 & Multas e penalidades & $G$ & 1 & 1 & 1 & 1 & 1 & 1 & 1 \\
\hline 2.8 & Acidentes & $G$ & 1 & 1 & 1 & 1 & 1 & 1 & 1 \\
\hline 2.9 & Investimentos & $M$ & 1 & 1 & 1 & 1 & 1 & 1 & 1 \\
\hline 2.10 & Treinamento & $M$ & 1 & 1 & 1 & 1 & 1 & 1 & 1 \\
\hline 3 & Desempenho Econômico & G & 4 & 5 & 6 & 5 & 6 & 7 & 7 \\
\hline 3.1 & Indicadores econômicos & $G$ & 1 & 1 & 1 & 1 & 1 & 1 & 1 \\
\hline 3.2 & Metas econômicas & $G$ & 0 & 0 & 0 & 0 & 0 & 0 & 0 \\
\hline 3.3 & Benefícios & $M$ & 0 & 0 & 1 & 1 & 0 & 1 & 1 \\
\hline 3.4 & $\begin{array}{l}\text { Retorno financeiro para as } \\
\text { comunidades }\end{array}$ & $M$ & 1 & 1 & 1 & 1 & 1 & 1 & 1 \\
\hline 3.5 & Contribuição econômica local & $M$ & 1 & 1 & 1 & 1 & 1 & 1 & 1 \\
\hline 3.6 & Valor agregado & $M$ & 0 & 0 & 0 & 0 & 1 & 1 & 1 \\
\hline 3.7 & Combate à pobreza & $M$ & 0 & 1 & 1 & 0 & 1 & 1 & 1 \\
\hline 3.8 & Pagamentos ao Governo & $M$ & 1 & 1 & 1 & 1 & 1 & 1 & 1 \\
\hline 4 & Desempenho Social & G & 11 & 11 & 11 & 11 & 12 & 12 & 12 \\
\hline 4.1 & Indicadores sociais & $G$ & 1 & 1 & 1 & 1 & 1 & 1 & 1 \\
\hline 4.2 & Metas sociais & $G$ & 1 & 1 & 1 & 1 & 1 & 1 & 1 \\
\hline 4.3 & Direitos Humanos & $M$ & 1 & 1 & 1 & 1 & 1 & 1 & 1 \\
\hline 4.4 & $\begin{array}{l}\text { Liberdade de associação e trabalho } \\
\text { infantil }\end{array}$ & $M$ & 1 & 1 & 1 & 1 & 1 & 1 & 1 \\
\hline 4.5 & Projetos comunitários ou fundações & $M$ & 1 & 1 & 1 & 1 & 1 & 1 & 1 \\
\hline 4.6 & Direitos sobre a terra & $M$ & 0 & 0 & 0 & 0 & 1 & 1 & 1 \\
\hline 4.7 & Impactos nas comunidades & $\mathrm{M}$ & 1 & 1 & 1 & 1 & 1 & 1 & 1 \\
\hline 4.8 & Mulheres empregadas & $M$ & 1 & 1 & 1 & 1 & 1 & 1 & 1 \\
\hline 4.9 & $\begin{array}{l}\text { Desenvolvimento das partes } \\
\text { interessadas }\end{array}$ & $M$ & 1 & 1 & 1 & 1 & 1 & 1 & 1 \\
\hline
\end{tabular}




\begin{tabular}{|c|c|c|c|c|c|c|c|c|c|}
\hline No & $\begin{array}{l}\text { Categoria } \\
\text { Informação }\end{array}$ & Ap & $\begin{array}{l}\text { Ano } 1 \\
00 / 01\end{array}$ & $\begin{array}{l}\text { Ano } 2 \\
01 / 02\end{array}$ & \begin{tabular}{|l|} 
Ano 3 \\
$02 / 03$
\end{tabular} & $\begin{array}{l}\text { Ano } 4 \\
03 / 04\end{array}$ & $\begin{array}{l}\text { Ano } 5 \\
04 / 05\end{array}$ & \begin{tabular}{|l|} 
Ano 6 \\
$05 / 06$
\end{tabular} & $\begin{array}{l}\text { Ano } 7 \\
06 / 07\end{array}$ \\
\hline 4.10 & Empregos diretos & $M$ & 1 & 1 & 1 & 1 & 1 & 1 & 1 \\
\hline 4.11 & $\begin{array}{l}\text { Segurança e meio ambiente para } \\
\text { terceirizados }\end{array}$ & $M$ & 1 & 1 & 1 & 1 & 1 & 1 & 1 \\
\hline 4.12 & Combate a corrupção e propina & $M$ & 1 & 1 & 1 & 1 & 1 & 1 & 1 \\
\hline 5 & Desempenho Ambiental & G & 10 & 11 & 12 & 12 & 13 & 14 & 14 \\
\hline 5.1 & Indicadores ambientais & $G$ & 1 & 1 & 1 & 1 & 1 & 1 & 1 \\
\hline 5.2 & Metas ambientais & $G$ & 1 & 1 & 1 & 1 & 1 & 1 & 1 \\
\hline 5.3 & Reabilitação & $M$ & 1 & 1 & 1 & 1 & 1 & 1 & 1 \\
\hline 5.4 & Provisões para reabilitação & $M$ & 0 & 1 & 1 & 1 & 1 & 1 & 1 \\
\hline 5.5 & Segurança de barragens e outros & $M$ & 1 & 0 & 1 & 0 & 1 & 1 & 1 \\
\hline 5.6 & Resíduos & $M$ & 1 & 1 & 1 & 1 & 1 & 1 & 1 \\
\hline 5.7 & Ecoeficiência dos produtos & $M$ & 0 & 1 & 1 & 1 & 1 & 1 & 1 \\
\hline 5.8 & Emissão de poeiras e particulados & $M$ & 0 & 0 & 0 & 0 & 0 & 0 & 0 \\
\hline 5.9 & Emissão de gases & $M$ & 1 & 1 & 1 & 1 & 1 & 1 & 1 \\
\hline 5.10 & $\begin{array}{l}\text { Consumo de recursos naturais não- } \\
\text { renováveis }\end{array}$ & $M$ & 0 & 1 & 0 & 0 & 0 & 1 & 1 \\
\hline 5.11 & Área afetada & $M$ & 1 & 1 & 1 & 1 & 1 & 1 & 1 \\
\hline 5.12 & Energia & $M$ & 1 & 1 & 1 & 1 & 1 & 1 & 1 \\
\hline 5.13 & Biodiversidade & $M$ & 1 & 0 & 1 & 1 & 1 & 1 & 1 \\
\hline 5.14 & Água & $M$ & 1 & 1 & 1 & 1 & 1 & 1 & 1 \\
\hline 5.15 & Plano de resposta a emergências & $M$ & 0 & 0 & 0 & 1 & 1 & 1 & 1 \\
\hline 6 & acessibilidade e Garantia & G & 5 & 6 & 6 & 8 & 8 & 8 & 8 \\
\hline 6.1 & Perfil do relatório & $G$ & 1 & 1 & 1 & 1 & 1 & 1 & 1 \\
\hline 6.2 & Técnicas de medição & $G$ & 0 & 0 & 0 & 0 & 0 & 0 & 0 \\
\hline 6.3 & Comparação - períodos & $G$ & 1 & 1 & 1 & 1 & 1 & 1 & 1 \\
\hline 6.4 & Comparação - padrões & $G$ & 0 & 0 & 0 & 1 & 1 & 1 & 1 \\
\hline 6.5 & Comparação - objetivos amplos & $G$ & 0 & 0 & 0 & 0 & 0 & 0 & 0 \\
\hline 6.6 & Contato & $G$ & 0 & 1 & 1 & 1 & 1 & 1 & 1 \\
\hline 6.7 & Fronteiras do relatório & $G$ & 1 & 1 & 1 & 1 & 1 & 1 & 1 \\
\hline 6.8 & Materialidade & $G$ & 0 & 0 & 0 & 1 & 1 & 1 & 1 \\
\hline 6.9 & Verificação de terceira parte & $G$ & 1 & 1 & 1 & 1 & 1 & 1 & 1 \\
\hline 6.10 & Avaliação do relatório & $G$ & 1 & 1 & 1 & 1 & 1 & 1 & 1 \\
\hline \multirow{2}{*}{62} & \multirow{2}{*}{$\begin{array}{l}\text { Total (absoluto) } \\
\text { (porcentagem) }\end{array}$} & & 43 & 47 & 49 & 52 & 55 & 58 & 58 \\
\hline & & & $69 \%$ & $76 \%$ & $79 \%$ & $84 \%$ & $89 \%$ & $94 \%$ & $94 \%$ \\
\hline
\end{tabular}




\section{APÊNDICE D - Roteiro completo - Cemex}

\begin{tabular}{|c|c|c|c|c|c|c|c|c|c|c|c|c|}
\hline No & $\begin{array}{l}\text { Categoria } \\
\text { Informação }\end{array}$ & $|A p|$ & \begin{tabular}{|c} 
Ano \\
1 \\
1997 \\
\end{tabular} & $\begin{array}{c}\text { Ano } \\
2 \\
1998 \\
\end{array}$ & $\begin{array}{c}\text { Ano } \\
3 \\
1999 \\
\end{array}$ & \begin{tabular}{|c} 
Ano \\
4 \\
2000 \\
\end{tabular} & \begin{tabular}{|c} 
Ano \\
5 \\
2001 \\
\end{tabular} & \begin{tabular}{|c} 
Ano \\
6 \\
2002 \\
\end{tabular} & \begin{tabular}{|c} 
Ano \\
7 \\
2003 \\
\end{tabular} & \begin{tabular}{|c} 
Ano \\
8 \\
2004 \\
\end{tabular} & $\begin{array}{c}\text { Ano } \\
9 \\
2005 \\
\end{array}$ & \begin{tabular}{|c} 
Ano \\
10 \\
2006 \\
\end{tabular} \\
\hline 1 & Contexto e Compromissos & G & 4 & 2 & 4 & 4 & 4 & 4 & 6 & 6 & 3 & 6 \\
\hline 1.1 & Perfil da empresa & $G$ & 1 & 0 & 1 & 1 & 1 & 1 & 1 & 1 & 1 & 1 \\
\hline 1.2 & Visão de sustentabilidade & $G$ & 1 & 0 & 1 & 1 & 1 & 1 & 1 & 1 & 1 & 1 \\
\hline 1.3 & Declaração do principal executivo & $G$ & 1 & 1 & 1 & 1 & 1 & 1 & 1 & 1 & 1 & 1 \\
\hline 1.4 & Identificação dos riscos & $G$ & 0 & 0 & 0 & 0 & 0 & 0 & 1 & 1 & 0 & 1 \\
\hline 1.5 & Conformidade legal & $M$ & 0 & 0 & 0 & 0 & 0 & 0 & 0 & 0 & 0 & 0 \\
\hline 1.6 & Governança & $G$ & 1 & 1 & 1 & 0 & 0 & 0 & 1 & 1 & 0 & 1 \\
\hline 1.7 & Influência & $G$ & 0 & 0 & 0 & 1 & 1 & 1 & 1 & 1 & 0 & 1 \\
\hline 2 & Gestão & $\mathbf{G}$ & 4 & 3 & 3 & 4 & 2 & 3 & 6 & 6 & 4 & 8 \\
\hline 2.1 & Cadeia de suprimentos & $G$ & 0 & 0 & 0 & 0 & 0 & 0 & 0 & 0 & 0 & 1 \\
\hline 2.2 & Partes interessadas & $\mathrm{G}$ & 0 & 0 & 0 & 0 & 0 & 0 & 1 & 1 & 1 & 1 \\
\hline & $\begin{array}{l}\text { Identificação das partes } \\
\text { interessadas }\end{array}$ & $G$ & 0 & 0 & 0 & 0 & 0 & 0 & 0 & 0 & 0 & 0 \\
\hline 2.4 & $\begin{array}{l}\text { Envolvimento das partes } \\
\text { interessadas }\end{array}$ & $G$ & 0 & 0 & 0 & 0 & 0 & 0 & 1 & 1 & 1 & 1 \\
\hline 2.5 & Resposta às partes interessadas & $G$ & 0 & 0 & 0 & 0 & 0 & 0 & 1 & 1 & 0 & 1 \\
\hline 2.6 & Envolvimento da comunidade local & $M$ & 1 & 1 & 1 & 1 & 0 & 0 & 1 & 1 & 1 & 1 \\
\hline 2.7 & Multas e penalidades & $G$ & 0 & 0 & 0 & 0 & 0 & 0 & 0 & 0 & 0 & 0 \\
\hline 2.8 & Acidentes & $G$ & 1 & 1 & 1 & 1 & 1 & 1 & 1 & 1 & 1 & 1 \\
\hline 2.9 & Investimentos & $M$ & 1 & 0 & 0 & 1 & 0 & 1 & 0 & 0 & 0 & 1 \\
\hline 2.10 & OTreinamento & $M$ & 1 & 1 & 1 & 1 & 1 & 1 & 1 & 1 & 0 & 1 \\
\hline 3 & Desempenho Econômico & G & 0 & 0 & 1 & 1 & 1 & 1 & 1 & 1 & 0 & 5 \\
\hline 3.1 & Indicadores econômicos & $G$ & 0 & 0 & 1 & 1 & 1 & 1 & 1 & 1 & 0 & 1 \\
\hline 3.2 & Metas econômicas & $G$ & 0 & 0 & 0 & 0 & 0 & 0 & 0 & 0 & 0 & 0 \\
\hline 3.3 & Benefícios & $M$ & 0 & 0 & 0 & 0 & 0 & 0 & 0 & 0 & 0 & 1 \\
\hline 3.4 & $\begin{array}{l}\text { Retorno financeiro para as } \\
\text { comunidades }\end{array}$ & $M$ & 0 & 0 & 0 & 0 & 0 & 0 & 0 & 0 & 0 & 1 \\
\hline 3.5 & Contribuição econômica local & $\mathrm{M}$ & 0 & 0 & 0 & 0 & 0 & 0 & 0 & 0 & 0 & 1 \\
\hline 3.6 & Valor agregado & $M$ & 0 & 0 & 0 & 0 & 0 & 0 & 0 & 0 & 0 & 0 \\
\hline 3.7 & Combate à pobreza & $M$ & 0 & 0 & 0 & 0 & 0 & 0 & 0 & 0 & 0 & 1 \\
\hline 3.8 & Pagamentos ao Governo & $\mathrm{M}$ & 0 & 0 & 0 & 0 & 0 & 0 & 0 & 0 & 0 & 0 \\
\hline 4 & Desempenho Social & $G$ & 4 & 3 & 4 & 6 & 3 & 3 & 7 & 7 & 7 & 11 \\
\hline 4.1 & Indicadores sociais & $G$ & 1 & 0 & 1 & 1 & 1 & 1 & 1 & 1 & 1 & 1 \\
\hline 4.2 & Metas sociais & $G$ & 1 & 0 & 0 & 1 & 1 & 0 & 1 & 1 & 1 & 1 \\
\hline 4.3 & Direitos Humanos & $M$ & 0 & 0 & 0 & 0 & 0 & 0 & 0 & 0 & 1 & 1 \\
\hline 4.4 & $\begin{array}{l}\text { Liberdade de associação e trabalho } \\
\text { infantil }\end{array}$ & $M$ & 0 & 0 & 0 & 0 & 0 & 0 & 0 & 0 & 0 & 1 \\
\hline 4.5 & Projetos comunitários ou fundações & $M$ & 1 & 1 & 1 & 1 & 1 & 1 & 1 & 1 & 1 & 1 \\
\hline 4.6 & Direitos sobre a terra & $M$ & 0 & 0 & 0 & 0 & 0 & 0 & 0 & 0 & 0 & 0 \\
\hline 4.7 & Impactos nas comunidades & $M$ & 0 & 0 & 0 & 0 & 0 & 0 & 1 & 1 & 1 & 1 \\
\hline 4.8 & Mulheres empregadas & $\mathrm{M}$ & 0 & 0 & 0 & 0 & 0 & 0 & 0 & 0 & 0 & 1 \\
\hline 4.9 & Desenvolvimento das partes & $|\mathrm{M}|$ & 0 & 1 & 0 & 1 & 0 & 0 & 1 & 1 & 1 & 1 \\
\hline
\end{tabular}




\begin{tabular}{|c|c|c|c|c|c|c|c|c|c|c|c|c|}
\hline No & $\begin{array}{l}\text { Categoria } \\
\text { Informação }\end{array}$ & $|A p|$ & \begin{tabular}{|c|} 
Ano \\
1 \\
1997
\end{tabular} & $\begin{array}{c}\text { Ano } \\
2 \\
1998\end{array}$ & \begin{tabular}{|c|} 
Ano \\
3 \\
1999
\end{tabular} & $\begin{array}{c}\text { Ano } \\
4 \\
2000\end{array}$ & \begin{tabular}{|c|} 
Ano \\
5 \\
2001
\end{tabular} & \begin{tabular}{|c} 
Ano \\
6 \\
2002
\end{tabular} & \begin{tabular}{|c|} 
Ano \\
7 \\
2003
\end{tabular} & \begin{tabular}{|c|} 
Ano \\
8 \\
2004
\end{tabular} & \begin{tabular}{|c|} 
Ano \\
9 \\
2005
\end{tabular} & $\begin{array}{c}\text { Ano } \\
10 \\
2006\end{array}$ \\
\hline & interessadas & & & & & & & & & & & \\
\hline 4.10 & Empregos diretos & $\mathrm{M}$ & 1 & 1 & 1 & 1 & 0 & 1 & 1 & 1 & 0 & 1 \\
\hline 4.11 & $\begin{array}{l}\text { Segurança e meio ambiente para } \\
1 \text { terceirizados }\end{array}$ & $M$ & 0 & 0 & 1 & 1 & 0 & 0 & 0 & 0 & 0 & 1 \\
\hline 4.12 & Combate a corrupção e propina & $M$ & 0 & 0 & 0 & 0 & 0 & 0 & 1 & 1 & 1 & 1 \\
\hline 5 & Desempenho Ambiental & $\mathbf{G}$ & 2 & 2 & 4 & 9 & 4 & 5 & 5 & 6 & 7 & 9 \\
\hline 5.1 & Indicadores ambientais & $G$ & 1 & 1 & 1 & 1 & 1 & 1 & 1 & 1 & 1 & 1 \\
\hline 5.2 & Metas ambientais & $G$ & 0 & 0 & 0 & 0 & 0 & 0 & 0 & 0 & 1 & 1 \\
\hline 5.3 & Reabilitação & $\mathrm{M}$ & 0 & 0 & 0 & 0 & 0 & 0 & 0 & 1 & 1 & 1 \\
\hline 5.4 & Provisões para reabilitação & $M$ & 0 & 0 & 0 & 0 & 0 & 0 & 0 & 0 & 0 & 0 \\
\hline 5.5 & Segurança de barragens e outros & $M$ & 0 & 0 & 0 & 0 & 0 & 0 & 0 & 0 & 0 & 0 \\
\hline 5.6 & Resíduos & $M$ & 0 & 0 & 0 & 1 & 0 & 0 & 0 & 0 & 0 & 0 \\
\hline 5.7 & Ecoeficiência dos produtos & $\mathrm{M}$ & 0 & 0 & 0 & 1 & 1 & 1 & 1 & 1 & 0 & 1 \\
\hline 5.8 & Emissão de poeiras e particulados & $M$ & 0 & 0 & 0 & 1 & 0 & 1 & 0 & 0 & 1 & 1 \\
\hline 5.9 & Emissão de gases & $M$ & 0 & 0 & 0 & 1 & 0 & 0 & 1 & 1 & 1 & 1 \\
\hline 5.10 & $\begin{array}{l}\text { Consumo de recursos naturais não- } \\
\text { renováveis }\end{array}$ & $M$ & 0 & 0 & 0 & 0 & 0 & 0 & 1 & 1 & 0 & 1 \\
\hline 5.11 & Área afetada & $\mathrm{M}$ & 0 & 0 & 0 & 0 & 0 & 0 & 0 & 0 & 0 & 0 \\
\hline 5.12 & Energia & $M$ & 1 & 1 & 1 & 1 & 1 & 1 & 0 & 0 & 1 & 1 \\
\hline 5.13 & Biodiversidade & $\mathrm{M}$ & 0 & 0 & 0 & 1 & 0 & 1 & 1 & 1 & 1 & 1 \\
\hline 5.14 & Água & $M$ & 0 & 0 & 1 & 1 & 1 & 0 & 0 & 0 & 0 & 0 \\
\hline 5.15 & Plano de resposta a emergências & $M$ & 0 & 0 & 1 & 1 & 0 & 0 & 0 & 0 & 0 & 0 \\
\hline 6 & acessibilidade e Garantia & $\mathbf{G}$ & 1 & 1 & 1 & 3 & 2 & 2 & 4 & 3 & 3 & 4 \\
\hline 6.1 & Perfil do relatório & $G$ & 0 & 0 & 0 & 0 & 0 & 1 & 1 & 1 & 1 & 1 \\
\hline 6.2 & Técnicas de medição & $G$ & 0 & 0 & 0 & 0 & 0 & 0 & 0 & 0 & 0 & 0 \\
\hline 6.3 & Comparação - períodos & $G$ & 1 & 1 & 1 & 1 & 1 & 0 & 1 & 1 & 1 & 1 \\
\hline 6.4 & Comparação - padrões & $\mathrm{G}$ & 0 & 0 & 0 & 1 & 0 & 0 & 0 & 0 & 0 & 0 \\
\hline 6.5 & Comparação - objetivos amplos & $G$ & 0 & 0 & 0 & 0 & 0 & 0 & 0 & 0 & 0 & 0 \\
\hline 6.6 & Contato & $G$ & 0 & 0 & 0 & 1 & 1 & 1 & 1 & 1 & 1 & 1 \\
\hline 6.7 & Fronteiras do relatório & $G$ & 0 & 0 & 0 & 0 & 0 & 0 & 1 & 0 & 0 & 1 \\
\hline 6.8 & Materialidade & $G$ & 0 & 0 & 0 & 0 & 0 & 0 & 0 & 0 & 0 & 0 \\
\hline 6.9 & Verificação de terceira parte & $G$ & 0 & 0 & 0 & 0 & 0 & 0 & 0 & 0 & 0 & 0 \\
\hline 6.10 & Avaliação do relatório & $G$ & 0 & 0 & 0 & 0 & 0 & 0 & 0 & 0 & 0 & 0 \\
\hline \multirow{2}{*}{62} & \multirow{2}{*}{$\begin{array}{l}\text { Total (absoluto) } \\
\text { (porcentagem) }\end{array}$} & & 15 & 11 & 17 & 27 & 16 & 18 & 29 & 29 & 24 & 43 \\
\hline & & & $24 \%$ & $18 \%$ & $27 \%$ & $44 \%$ & $\mid 26 \%$ & $29 \%$ & $47 \%$ & $\mid 47 \%$ & $39 \%$ & $69 \%$ \\
\hline
\end{tabular}




\section{APÊNDICE E - Roteiro completo - Lafarge}

\begin{tabular}{|c|c|c|c|c|c|c|c|c|}
\hline & $\begin{array}{l}\text { Categoria } \\
\text { Informação }\end{array}$ & $A p$ & $\begin{array}{l}\text { Ano } 1 \\
2001\end{array}$ & $\begin{array}{c}\text { Ano } 2 \\
2002\end{array}$ & $\begin{array}{c}\text { Ano } 3 \\
2003\end{array}$ & $\begin{array}{c}\text { Ano } 4 \\
2004\end{array}$ & $\begin{array}{l}\text { Ano } 5 \\
2005\end{array}$ & \begin{tabular}{|l} 
Ano 6 \\
2006
\end{tabular} \\
\hline 1 & Contexto e Compromissos & $\mathbf{G}$ & 5 & 6 & 5 & 5 & 7 & 5 \\
\hline 1.1 & Perfil da empresa & $G$ & 1 & 1 & 1 & 1 & 1 & 1 \\
\hline 1.2 & Visão de sustentabilidade & $\mathrm{G}$ & 1 & 1 & 1 & 1 & 1 & 1 \\
\hline 1.3 & Declaração do principal executivo & $G$ & 1 & 1 & 1 & 1 & 1 & 1 \\
\hline 1.4 & Identificação dos riscos & $G$ & 0 & 0 & 0 & 0 & 1 & 0 \\
\hline 1.5 & Conformidade legal & $\mathrm{M}$ & 1 & 1 & 0 & 0 & 1 & 0 \\
\hline 1.6 & Governança & $\mathrm{G}$ & 0 & 1 & 1 & 1 & 1 & 1 \\
\hline 1.7 & Influência & $G$ & 1 & 1 & 1 & 1 & 1 & 1 \\
\hline 2 & Gestão & G & 8 & 8 & 6 & 6 & 8 & 7 \\
\hline 2.1 & Cadeia de suprimentos & $G$ & 1 & 1 & 0 & 1 & 1 & 1 \\
\hline 2.2 & Partes interessadas & $\mathrm{G}$ & 1 & 1 & 0 & 0 & 0 & 0 \\
\hline 2.3 & Identificação das partes interessadas & $G$ & 0 & 0 & 0 & 0 & 0 & 0 \\
\hline 2.4 & Envolvimento das partes interessadas & $\mathrm{G}$ & 1 & 1 & 1 & 1 & 1 & 1 \\
\hline 2.5 & Resposta às partes interessadas & $G$ & 1 & 1 & 1 & 1 & 1 & 1 \\
\hline 2.6 & Envolvimento da comunidade local & $M$ & 1 & 1 & 1 & 0 & 1 & 1 \\
\hline 2.7 & Multas e penalidades & $G$ & 0 & 0 & 0 & 1 & 1 & 0 \\
\hline 2.8 & Acidentes & $\mathrm{G}$ & 1 & 1 & 1 & 1 & 1 & 1 \\
\hline 2.9 & Investimentos & $M$ & 1 & 1 & 1 & 1 & 1 & 1 \\
\hline 2.10 & Treinamento & $M$ & 1 & 1 & 1 & 0 & 1 & 1 \\
\hline 3 & Desempenho Econômico & $\mathbf{G}$ & 5 & 5 & 4 & 5 & 4 & 5 \\
\hline 3.1 & Indicadores econômicos & $G$ & 1 & 1 & 1 & 1 & 1 & 1 \\
\hline 3.2 & Metas econômicas & $G$ & 1 & 1 & 1 & 0 & 0 & 0 \\
\hline 3.3 & Benefícios & $\mathrm{M}$ & 1 & 1 & 1 & 1 & 1 & 1 \\
\hline 3.4 & Retorno financeiro para as comunidades & $M$ & 0 & 0 & 0 & 1 & 1 & 1 \\
\hline 3.5 & Contribuição econômica local & $\mathrm{M}$ & 1 & 1 & 0 & 1 & 0 & 0 \\
\hline 3.6 & Valor agregado & $\mathrm{M}$ & 0 & 0 & 0 & 0 & 0 & 1 \\
\hline 3.7 & Combate à pobreza & $M$ & 0 & 1 & 0 & 0 & 0 & 0 \\
\hline 3.8 & Pagamentos ao Governo & $M$ & 1 & 0 & 1 & 1 & 1 & 1 \\
\hline 4 & Desempenho Social & $\mathbf{G}$ & 11 & 10 & 10 & 11 & 10 & 9 \\
\hline 4.1 & Indicadores sociais & $G$ & 1 & 1 & 1 & 1 & 1 & 1 \\
\hline 4.2 & Metas sociais & $G$ & 1 & 1 & 1 & 1 & 1 & 1 \\
\hline 4.3 & Direitos Humanos & $M$ & 1 & 1 & 1 & 1 & 1 & 0 \\
\hline 4.4 & Liberdade de associação e trabalho infantil & $M$ & 1 & 0 & 1 & 1 & 1 & 1 \\
\hline 4.5 & Projetos comunitários ou fundações & $\mathrm{M}$ & 1 & 1 & 1 & 1 & 1 & 1 \\
\hline 4.6 & Direitos sobre a terra & $\mathrm{M}$ & 1 & 0 & 0 & 0 & 0 & 0 \\
\hline 4.7 & Impactos nas comunidades & $M$ & 1 & 1 & 1 & 1 & 1 & 1 \\
\hline 4.8 & Mulheres empregadas & $M$ & 1 & 1 & 1 & 1 & 1 & 1 \\
\hline 4.9 & Desenvolvimento das partes interessadas & $\mathrm{M}$ & 1 & 1 & 0 & 1 & 1 & 0 \\
\hline 4.10 & Empregos diretos & $M$ & 1 & 1 & 1 & 1 & 1 & 1 \\
\hline 4.11 & $\begin{array}{l}\text { Segurança e meio ambiente para } \\
\text { terceirizados }\end{array}$ & $M$ & 1 & 1 & 1 & 1 & 0 & 1 \\
\hline
\end{tabular}




\begin{tabular}{|c|c|c|c|c|c|c|c|c|}
\hline No & $\begin{array}{l}\text { Categoria } \\
\text { Informação }\end{array}$ & Ap & $\begin{array}{c}\text { Ano } 1 \\
2001\end{array}$ & $\begin{array}{l}\text { Ano } 2 \\
2002 \\
\end{array}$ & $\begin{array}{l}\text { Ano } 3 \\
2003 \\
\end{array}$ & $\begin{array}{c}\text { Ano } 4 \\
2004 \\
\end{array}$ & $\begin{array}{l}\text { Ano } 5 \\
2005\end{array}$ & $\begin{array}{l}\text { Ano } 6 \\
2006 \\
\end{array}$ \\
\hline 4.12 & Combate a corrupção e propina & $M$ & 0 & 1 & 1 & 1 & 1 & 1 \\
\hline 5 & Desempenho Ambiental & G & 11 & 13 & 10 & 12 & 12 & 12 \\
\hline 5.1 & Indicadores ambientais & $G$ & 1 & 1 & 1 & 1 & 1 & 1 \\
\hline 5.2 & Metas ambientais & $G$ & 1 & 1 & 1 & 1 & 1 & 1 \\
\hline 5.3 & Reabilitação & $M$ & 1 & 1 & 1 & 1 & 1 & 1 \\
\hline 5.4 & Provisões para reabilitação & $M$ & 0 & 1 & 0 & 1 & 1 & 1 \\
\hline 5.5 & Segurança de barragens e outros & $M$ & 0 & 0 & 0 & 0 & 0 & 0 \\
\hline 5.6 & Resíduos & $M$ & 1 & 1 & 1 & 1 & 1 & 1 \\
\hline 5.7 & Ecoeficiência dos produtos & $M$ & 1 & 1 & 1 & 1 & 1 & 1 \\
\hline 5.8 & Emissão de poeiras e particulados & $M$ & 1 & 1 & 1 & 1 & 1 & 1 \\
\hline 5.9 & Emissão de gases & $M$ & 1 & 1 & 1 & 1 & 1 & 1 \\
\hline 5.10 & $\begin{array}{l}\text { Consumo de recursos naturais não- } \\
\text { renováveis }\end{array}$ & $M$ & 1 & 1 & 1 & 1 & 1 & 1 \\
\hline 5.11 & Área afetada & $M$ & 0 & 0 & 0 & 0 & 0 & 0 \\
\hline 5.12 & Energia & $M$ & 1 & 1 & 1 & 1 & 1 & 1 \\
\hline 5.13 & Biodiversidade & $M$ & 1 & 1 & 0 & 1 & 1 & 1 \\
\hline 5.14 & Água & $M$ & 1 & 1 & 1 & 1 & 1 & 1 \\
\hline 5.15 & Plano de resposta a emergências & $M$ & 0 & 1 & 0 & 0 & 0 & 0 \\
\hline 6 & acessibilidade e Garantia & G & 7 & 6 & 5 & 8 & 8 & 8 \\
\hline 6.1 & Perfil do relatório & $G$ & 1 & 1 & 1 & 0 & 0 & 0 \\
\hline 6.2 & Técnicas de medição & $G$ & 0 & 0 & 0 & 1 & 1 & 1 \\
\hline 6.3 & Comparação - períodos & $G$ & 1 & 1 & 1 & 1 & 1 & 1 \\
\hline 6.4 & Comparação - padrões & $G$ & 0 & 0 & 0 & 0 & 0 & 0 \\
\hline 6.5 & Comparação - objetivos amplos & $G$ & 1 & 1 & 0 & 1 & 1 & 1 \\
\hline 6.6 & Contato & $G$ & 1 & 1 & 1 & 1 & 1 & 1 \\
\hline 6.7 & Fronteiras do relatório & $G$ & 1 & 1 & 1 & 1 & 1 & 1 \\
\hline 6.8 & Materialidade & $G$ & 0 & 0 & 0 & 1 & 1 & 1 \\
\hline 6.9 & Verificação de terceira parte & $G$ & 1 & 0 & 0 & 1 & 1 & 1 \\
\hline 6.10 & Avaliação do relatório & $G$ & 1 & 1 & 1 & 1 & 1 & 1 \\
\hline \multirow{2}{*}{62} & \multirow{2}{*}{$\begin{array}{l}\text { Total (absoluto) } \\
\text { (porcentagem) }\end{array}$} & & 47 & 48 & 40 & 47 & 49 & 46 \\
\hline & & & $76 \%$ & $77 \%$ & $65 \%$ & $76 \%$ & $79 \%$ & $74 \%$ \\
\hline
\end{tabular}




\section{APÊNDICE F - Roteiro completo - Samarco}

\begin{tabular}{|c|c|c|c|c|c|c|c|}
\hline No & $\begin{array}{l}\text { Categoria } \\
\text { Informação }\end{array}$ & Ap & $\begin{array}{l}\text { Ano } 1 \\
2002\end{array}$ & $\begin{array}{l}\text { Ano } 2 \\
2003\end{array}$ & $\begin{array}{l}\text { Ano } 3 \\
2004\end{array}$ & $\begin{array}{l}\text { Ano } 4 \\
2005\end{array}$ & $\begin{array}{l}\text { Ano } 5 \\
2006\end{array}$ \\
\hline 1 & Contexto e Compromissos & G & 5 & 5 & 6 & 6 & 7 \\
\hline 1.1 & Perfil da empresa & $G$ & 1 & 1 & 1 & 1 & 1 \\
\hline 1.2 & Visão de sustentabilidade & $G$ & 0 & 0 & 0 & 0 & 1 \\
\hline 1.3 & Declaração do principal executivo & $G$ & 1 & 1 & 1 & 1 & 1 \\
\hline 1.4 & Identificação dos riscos & $G$ & 1 & 0 & 1 & 1 & 1 \\
\hline 1.5 & Conformidade legal & $\mathrm{M}$ & 0 & 1 & 1 & 1 & 1 \\
\hline 1.6 & Governança & $G$ & 1 & 1 & 1 & 1 & 1 \\
\hline 1.7 & Influência & $G$ & 1 & 1 & 1 & 1 & 1 \\
\hline 2 & Gestão & G & 9 & 9 & 9 & 9 & 9 \\
\hline 2.1 & Cadeia de suprimentos & $G$ & 1 & 0 & 1 & 1 & 1 \\
\hline 2.2 & Partes interessadas & $G$ & 1 & 1 & 1 & 1 & 1 \\
\hline 2.3 & Identificação das partes interessadas & $G$ & 1 & 1 & 0 & 0 & 0 \\
\hline 2.4 & Envolvimento das partes interessadas & $G$ & 1 & 1 & 1 & 1 & 1 \\
\hline 2.5 & Resposta às partes interessadas & $G$ & 1 & 1 & 1 & 1 & 1 \\
\hline 2.6 & Envolvimento da comunidade local & $\mathrm{M}$ & 1 & 1 & 1 & 1 & 1 \\
\hline 2.7 & Multas e penalidades & $G$ & 0 & 1 & 1 & 1 & 1 \\
\hline 2.8 & Acidentes & $G$ & 1 & 1 & 1 & 1 & 1 \\
\hline 2.9 & Investimentos & $M$ & 1 & 1 & 1 & 1 & 1 \\
\hline 2.10 & Treinamento & $M$ & 1 & 1 & 1 & 1 & 1 \\
\hline 3 & Desempenho Econômico & G & 5 & 6 & 6 & 6 & 6 \\
\hline 3.1 & Indicadores econômicos & $G$ & 1 & 1 & 1 & 1 & 1 \\
\hline 3.2 & Metas econômicas & $G$ & 0 & 0 & 0 & 0 & 0 \\
\hline 3.3 & Benefícios & $\mathrm{M}$ & 1 & 1 & 1 & 1 & 1 \\
\hline 3.4 & Retorno financeiro para as comunidades & $M$ & 1 & 1 & 1 & 1 & 1 \\
\hline 3.5 & Contribuição econômica local & $M$ & 0 & 1 & 1 & 1 & 1 \\
\hline 3.6 & Valor agregado & $\mathrm{M}$ & 1 & 1 & 1 & 1 & 1 \\
\hline 3.7 & Combate à pobreza & $M$ & 0 & 0 & 0 & 0 & 0 \\
\hline 3.8 & Pagamentos ao Governo & $\mathrm{M}$ & 1 & 1 & 1 & 1 & 1 \\
\hline 4 & Desempenho Social & G & 11 & 11 & 11 & 11 & 11 \\
\hline 4.1 & Indicadores sociais & $G$ & 1 & 1 & 1 & 1 & 1 \\
\hline 4.2 & Metas sociais & $\mathrm{G}$ & 1 & 1 & 1 & 1 & 1 \\
\hline 4.3 & Direitos Humanos & $\mathrm{M}$ & 1 & 1 & 1 & 1 & 1 \\
\hline 4.4 & Liberdade de associação e trabalho infantil & $M$ & 1 & 1 & 1 & 1 & 1 \\
\hline 4.5 & Projetos comunitários ou fundações & $\mathrm{M}$ & 1 & 1 & 1 & 1 & 1 \\
\hline 4.6 & Direitos sobre a terra & $M$ & 0 & 0 & 0 & 0 & 0 \\
\hline 4.7 & Impactos nas comunidades & $\mathrm{M}$ & 1 & 1 & 1 & 1 & 1 \\
\hline 4.8 & Mulheres empregadas & $\mathrm{M}$ & 1 & 1 & 1 & 1 & 1 \\
\hline 4.9 & Desenvolvimento das partes interessadas & $\mathrm{M}$ & 1 & 1 & 1 & 1 & 1 \\
\hline 4.10 & Empregos diretos & $M$ & 1 & 1 & 1 & 1 & 1 \\
\hline 4.11 & Segurança e meio ambiente para terceirizados & $M$ & 1 & 1 & 1 & 1 & 1 \\
\hline 4.12 & Combate a corrupção e propina & $M$ & 1 & 1 & 1 & 1 & 1 \\
\hline
\end{tabular}




\begin{tabular}{|c|c|c|c|c|c|c|c|}
\hline No & $\begin{array}{l}\text { Categoria } \\
\text { Informação }\end{array}$ & Ap & $\begin{array}{l}\text { Ano } 1 \\
2002\end{array}$ & $\begin{array}{l}\text { Ano } 2 \\
2003\end{array}$ & $\begin{array}{l}\text { Ano } 3 \\
2004\end{array}$ & $\begin{array}{l}\text { Ano } 4 \\
2005\end{array}$ & $\begin{array}{l}\text { Ano } 5 \\
2006\end{array}$ \\
\hline 5 & Desempenho Ambiental & G & 8 & 10 & 11 & 11 & 11 \\
\hline 5.1 & Indicadores ambientais & $G$ & 1 & 1 & 1 & 1 & 1 \\
\hline 5.2 & Metas ambientais & G & 1 & 0 & 1 & 1 & 1 \\
\hline 5.3 & Reabilitação & $\mathrm{M}$ & 1 & 1 & 1 & 1 & 1 \\
\hline 5.4 & Provisões para reabilitação & $\mathrm{M}$ & 0 & 0 & 0 & 0 & 0 \\
\hline 5.5 & Segurança de barragens e outros & $M$ & 1 & 1 & 1 & 1 & 1 \\
\hline 5.6 & Resíduos & $\mathrm{M}$ & 1 & 1 & 1 & 1 & 1 \\
\hline 5.7 & Ecoeficiência dos produtos & $\mathrm{M}$ & 0 & 0 & 0 & 0 & 0 \\
\hline 5.8 & Emissão de poeiras e particulados & $\mathrm{M}$ & 1 & 1 & 1 & 1 & 1 \\
\hline 5.9 & Emissão de gases & M & 0 & 1 & 1 & 1 & 1 \\
\hline 5.10 & Consumo de recursos naturais não-renováveis & $\mathrm{M}$ & 0 & 0 & 0 & 0 & 0 \\
\hline 5.11 & Área afetada & $\mathrm{M}$ & 0 & 1 & 1 & 1 & 1 \\
\hline 5.12 & Energia & $\mathrm{M}$ & 1 & 1 & 1 & 1 & 1 \\
\hline 5.13 & Biodiversidade & $\mathrm{M}$ & 0 & 1 & 1 & 1 & 1 \\
\hline 5.14 & Água & $\mathrm{M}$ & 1 & 1 & 1 & 1 & 1 \\
\hline 5.15 & Plano de resposta a emergências & $\mathrm{M}$ & 0 & 0 & 0 & 0 & 0 \\
\hline 6 & acessibilidade e Garantia & $\mathbf{G}$ & 1 & 5 & 5 & 5 & 5 \\
\hline 6.1 & Perfil do relatório & $\mathrm{G}$ & 0 & 1 & 1 & 1 & 1 \\
\hline 6.2 & Técnicas de medição & $\mathrm{G}$ & 0 & 0 & 0 & 0 & 0 \\
\hline 6.3 & Comparação - períodos & G & 1 & 1 & 1 & 1 & 1 \\
\hline 6.4 & Comparação - padrões & $\mathrm{G}$ & 0 & 0 & 1 & 1 & 1 \\
\hline 6.5 & Comparação - objetivos amplos & $G$ & 0 & 1 & 0 & 0 & 0 \\
\hline 6.6 & Contato & G & 0 & 1 & 1 & 1 & 1 \\
\hline 6.7 & Fronteiras do relatório & G & 0 & 0 & 0 & 0 & 0 \\
\hline 6.8 & Materialidade & $\mathrm{G}$ & 0 & 0 & 0 & 0 & 0 \\
\hline 6.9 & Verificação de terceira parte & $G$ & 0 & 0 & 0 & 0 & 0 \\
\hline 6.10 & Avaliação do relatório & G & 0 & 1 & 1 & 1 & 1 \\
\hline \multirow{2}{*}{62} & \multirow{2}{*}{$\begin{array}{l}\text { Total (absoluto) } \\
\text { (porcentagem) }\end{array}$} & & 39 & 46 & 48 & 48 & 49 \\
\hline & & & $63 \%$ & $74 \%$ & $77 \%$ & $77 \%$ & $79 \%$ \\
\hline
\end{tabular}




\section{APÊNDICE G - Gráficos da evolução temporal de cada categoria}

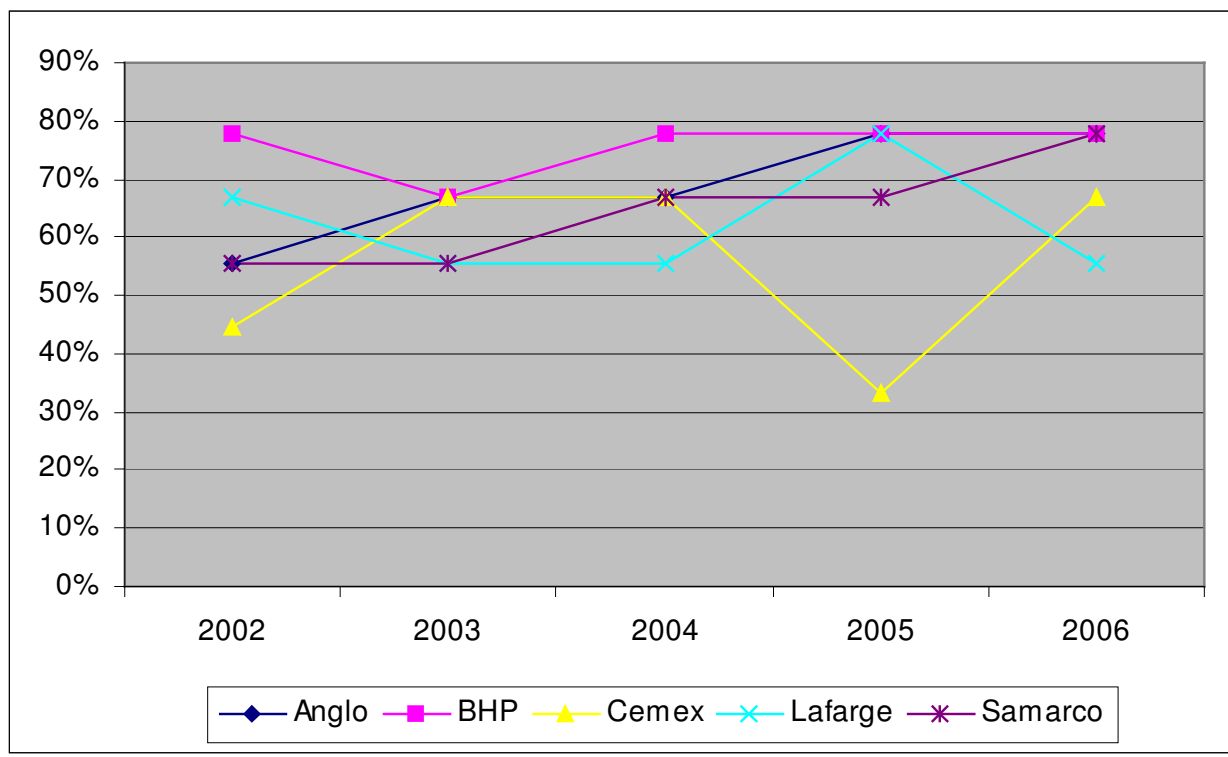

Figura 11 - Evolução temporal da categoria "Contexto e Compromissos"

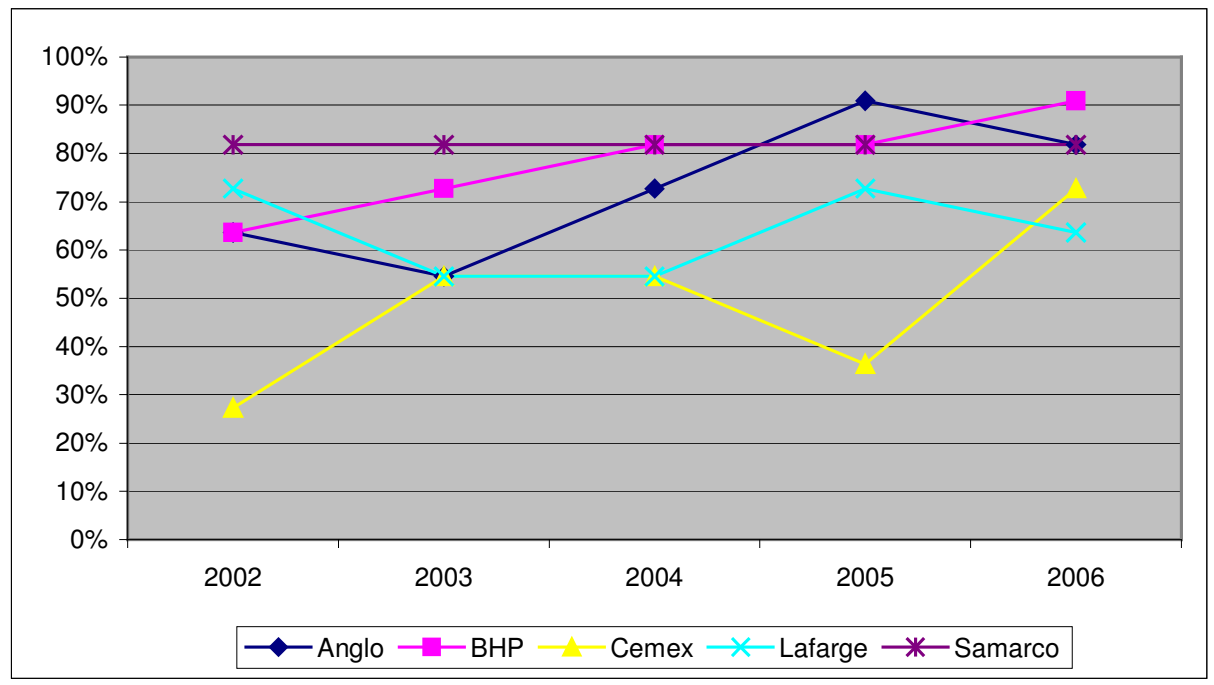

Figura 12 - Evolução temporal da categoria "Gestão" 


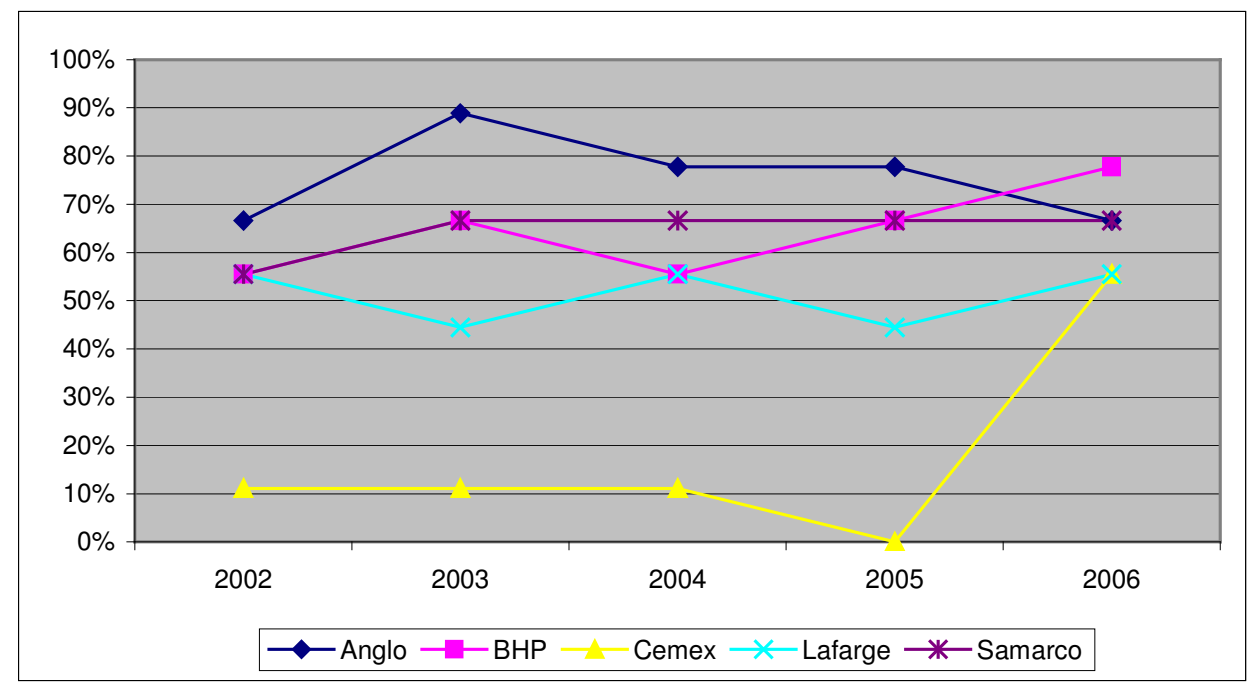

Figura 13 - Evolução temporal da categoria "Desempenho econômico"

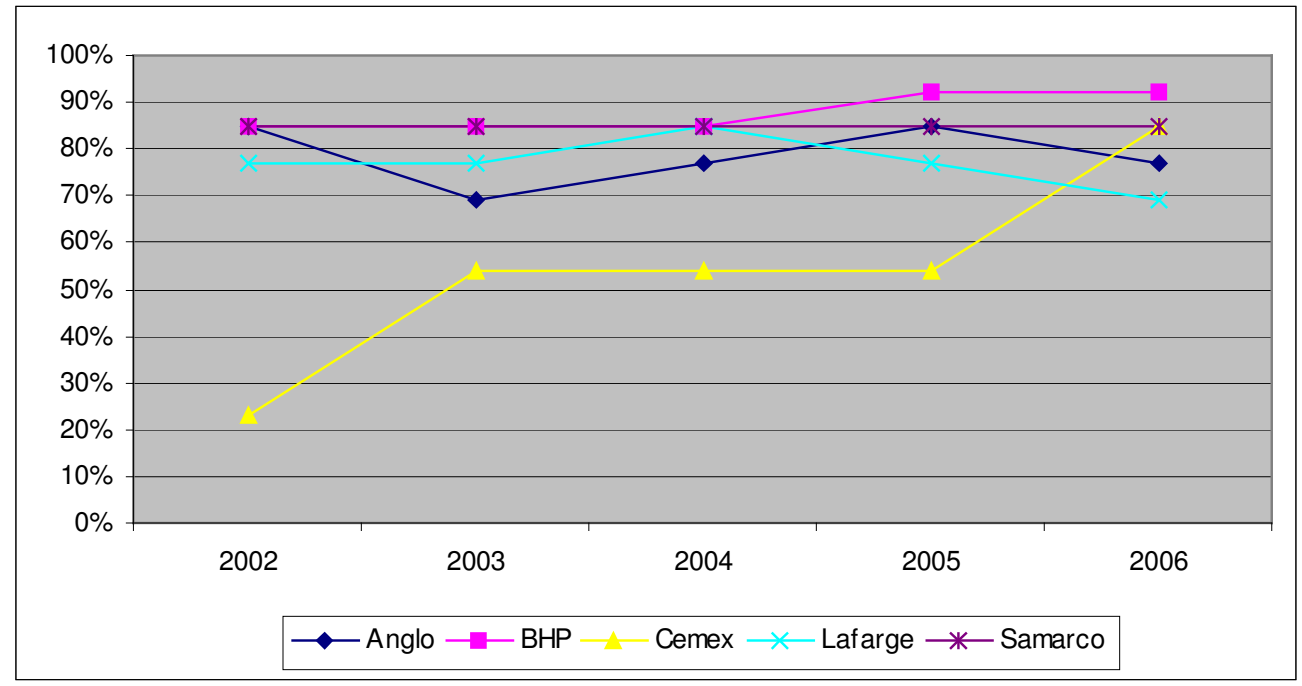

Figura 14 - Evolução temporal da categoria "Desempenho social" 


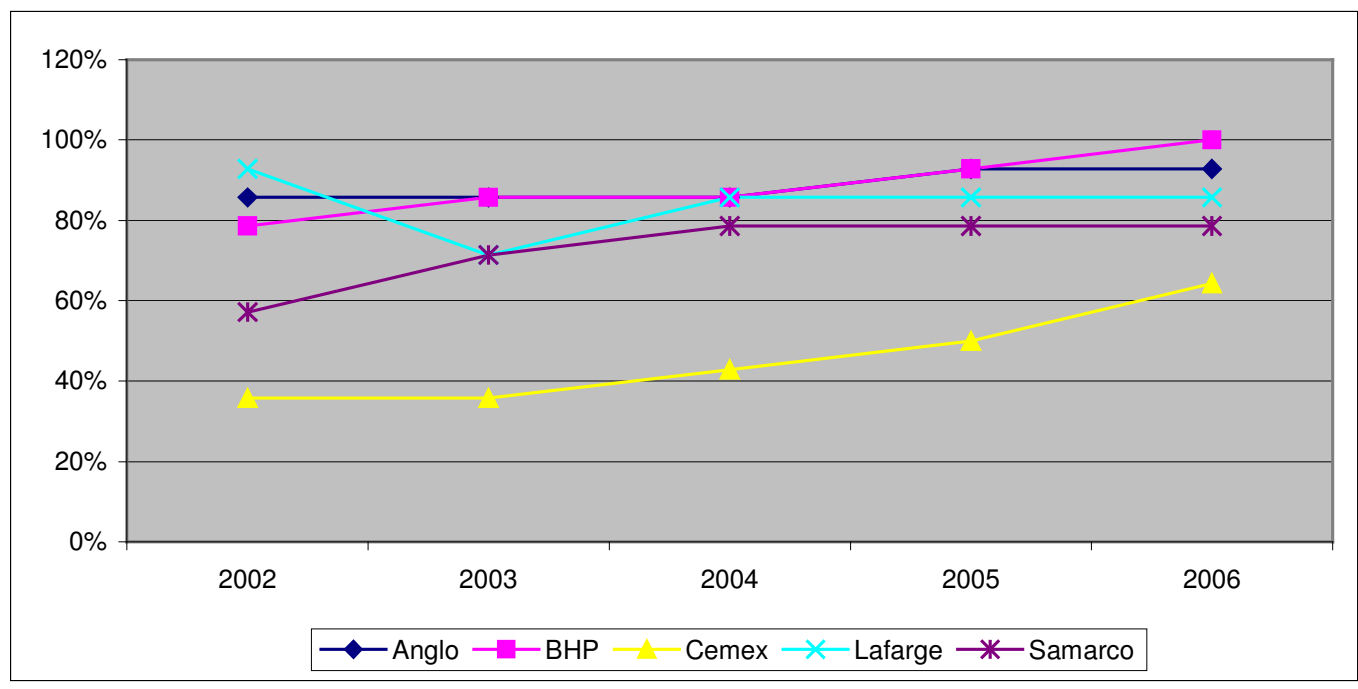

Figura 15 - Evolução temporal da categoria "Desempenho ambiental"

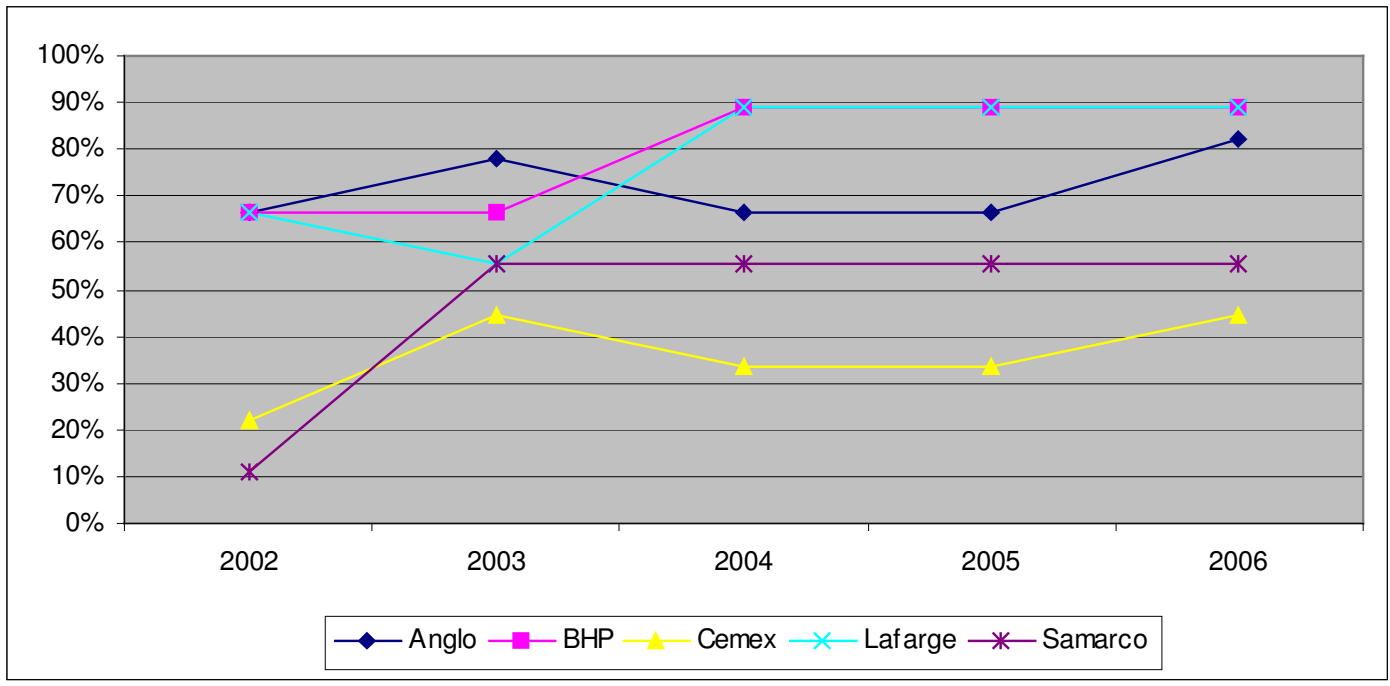

Figura 16 - Evolução temporal da categoria "Acessibilidade e Garantia" 
ANEXOS

\section{ANEXO A - Metodologia de avaliação da consultoria Sustainability}

Context and Commitments

1 Company and Industry Profile

2 Top Management Statement

3 Economic Issue Identification

4 Social Issue Identification

5 Environmental Issue Identification

6 Stakeholder Engagement and Involvement in Issue Identification and Prioritization

7 Decision-making: Values, Principles and Policies for SD Accountability

8 Decision-making: SD Implementation Challenges

9 Decision-making: The Business Case

10 Sustainable Development Vision: An Organization's View of the Future

\section{Management Quality}

11 Internal Alignment: Governance and Organizational Accountability

12 Internal Alignment: Managing the Economic Dimension

13 Internal Alignment: Managing the Social Dimension

14 Internal Alignment: Environmental (and EHS) Management Systems

15 Decision-making: Measuring SD Performance

16 External Alignment: Supply Chain SD Management

17 External Alignment: Public Policy

18 External Alignment: Industry Influence

19 External Alignment: Customer Influence

Performance over Reporting Period

20 Economic - Financial Performance Overview

21 Economic - Tangible and Intangible Investments

22 Economic Impacts - Investors

23 Economic Impacts - Employees

24 Economic impact - Governments

25 Economic Impact - Community

26 Social and Ethical: Workplace: Workplace Quality

27 Social and Ethical: Workplace: Health and Safety

28 Social and Ethical: Workplace: Diversity (Non-discrimination)

29 Social and Ethical: Workplace: Ethical Labor Practices

30 Social and Ethical: Human Rights

31 Social and Ethical: Community Social Impact and Development

32 Social and Ethical: Integrity

33 Environmental: Inputs: Energy Use

34 Environmental: Inputs: Materials and Waste

35 Environmental: Inputs: Water Use and Releases

36 Environmental: Outputs: Air Emissions (non-CO2)

37 Environmental: Outputs: CO2/Greenhouse Gases/Climate Change

38 Environmental: Land Use/Habitat Stewardship/Biodiversity

39 Environmental: Transportation and Logistics

40 Multi-Dimensional: Environmental and Social Accounting

41 Multi-Dimensional: Product and Service Impacts

42 Multi-Dimensional: Compliance, Fines and Liabilities

Accessibility and Assurance

43 Reporting Commitment and Policy

44 Scope and Geographic Coverage

45 Assurance mechanisms

46 Stakeholder Perception of Performance

47 Accessibility of Information

48 Accessibility of Design

Fonte: Sustainability (2006) 


\section{ANEXO B - Rankings}

Tabela 29 - Ranking Covalence Ethical 2005 - Mining \& Metals

\begin{tabular}{cl}
\hline Posição & Empresa \\
\hline 1 & Alcoa \\
\hline 2 & Alcan \\
\hline 3 & Anglo American \\
\hline 4 & POSCO \\
\hline 5 & Companhia Vale do Rio Doce \\
\hline 6 & Gold Fields \\
\hline 7 & WMC Resources Ltd. \\
\hline 8 & Impala Platinum \\
\hline 9 & Falconbridge \\
\hline 10 & JFE Holdings Inc. \\
\hline 11 & Rio Tinto \\
\hline 12 & Kinross \\
\hline 13 & Nippon Steel \\
\hline 14 & Placer Dome \\
\hline 15 & Alumina Ltd. \\
\hline 16 & Harmony Gold \\
\hline 17 & China Steel Corp. \\
\hline 18 & BHP Billiton \\
\hline 19 & Inco \\
\hline 20 & Barrick \\
\hline 21 & Gencor Ltd. \\
\hline 22 & Newmont \\
\hline & Fonte: Covalence (2006) \\
\hline
\end{tabular}

Tabela 30 - Ranking RMG 2004 - Metal Mining

\begin{tabular}{cllc}
\hline Posição & \multicolumn{1}{c}{ Empresa } & \multicolumn{1}{c}{ País } & $\begin{array}{c}\text { \% do valor de } \\
\text { produção mundial }\end{array}$ \\
\hline 1 & Anglo American plc & Reino Unido & 6.7 \\
\hline 2 & BHP Billiton Group & Austrália & 3.9 \\
\hline 3 & Rio Tinto plc & Reino Unido & 3.8 \\
\hline 4 & Norilsk Nickel (MMC) JSC & Rússia & 3.1 \\
\hline 5 & Cia Vale do Rio Doce & Brasil & 2.9 \\
\hline 6 & Corporacion Nacional del Cobre de Chile & Chile & 2.1 \\
\hline 7 & Newmont Mining Corp & EUA & 2.0 \\
\hline 8 & Noranda Inc & Canadá & 1.4 \\
\hline 9 & Barrick Gold Corp & Canadá & 1.3 \\
\hline 10 & Phelps Dodge Corp & EUA & 1.3 \\
\hline
\end{tabular}

Fonte: Raw Materials Group (2006) 
Tabela 31 - Ranking FT Global 2005

\begin{tabular}{cllll}
\hline Posição & \multicolumn{1}{c}{ Empresa } & \multicolumn{1}{c}{ País } & $\begin{array}{c}\text { Valor de } \\
\text { mercado } \text { (U\$ } \\
\text { milhões) }\end{array}$ & Setor \\
\hline 32 & BHP Billiton & Australia/UK & $116,692.40$ & Mining \\
\hline 61 & Rio Tinto & Australia/UK & $79,423.40$ & Mining \\
\hline 103 & Anglo American & UK & $58,675.90$ & Mining \\
\hline 117 & CVRD & Brazil & $54,394.90$ & Industrial Metals \\
\hline 185 & Norsk Hydro & Norway & $35,827.00$ & Industrial Metals \\
\hline 262 & Alcoa & US & $26,642.80$ & Industrial Metals \\
\hline 269 & Nippon Steel & Japan & $26,307.20$ & Industrial Metals \\
\hline 280 & Arcelor & France & $25,186.40$ & Industrial Metals \\
\hline 294 & Cemex & Mexico & $24,432.30$ & Construction \& materials \\
\hline 304 & Saint Gobain & France & $24,087.80$ & Construction \& materials \\
\hline 310 & JFE Holdings & Japan & $23,640.70$ & Industrial Metals \\
\hline 326 & POSCO & South Korea & $22,477.50$ & Industrial Metals \\
\hline 341 & Barrick Gold & Canada & $21,727.80$ & Mining \\
\hline 342 & Newmont Mining & US & $21,658.00$ & Mining \\
\hline 360 & Tenaris & Argentina & $20,881.00$ & Industrial Metals \\
\hline 369 & Sumitomo Metal & Japan & $20,569.70$ & Industrial Metals \\
\hline 373 & Xstrata & UK & $20,439.10$ & Mining \\
\hline 376 & MMC Norilsk Nickel & Russia & $20,171.30$ & Industrial Metals \\
\hline 382 & Lafarge & France & $19,913.30$ & Construction \& materials \\
\hline 387 & Anglo Platinum & South Africa & $19,836.70$ & Mining \\
\hline 392 & Vinci & France & $19,509.80$ & Construction \& materials \\
\hline 404 & CRH & Ireland & $18,733.30$ & Construction \& materials \\
\hline 417 & Holcim & Switzerland & $18,262.80$ & Construction \& materials \\
\hline 432 & Bouygues & France & $17,845.90$ & Construction \& materials \\
\hline 438 & Asahi Glass & Japan & $17,681.00$ & Construction \& materials \\
\hline 455 & Alcan & Canada & $17,073.80$ & Industrial Metals \\
\hline 473 & Phelps Dodge & US & $16,390.10$ & Industrial Metals \\
\hline 477 & Nucor & US & $16,285.50$ & Industrial Metals \\
\hline & & Fonte: The Financial Times & $(2006)$ & \\
\hline
\end{tabular}

Fonte: The Financial Times (2006)

Tabela 32 - Ranking Fortune Global 2005

\begin{tabular}{clccl}
\hline Posição & Empresa & $\begin{array}{c}\text { Receita (U\$ } \\
\text { milhões) }\end{array}$ & $\begin{array}{c}\text { Lucro (U\$ } \\
\text { milhões) }\end{array}$ & \multicolumn{1}{c}{ Setor } \\
\hline 123 & Saint-Gobain & 43626 & 1571 & Building Materials, Glass \\
\hline 137 & Arcelor & 40521 & 4779 & Metals \\
\hline 168 & Nippon Steel & 34502 & 3037 & Metals \\
\hline 195 & BHP Billiton & 29587 & 6398 & Mining \& Crude Oil \\
\hline 196 & Anglo American & 29434 & 3521 & Mining \& Crude Oil \\
\hline 208 & Mittal Steel & 28132 & 3365 & Metals \\
\hline 214 & RAG & 27762 & 211 & Mining \& Crude Oil \\
\hline 218 & JFE Holdings & 27366 & 2879 & Metals \\
\hline 222 & Norsk Hydro & 27033 & 2427 & Metals \\
\hline 225 & Alcoa & 26601 & 1233 & Metals \\
\hline 236 & POSCO & 25678 & 3916 & Metals \\
\hline 296 & Baosteel Group & 21501 & 1395 & Metals \\
\hline 310 & Rio Tinto Group & 20742 & 5215 & Mining \& Crude Oil \\
\hline 313 & Alcan & 20659 & 129 & Metals \\
\hline 325 & Lafarge & 19843 & 1362 & Building Materials, Glass \\
\hline & & &
\end{tabular}


conclusão

\begin{tabular}{llccl}
\hline 352 & Corus Group & 18429 & 821 & Metals \\
\hline 361 & CRH & 17954 & 1240 & Building Materials, Glass \\
\hline 396 & EnCana & 16801 & 3426 & Mining \& Crude Oil \\
\hline 402 & Oil \& Natural Gas & 16609 & 3482 & Mining \& Crude Oil \\
\hline 412 & Occidental Petroleum & 16286 & 5281 & Mining \& Crude Oil \\
\hline 443 & Surgutneftegas & 15154 & 4046 & Mining \& Crude Oil \\
\hline 451 & Cemex & 14935 & 2058 & Building Materials, Glass \\
\hline 458 & Holcim & 14820 & 1236 & Building Materials, Glass \\
\hline 461 & Kobe Steel & 14726 & 747 & Metals \\
\hline 490 & United States Steel & 14039 & 910 & Metals \\
\hline 497 & Asahi Glass & 13864 & 545 & Building Materials, Glass \\
\hline
\end{tabular}

Fonte: Cable News Network (2006)

Tabela 33 - Ranking Forbes Global 2005

\begin{tabular}{|c|c|c|c|c|c|c|c|}
\hline Posição & Empresa & País & Setor & $\begin{array}{c}\text { Vendas } \\
\text { (\$bil) }\end{array}$ & $\begin{array}{l}\text { Lucro } \\
\text { (\$bil) }\end{array}$ & $\begin{array}{l}\text { Ativos } \\
\text { (\$bil) }\end{array}$ & $\begin{array}{c}\text { Valor de } \\
\text { Mercado } \\
\text { (\$bil) }\end{array}$ \\
\hline 101 & BHP Billiton & Australia/UK & Materials & 29.84 & 6.05 & 41.39 & 109.13 \\
\hline 116 & Anglo American & UK & Materials & 27.89 & 3.34 & 51.55 & 55.67 \\
\hline 155 & Arcelor & Luxembourg & Materials & 39.01 & 4.49 & 40.62 & 22.55 \\
\hline 159 & Rio Tinto & UK/Australia & Materials & 18.34 & 5.03 & 29.75 & 74.5 \\
\hline 173 & Nippon Steel & Japan & Materials & 31.62 & 2.06 & 35.65 & 27.23 \\
\hline 181 & Saint-Gobain & France & Construction & 43.45 & 1.47 & 41.91 & 23.05 \\
\hline 186 & Mittal Steel & Netherlands & Materials & 26.86 & 3.21 & 30.29 & 24.13 \\
\hline 212 & Alcoa & United States & Materials & 26.16 & 1.24 & 33.7 & 25.52 \\
\hline 214 & JFE Holdings & Japan & Materials & 26.16 & 1.49 & 33.63 & 21.85 \\
\hline 216 & Posco & South Korea & Materials & 23.16 & 3.68 & 23.26 & 20.65 \\
\hline 235 & Bouygues & France & Construction & 31.75 & 1.16 & 33.19 & 17.73 \\
\hline 237 & ThyssenKrupp Group & Germany & Materials & 50.56 & 1.22 & 42.08 & 13.03 \\
\hline 243 & Cemex & Mexico & Construction & 15.33 & 2.11 & 26.44 & 23.82 \\
\hline 254 & Lafarge & France & Construction & 18.88 & 1.3 & 32.59 & 18.37 \\
\hline 260 & Vinci Group & France & Construction & 26.49 & 0.99 & 31.56 & 18.26 \\
\hline 274 & International Paper & United States & Materials & 24.1 & 1.1 & 28.56 & 16.07 \\
\hline 305 & Vale do Rio Doce & Brazil & Materials & 10.37 & 2.43 & 15.97 & 53.22 \\
\hline 318 & Weyerhaeuser & United States & Materials & 22.63 & 0.73 & 28.23 & 16.6 \\
\hline 340 & Areva Group & France & Materials & 15.07 & 0.58 & 33.46 & 22.63 \\
\hline 363 & $\mathrm{CRH}$ & Ireland & Construction & 16.66 & 1.03 & 16.1 & 17.52 \\
\hline 374 & Sumitomo Metal Inds & Japan & Materials & 11.54 & 1.03 & 17.86 & 21.6 \\
\hline 382 & Holcim & Switzerland & Construction & 11.59 & 0.8 & 22.59 & 17.59 \\
\hline 406 & Centex & United States & Construction & 14.45 & 1.27 & 22.42 & 8.37 \\
\hline 430 & Norilsk Nickel & Russia & Materials & 7.29 & 1.9 & 13.63 & 17.81 \\
\hline 438 & DR Horton & United States & Construction & 14.25 & 1.54 & 12.81 & 10.65 \\
\hline 445 & ACS Group & Spain & Construction & 14.87 & 0.62 & 17.06 & 13.13 \\
\hline 446 & Pulte Homes & United States & Construction & 14.69 & 1.49 & 13.05 & 9.93 \\
\hline 458 & Masco & United States & Construction & 12.64 & 0.94 & 12.6 & 13.45 \\
\hline 461 & Asahi Glass & Japan & Construction & 12.93 & 0.51 & 17.52 & 16.71 \\
\hline 466 & Grupo Ferrovial & Spain & Construction & 9.86 & 0.76 & 22.58 & 10.49 \\
\hline 475 & Lennar & United States & Construction & 13.87 & 1.36 & 12.54 & 9.43 \\
\hline 508 & Phelps Dodge & United States & Materials & 8.29 & 1.57 & 10.36 & 14.02 \\
\hline 510 & Xstrata & Switzerland & Materials & 6.36 & 1.1 & 12.2 & 18.44 \\
\hline 518 & Kobe Steel & Japan & Materials & 13.47 & 0.48 & 17.43 & 11.43 \\
\hline
\end{tabular}




\begin{tabular}{|c|c|c|c|c|c|c|c|}
\hline Posição & Empresa & País & Setor & $\begin{array}{c}\text { Vendas } \\
\text { (\$bil) }\end{array}$ & $\begin{array}{l}\text { Lucro } \\
\text { (\$bil) }\end{array}$ & $\begin{array}{c}\text { Ativos } \\
\text { (\$bil) }\end{array}$ & $\begin{array}{c}\text { Valor de } \\
\text { Mercado } \\
\text { (\$bil) }\end{array}$ \\
\hline 525 & China Shenhua Energy & China & Materials & $\overline{4.74}$ & 1.08 & 13.18 & 27.51 \\
\hline 530 & Nucor & United States & Materials & 12.7 & 1.31 & 7.14 & 13.39 \\
\hline 535 & Falconbridge & Canada & Materials & 8.46 & 0.91 & 12.42 & 11.99 \\
\hline 572 & Corus Group & UK & Materials & 17.91 & 0.86 & 13.66 & 5.61 \\
\hline 616 & UPM-Kymmene & Finland & Materials & 11.05 & 0.31 & 17.95 & 11.1 \\
\hline 626 & US Steel & United States & Materials & 14.04 & 0.91 & 9.82 & 6.22 \\
\hline 640 & Alcan & Canada & Materials & 21.1 & 0.13 & 25.71 & 16.25 \\
\hline 648 & China Steel & Taiwan & Materials & 6.04 & 1.62 & 8.15 & 9.53 \\
\hline 675 & Baoshan Iron \& Steel & China & Materials & 7.05 & 1.13 & 7.75 & 9.47 \\
\hline 678 & Daiwa House Industry & Japan & Construction & 12.74 & 0.38 & 11.97 & 8.84 \\
\hline 686 & Oji Paper & Japan & Materials & 11.06 & 0.4 & 14.89 & 6.97 \\
\hline 700 & Hanson & UK & Construction & 6.38 & 0.67 & 11.13 & 8.77 \\
\hline 708 & Inco & Canada & Materials & 4.69 & 0.87 & 12.01 & 9.3 \\
\hline 713 & FCC Group & Spain & Construction & 8.38 & 0.5 & 10.48 & 8.88 \\
\hline 717 & Skanska & Sweden & Construction & 18.25 & 0.4 & 9.18 & 6.74 \\
\hline 720 & Newmont Mining & United States & Materials & 4.41 & 0.32 & 13.99 & 23.61 \\
\hline 739 & Severstal & Russia & Materials & 6.89 & 1.45 & 6.58 & 7.15 \\
\hline 741 & Sacyr Vallehermoso & Spain & Construction & 5.2 & 0.49 & 16.91 & 7.72 \\
\hline 753 & Stora Enso & Finland & Materials & 15.59 & -0.15 & 21.3 & 11.26 \\
\hline 755 & Teck Cominco & Canada & Materials & 3.83 & 1.17 & 7.64 & 12.7 \\
\hline 760 & KB Home & United States & Construction & 9.44 & 0.84 & 7.75 & 5.49 \\
\hline 763 & Sekisui House & Japan & Construction & 13.24 & 0.23 & 10.93 & 10.21 \\
\hline 764 & Steel Authority of India & India & Materials & 6.83 & 1.58 & 6.61 & 5.93 \\
\hline 770 & Novolipetsk Steel & Russia & Materials & 4.7 & 1.84 & 5.17 & 12.05 \\
\hline 797 & Obayashi & Japan & Construction & 13.11 & 0.23 & 17.15 & 5.42 \\
\hline 806 & Grupo Mexico & Mexico & Materials & 5.48 & 0.67 & 9.43 & 6.66 \\
\hline 832 & SCA-Svenska Cellulosa & Sweden & Materials & 12.11 & 0.05 & 16.99 & 9.79 \\
\hline 833 & Siam Cement & Thailand & Construction & 4.95 & 0.94 & 6.63 & 7.42 \\
\hline 834 & Acciona & Spain & Construction & 5.49 & 0.31 & 12.84 & 8.83 \\
\hline 844 & Usiminas & Brazil & Materials & 4.6 & 1.14 & 6.06 & 7.83 \\
\hline 853 & Shimizu & Japan & Construction & 13.85 & 0.19 & 15.28 & 5.58 \\
\hline 857 & CSN-Cia Siderurgica & Brazil & Materials & 3.69 & 0.75 & 9.12 & 7.92 \\
\hline
\end{tabular}

Fonte: Forbes.Com (2006) 


\section{ANEXO C - Diretrizes para elaboração de relatórios}

Quadro 12 - Algumas diretrizes para elaboração de relatórios não-financeiros

\begin{tabular}{|c|c|c|}
\hline $\mathrm{Ano}^{11}$ & Programa & Responsável \\
\hline 1997 & Social Accountability 8000 (SA 8000) & Social Accountability International \\
\hline 1998 & $\begin{array}{l}\text { CEFIC Responsible Care HSE Reporting } \\
\text { Guidelines }\end{array}$ & European Chemical Industry Council \\
\hline 1998 & Balanço Social Ibase & $\begin{array}{l}\text { Instituto Brasileiro de Análise Sociais e } \\
\text { Econômicas (Ibase) }\end{array}$ \\
\hline 1999 & AccountAbility 1000 (AA 1000) & Institute of Social and Ethical Accountability \\
\hline 1999 & $\begin{array}{llll}\text { ISO } 14031-\text { Environmental Performance } \\
\text { Evaluation }\end{array}$ & $\begin{array}{ll}\text { International } & \text { Organization } \\
\text { Standardization } & \\
\end{array}$ \\
\hline 2000 & Global Reporting Initiative (GRI) & Global Reporting Initiative \\
\hline 2000 & $\begin{array}{l}\text { Measuring Eco-Efficiency: A Guide for } \\
\text { Companies to Report Performance }\end{array}$ & WBCSD \\
\hline 2000 & $\begin{array}{l}\text { Indicadores Ethos de Responsabilidade } \\
\text { Social }\end{array}$ & Instituto Ethos \\
\hline 2002 & $\begin{array}{l}\text { The Cement Sustainability Initiative - Our } \\
\text { agenda for action }\end{array}$ & $\begin{array}{l}\text { World Business Council for Sustainable } \\
\text { Development }\end{array}$ \\
\hline 2003 & Indicadores Ethos Setoriais - Mineração & Instituto Ethos \\
\hline 2004 & Greenhouse Gas Protocol Initiative & World Resources Institute (WRI) e WBCSD \\
\hline 2005 & $\begin{array}{l}\text { Australian Minerals Industry Framework for } \\
\text { Sustainable Development ("Enduring } \\
\text { Value") - Antigo Australian Minerals Industry } \\
\text { Code for Environmental Management de } \\
1996\end{array}$ & Minerals Council of Australia \\
\hline 2005 & $\begin{array}{l}\text { Reporting against the ICMM Sustainable } \\
\text { Development Principles }\end{array}$ & ICMM \\
\hline 2005 & The Mining and Metals Sector Supplement & Global Reporting Initiative \\
\hline 2005 & $\begin{array}{l}\text { A Practical Guide to Communication on } \\
\text { Progress }\end{array}$ & United Nations Global Compact \\
\hline
\end{tabular}

Fonte: Adaptado de SUSTAINABILITY e UNEP (2000)

\footnotetext{
${ }^{17}$ Ano de publicação ou ano da última revisão
} 
